NBSiFf BD-2087

Testing Flat-Plate Water-Heating
Solar Collectors in Accordance
With the BSE and ASHRAE
Procedures

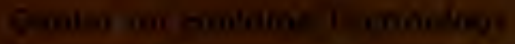

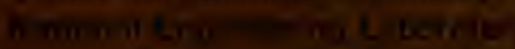

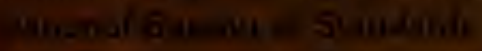

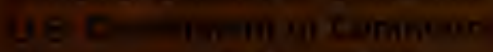

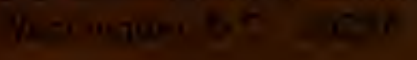

$Q$

100

.456

80-2087

1980 



\section{TESTING FLAT-PLATE WATER-HEATING SOLAR COLLECTORS IN ACCORDANCE WITH THE BSE AND ASHRAE PROCEDURES}

John P. Jenkins and James E. Hill

Center for Building Technology National Engineering Laboratory National Bureau of Standards U.S. Department of Commerce Washington, D.C. 20234

August 1980

Prepared for

Department of Energy

Institutional Programs Branch

Market Development Division

Office of Solar Applications

Washington, D.C. 20545

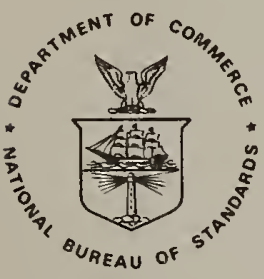

U.S. DEPARTMENT OF COMMERCE, Philip M. Klutznick, Secretary

Luther H. Hodges, Jr., Deputy Secretary

Jordan J. Baruch, Assistant Secretary for Productivity. Technolcgy, and Innovation

NATIONAL BUREAU OF STANDARDS, Ernest Ambler, Director 

TESTING FLAT-PLATE WATER-HEATING SOLAR COLLECTORS IN ACCORDANCE WITH THE BSE AND ASHRAE PROCEDURES

\section{by}

J. P. Jenkins and J. E. Hill

\section{ABSTRACT}

Five solar collectors were tested according to the BSE and ASHRAE test procedures, and the results compared. All five collectors tested were modular, flat-plate, and water-heating, and included single-and double-glazed designs with and without selectively-coated absorbers. In both procedures, collector efficiency curves are determined. The ASHRAE procedure consists exclusively of cutdoor testing, whereas the BSE procedure requires a combination of outdoor and indoor testing (no irradiation) to determine the collector's optical and thermal loss characteristics, respectively. During the indoor testing in this study, the environmental test conditions were controlled and regulated by use of specially built environmental simulators to investigate the effect of wind and "sky" temperature on the thermal loss characteristics of the collectors. The simulators provided stable, uniform wind speeds in the range of 0 to $7.1 \mathrm{~m} / \mathrm{s}$ across the collectors and "sky" temperatures above the collector ranging from $t_{a}$ (ambient air temperature) to $t_{a}-19^{\circ} \mathrm{K}$.

Key Words: Instantaneous efficiency; optical efficiency; solar collectors; thermal losses; thermal performance testing. 
TABLE OF CONTENTS

Page

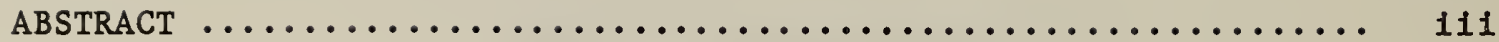

1. INTRODUCTION $\ldots \ldots \ldots \ldots \ldots \ldots \ldots \ldots \ldots \ldots \ldots \ldots \ldots \ldots \ldots \ldots \ldots \ldots$

2. BSE COLLECTOR TEST PROCEDURE ..................... 2

3. RELATIONSHIP BETWEEN THE BSE COLLECTOR TEST PROCEDURE AND

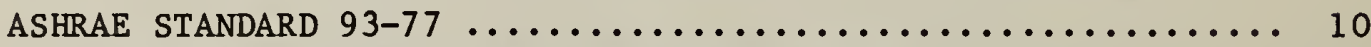

4. EXPERIMENTAL EQUIPMENT AND INSTRUMENTATION $\ldots \ldots \ldots \ldots \ldots \ldots \ldots \ldots$.

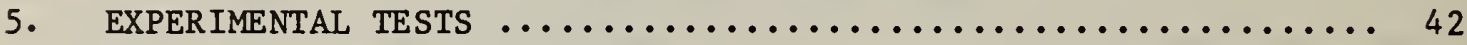

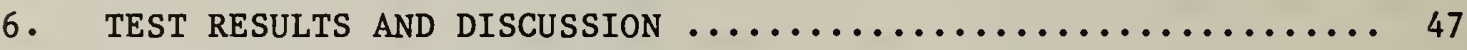

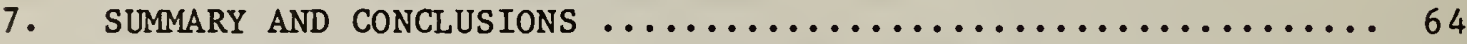

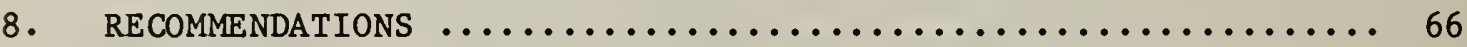

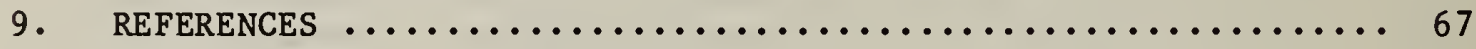

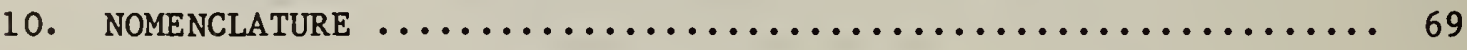

APPENDIX A. ANALYSIS OF PROPAGATED RANDOM MEASUREMENT UNCERTAINTIES 


\section{INTRODUCTION}

In May 1978, the European Bundesverband Solarenergie (BSE) Working Group completed and adopted "Guidelines and Directions for Determining the Usability of Solar Collectors" [1]. Part A of [1] describes tests and procedures for determining the thermal performance of solar collectors.

The BSE procedure prescribes that the optical efficiency and thermal loss characteristics of a collector be determined independently through a series of outdoor and indoor tests. The optical efficiency is determined through outdoor testing in which the operating conditions are regulated so that the collector experiences negligible heat loss. The thermal loss characteristics are determined under indoor laboratory conditions with zero irradiance, by circulating the working fluid through the collector over a range of operatirg temperatures above ambient air temperature. The two separately determined properties are then used to construct the collector's normal incidence efficiency curve as a function of various operating conditions.

The BSE collector test procedure developed out of a need to improve the reproducibility of collector test results and decrease the time required for testing. Reproducibility of test results is improved by reducing the outdoor testing to a minimum and combining it with indoor testing under controlled laboratory conditions. The indoor testing also reduces the required test time by minimizing the dependence of testing upon outdoor weather conditions.

As part of the National Bureau of Standards effort to develop and refine collector test standards, a review and experimental evaluation of the BSE procedure was undertaken. The approach was to compare the results from using the BSE procedure with those obtained from using ASHRAE Standard 93-77. Five commercially available collectors were tested according to both procedures and the resulting near-normal-incidence instantaneous collector efficiency curves were compared. The determination of collector time constant as well as the incident angle modifier was not investigated due to the near- * identical test requirements for each in both procedures.

Conceptually, the BSE procedure is not new. Prior research completed by Symons [3], Christie [4], Smith [5], Whillier [6], and Reed [7] have all involved similar approaches. However, there has been a reluctance to adopt such a technique because of the uncertainty associated with indoor deterisined thermal losses accurately reflecting collector thermal losses experienced outdoors. Within this study, a wide spectrum of collectors were tested and analyzed to assess the magnitude of such thermal loss discrepancies. In addition, realizing that discrepancies will exist, collector thermal losses were experimentally evaluated under a variety of indoor environmental conditions to determine, if possible, what indoor test conditions would give test results which would best reflect outdoor collector thermal losses. 


\section{General Principles}

The useful energy output under quasi-steady state conditions per unit time of solar collector, $Q_{u}$, is the difference between the incident solar radiation absorbed by the absorber surface, $\dot{Q}_{0}$, and the rate of thermal energy dissipated into the environment, $\dot{Q}_{L}$.

$$
\dot{\mathrm{Q}}_{\mathrm{u}}=\left(\dot{\mathrm{Q}}_{\mathrm{o}}-\dot{\mathrm{Q}}_{\mathrm{L}}\right)
$$

Based upon the usual definition of collector efficiency*, $n$

$$
\eta=\dot{\mathrm{Q}}_{\mathrm{u}} /\left(\mathrm{G} \cdot \mathrm{A}_{\mathrm{a}}\right)
$$

where

$G=$ hemispherical solar irradiance

$A_{a}=$ collector aperture area

When $\dot{\mathrm{Q}}_{\mathrm{L}}=0$

$$
n_{0}=\dot{Q}_{0} /\left(G \cdot A_{a}\right) \text {, }
$$

Substituting equations (2) and (3) into (1) yields

$$
\eta=\eta_{0}-\dot{Q}_{L} /\left(G \cdot A_{a}\right)
$$

The two terms on the right side of equation (4), $\eta_{0}$ and $\dot{Q}_{L} /\left(G \cdot A_{a}\right)$, represent the collector optical efficiency and overall thermal losses, respectively. The significance of each term can be visualized by looking at the $1000 \mathrm{~W} / \mathrm{m}^{2}$ collector efficiency curve in Figure 1. The collector optical efficiency, $\eta_{0}$, is represented by the curve intercept whereas the slope is indicative of the collector overall thermal losses.

The BSE procedure prescribes a series of tests for determining the collector efficiency by independently measuring the optical efficiency, $\eta_{0}$, and the thermal losses, $\dot{Q}_{L}$, experimentally through a combination of outdoor and indoor testing.

*ASHRAE Standard 93-77 uses gross collector area in equation (2). Aperture area is used throughout this paper in order to compare the results of the ASHRAE and BSE procedures on the same basis. 


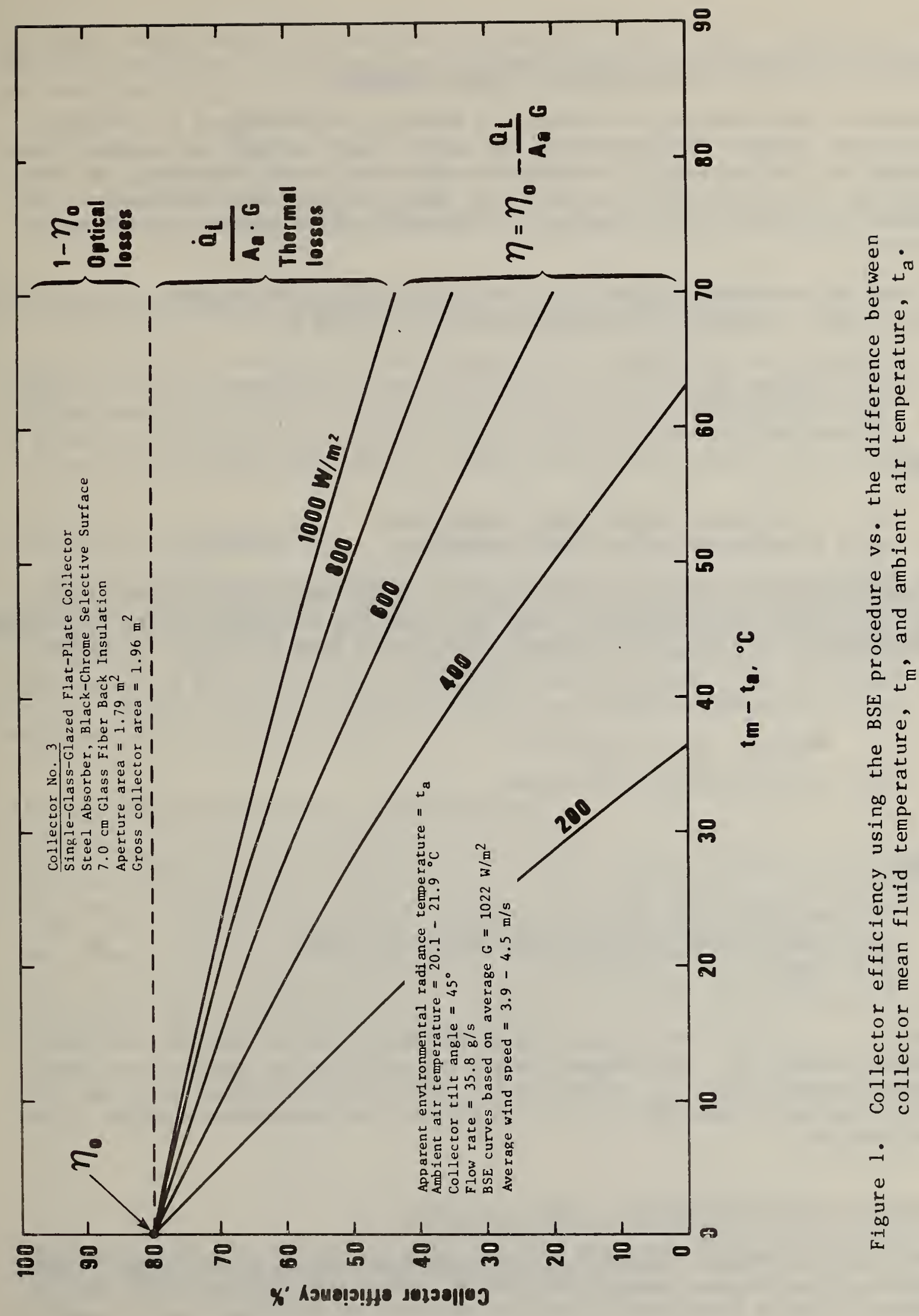




\section{Optical Efficiency Determination (Outdoor Testing)}

Collector instantaneous efficiency, in general, is determined by testing a collector outdoors and monitoring the useful energy output and incident solar radiation. The collector is operating under quasi-steady operating and environmental conditions and measurements of mass flow rate and temperature rise across the collector are required to determine the collector useful energy output.

In the BSE procedure to obtain the collector optical efficiency, $n_{0}$, the collector mean absorber fluid temperature, $t_{m}$, defined by

$$
t_{m}=\frac{t_{f, o}+t_{f, i}}{2}
$$

where

$$
\begin{aligned}
& t_{f, o}=\text { collector outlet fluid temperature } \\
& t_{f, i}=\text { collector inlet fluid temperature }
\end{aligned}
$$

is regulated such that it is within $+10^{\circ} \mathrm{C}$ of the ambient air temperature, $t_{a}$. The result is negligible heat loss from the collector to the surrounding environment. Since $Q_{L} \simeq 0$, $n_{0}$ can be calculated from equation ( 3 ), using

$$
\dot{Q}_{0}=\frac{\dot{m}_{p} \int_{\tau}^{\tau_{2}}\left(t_{f, 0}-t_{f, i}\right) d \tau}{\tau_{2}-\tau_{1}}
$$

where

$\dot{\mathrm{m}}=$ mass flow rate through collector

$\begin{aligned} C_{P} & =\text { specific heat of the collector working fluid } \\ q & =\text { time }\end{aligned}$

When $\left|t_{m}-t_{a}\right|>10^{\circ} \mathrm{C}, \eta_{0}$ must be corrected to account for the collector thermal losses, $\dot{Q}_{L}$. The thermal losses are added to the measured collector useful energy output, $\dot{Q}_{u}$, to obtain $\dot{Q}_{0}$. The correction value of $\dot{Q}_{L}$ can be determined for a specific $\left(t_{m}-t_{a}\right)$ following the procedures outlined in the next section.

\section{Thermal losses Determination (Indoor Testing)}

The collector thermal losses, $\dot{Q}_{L}$, are determined within a controlled indoor laboratory environment under zero $\left(<1 \mathrm{~W} / \mathrm{m}^{2}\right)$ solar irradiation conditions. A working fluid is circulated in reverse through the collector over a range of 
operating temperatures above ambient, specifically $\left(t_{m}-t_{a}\right)=30^{\circ}, 50^{\circ}, 70^{\circ}$ and $90^{\circ} \mathrm{C}$, while the fluid flow rate and temperature drop across the collector are monitored. $\dot{Q}_{L}$ is then determined by:

$$
\dot{Q}_{L}=\frac{\dot{m}_{p} \int_{\tau_{1}}^{\tau_{2}}\left(t_{f, 0}-t_{f, 1}\right) d \tau}{\tau_{2}-\tau_{1}}
$$

$\dot{Q}_{L}$ is then plotted as a function of $\left(t_{m}-t_{a}\right)$ as in Figure 2 .

During the indoor testing, the environmental test conditions are regulated such that the air temperature remains between 15 to $25^{\circ} \mathrm{C}$ ( 59 to $77^{\circ} \mathrm{F}$ ) while the wind speed $7-9 \mathrm{~cm}(2.7-3.5 \mathrm{in})$ above the collector stays above $4 \mathrm{~m} / \mathrm{s}$ $(9 \mathrm{mi} / \mathrm{h})$. In addition, the apparent environmental radiance temperature*, $t$ env, must not deviate from the air temperature by more than $\pm 3^{\circ} \mathrm{K}\left( \pm 5.4^{\circ} \mathrm{R}\right)$.

\section{Collector Test Requirements}

The BSE procedure test requirements regarding the allowable environmental test conditions, measurement uncertainties, and range of operating test conditions are tabulated in Tables 1,2 and 3. The BSE test requirements are separated into outdoor, $\left(\eta_{0}\right)$, and indoor, $\left(\dot{Q}_{L}\right)$, testing and are presented along with ASHRAE Standard 93-77 collector test requirements. Notice that the requirements for outdoor testing following the BSE and ASHRAE Standard 93-77 are near identical in all categories.

\section{Collector Thermal Performance - Data Display}

Using the results obtained from both outdoor and indoor testing, a family of collector efficiency curves are produced as shown in Figure 1. The collector efficiency is plotted as a function of $\left(t_{m}-t_{a}\right)$ for various solar radiation levels. The collector curves are generated using equation (4). $\dot{Q}_{L}$ is obtained as a function of $\left(t_{m}-t_{a}\right)$ from the experimental indoor heat loss tests, A from the collector geometry, while G, the solar irradiance level, is selected for the required curve. The solar irradiance levels required to be used are $1000,800,600,400$ and $200 \mathrm{w} / \mathrm{m}^{2}$.

* Temperature of a perfectly black environment which would radiate the same amount of thermal radiation as the real environment. 


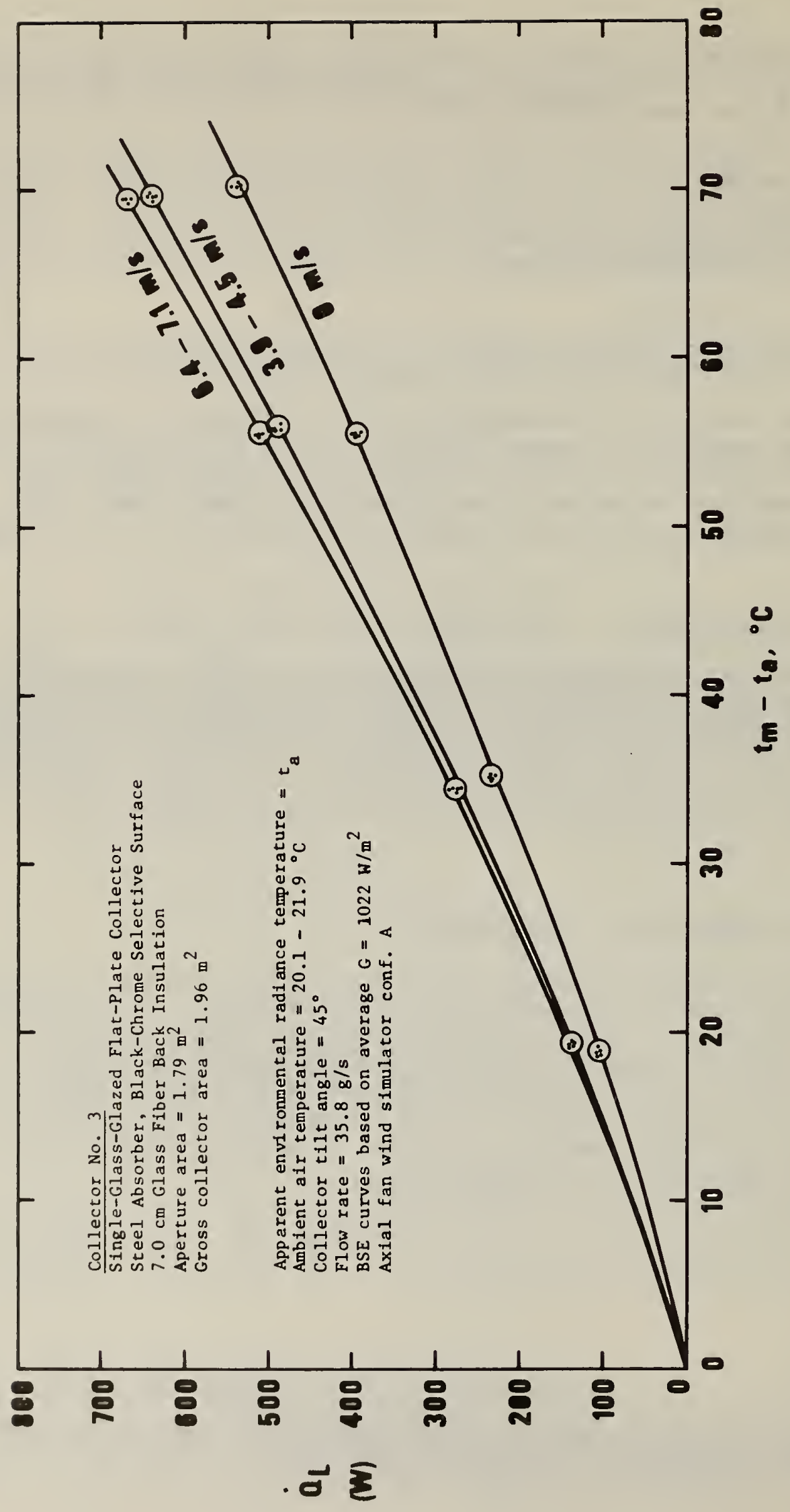

㟧

i

旦

옥

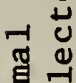

.

돈

도

7

3

วิ

- \&

는류

U

구ㅇㅝㅛ

㲾 
Table 1

Environmental Test Conditions Allowed Within The ASHRAE 93-77 And BSE Collector Test Procedures

\begin{tabular}{|c|c|c|c|}
\hline Environmental Parameter & $\begin{array}{l}\text { ASHRAE Standard } \\
93-77 \\
\end{array}$ & $\begin{array}{c}\text { BSE* } \\
\text { n-Determination, } \\
\text { Outdoor Testing }\end{array}$ & $\begin{array}{c}\text { BSE* } \\
\dot{\mathrm{P}}_{\mathrm{L}} \text {-Determination, } \\
\text { Indoor Testing }\end{array}$ \\
\hline Ambient air temperature & range $<30^{\circ} \mathrm{C}$ & no limits & $15-25^{\circ} \mathrm{C}$ \\
\hline $\begin{array}{l}\text { Wind velocity across } \\
\text { collector }\end{array}$ & $\begin{array}{l}\text { should be } \leq 4.5 \\
\mathrm{~m} / \mathrm{s}\end{array}$ & $>4 \mathrm{~m} / \mathrm{s}$ & $>4 \mathrm{~m} / \mathrm{s}$ \\
\hline $\begin{array}{l}\text { Total solar irradiance } \\
\text { within collector plane }\end{array}$ & $>630 \mathrm{~W} / \mathrm{m}^{2}$ & no minimum & $<1 \mathrm{~W} / \mathrm{m}^{2}$ \\
\hline $\begin{array}{l}\text { Beam solar irradiance } \\
\text { incident angle }\end{array}$ & $<30^{\circ}$ & $<30^{\circ}$ & - \\
\hline Foreground reflectance & $<0.20$ & $<0.20$ & \\
\hline $\begin{array}{l}\text { Apparent environmental } \\
\text { radiance temperature }\end{array}$ & - & $\underline{-}$ & $<t_{a} \pm 3^{\circ} \mathrm{k}$ \\
\hline
\end{tabular}

*BSE Guidelines and Directions for Determining the Usability of Solar Collectors, [1] 


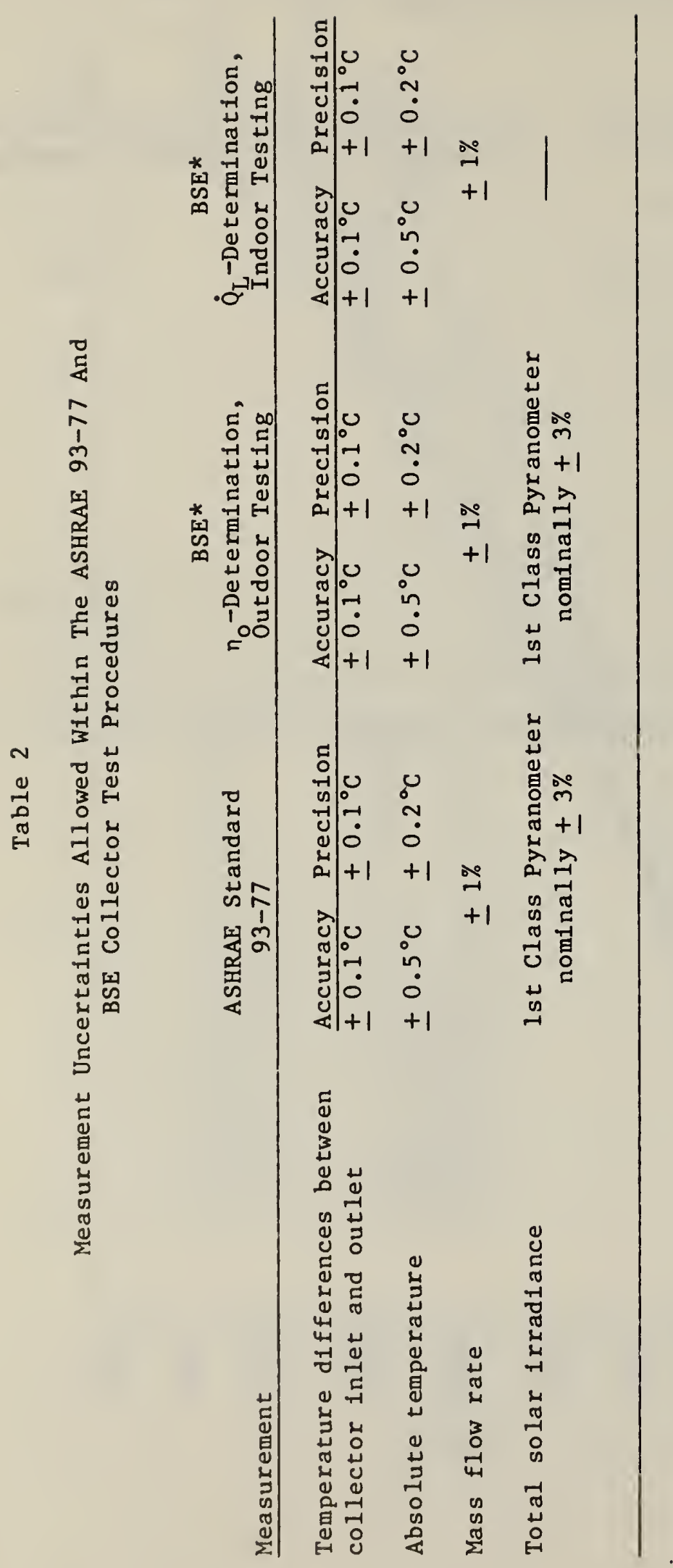


Table 3

Operating Test Conditions Required Within The ASHRAE 93-77 And BSE Collector Test Procedures

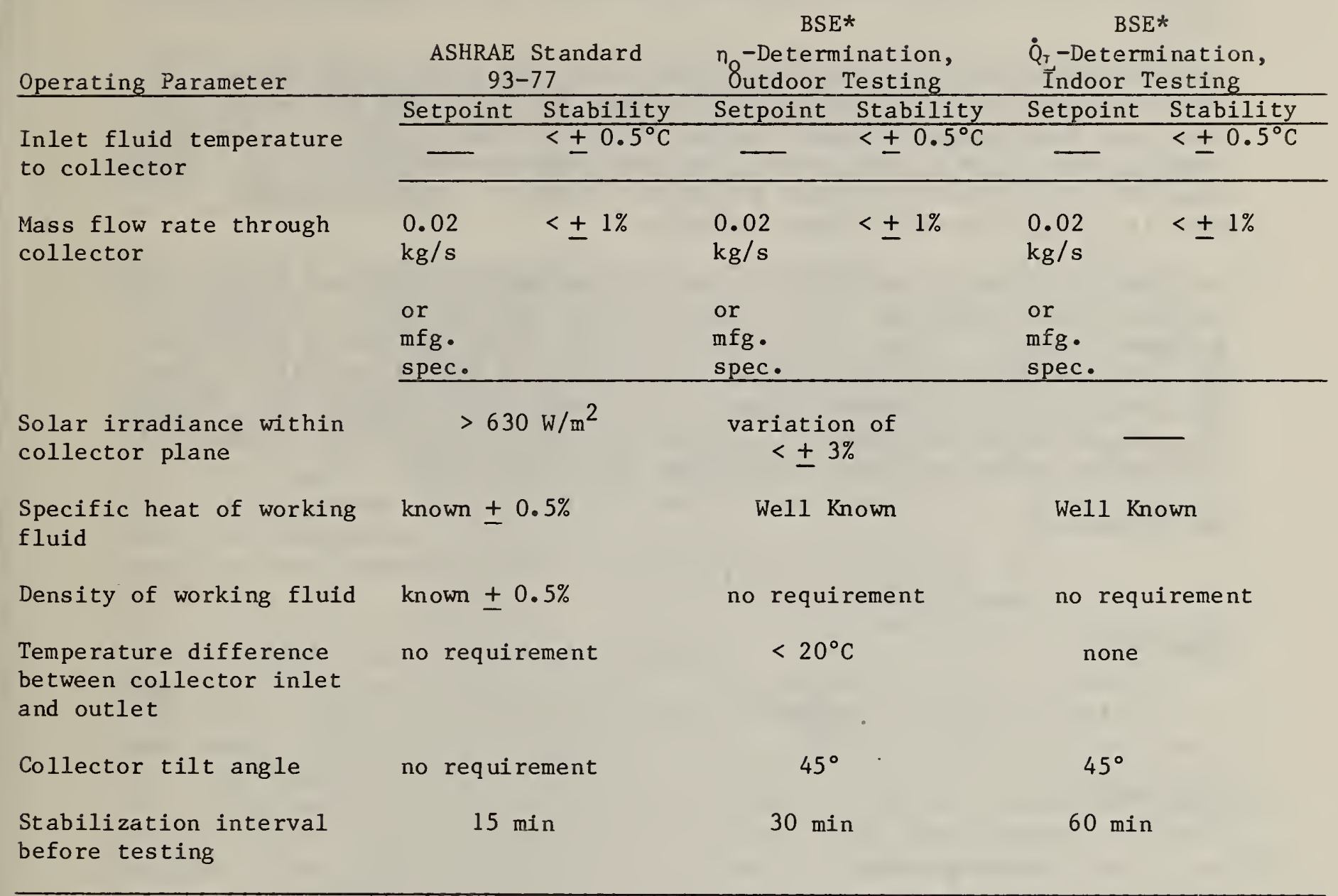




\section{RELATIONSHIP BETWEEN THE BSE COLLECTOR TEST PROCEDURE} AND ASHRAE STANDARD 93-77

Transposing the BSE Thermal Performance Results to an ASHRAE Efficiency Curve

The BSE and ASHRAE test procedures each prescribe a different format for reporting the collector thermal performance results. The BSE results consist of a family of efficiency curves (for different values of irradiance levels) plotted as a function of the operating temperatures, $t_{m}{ }^{-t} a$. ASHRAE Standard 93-77 prescribes that a single efficiency curve be plotted with $\left(t_{f, 1}-t_{a}\right) / G$ as the $x$-axis variable.

In order to obtain a meaningful comparison between the BSE and ASHRAE collector performance results, it is essential that the results be presented in a common format. Consequently, the procedure below outlines a technique for transposing the BSE efficiency curves into an ASHRAE efficiency curve. The basic difference between them is the $x$-axis term, $\left(t_{m}-t_{a}\right)$, for BSE and $\left(t_{f} i^{-t}{ }_{a}\right) / G$ for $S t a n d a r d 93-77$. Therefore, the technique for transposing efficiency curves involves transposing the $x$-axis terms.

By definition

Therefore

$$
\eta=\frac{\dot{m} c_{p}\left(t_{f, o}-t_{f, i}\right)}{A_{a} G}
$$

$$
\left(t_{f, o}-t_{f, i}\right)=\frac{n(G) A_{a}}{t C_{p}}
$$

Considering

$$
t_{m}=\frac{\left(t_{f, o}+t_{f, i}\right)}{2}
$$

then

$$
\left(t_{f, 1}-t_{m}\right)=-\frac{\eta(G) A_{a}}{2(\text { hㅏ }) C_{p}}
$$

Finally

$$
\frac{\left[t_{m}-t_{a}\right]-\frac{n(G) A}{2(\dot{m}) C_{P}}}{G}=\frac{\left(t_{f, i}-t_{a}\right)}{G}
$$

When transposing the BSE efficiency curves into an ASHRAE curve, data points are selected along one of the BSE efficiency curves, each with a corresponding $\eta$ and $\left(t_{m}-t_{a}\right)$. Knowing $n$ and $\left(t_{m}-t_{a}\right)$ for each point and $G, A_{a}$, $h$, and $C_{p}$ for the BSE efficiency curve, $\left(t_{f, i}-t_{a}\right) / G$ can be calculated for each data 
point using equation (11). Finally, by replotting each data point using the original efficiency value and the calculated value of $\left(t_{f, i}-t_{a}\right) / G$ for each point, the ASHRAE curve results.

Uncertainties Associated with the BSE and ASHRAE Collector Thermal Performance Results

Figures 3 through 6 illustrate the range of expected uncertainties and possible extremes associated with the thermal performance curves for collector no. 3* using the BSE and ASHRAE 93-77 collector test procedures. Figure 5 is not required by the BSE procedure but is included here to address the uncertainty in the BSE efficiency curve after being transposed into an ASHRAE format.

In each figure, the overall uncertainty is segmented into two components, the meteorological and measurement uncertainty. Meteorological uncertainty, illustrated by the separation of the solid curves, represents the possible extremes due to the allowable variation in meterological conditions during testing. The measurement uncertainty, illustrated by the separation of the dashed lines superimposed upon the meterological extremes, is a representation of the random uncertainty associated with individual measurements of solar irradiance, fluid flow rate, temperature, and working fluid thermophysical properties in determining the plotted parameters. The rectangles bound the measurement uncertainty associated with of both the $\mathrm{x}$ and $\mathrm{y}$ axis parameters for selected points along each of the curves.

The meterological extremes were determined for both the BSE and ASHRAE curves using a computer model $[8,9]$ based upon the traditional heat transfer relations for flat plate collectors [10]. Minor modifications were made to allow for an input of zero solar irradiance and to provide proper convergence when iteratively determining $\dot{Q}_{L}$. The complete details of the computer model and equations and how they were solved are given in the Appendices of $[8,9]$. The meterological test conditions used as program inputs are indicated on each of the curves. Considering the lack of BSE requirements for levels of total solar irradiance within the collector plane $G$, and diffuse percentage $G_{d}$ typical extremes of 200 and $1000 \mathrm{~W} / \mathrm{m}^{2}$ and 0 and $50 \%$, respectively, were selected. Likewise for the Standard 93-77 efficiency curve, $G_{d}$ extremes were selected at 0 and $50 \%$. To ensure the accuracy of the analytical modeling used to determine collector thermal performance at the meteorological extremes, the results were first validated against experimental data at NBS. Complete experimental data was available from the testing of collector no. 3 according to the BSE and ASHRAE test procedures. The two sets of meteorological extremes of Figure 4 represent the extremes associated with the BSE efficiency curves of 1000 and $200 \mathrm{~W} / \mathrm{m}^{2}$. Realizing that the BSE efficiency curves are constructed from independent determinations of $n_{0}$ and $\dot{Q}_{L}$, the worst case combination of the two was used to obtain the high and low meteorological extremes.

* Collector no. 3 is a flat plate single glass glazed collector with a black chrome selective absorber coating. A description of all collectors used in this study is given in Table 7 . 


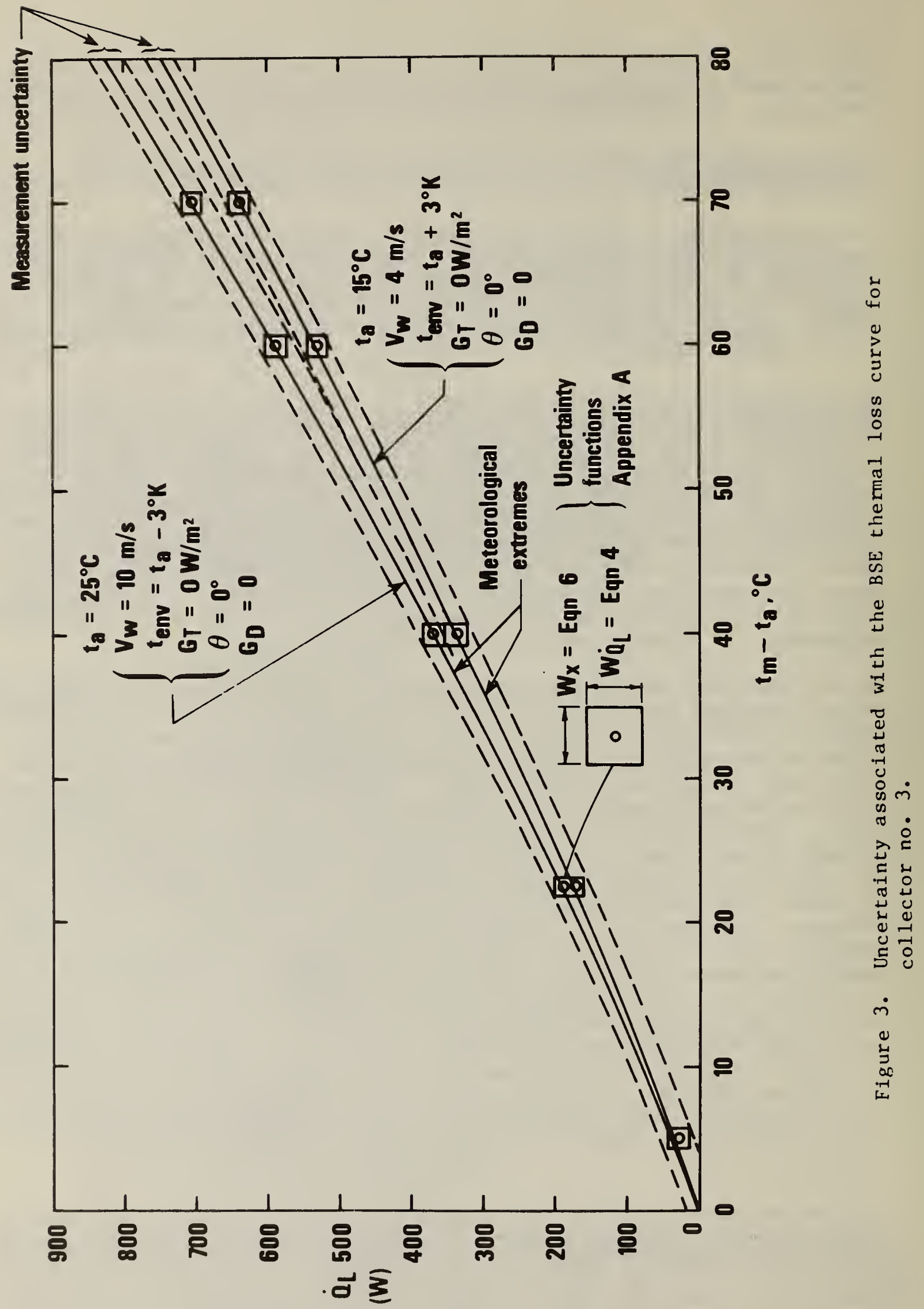




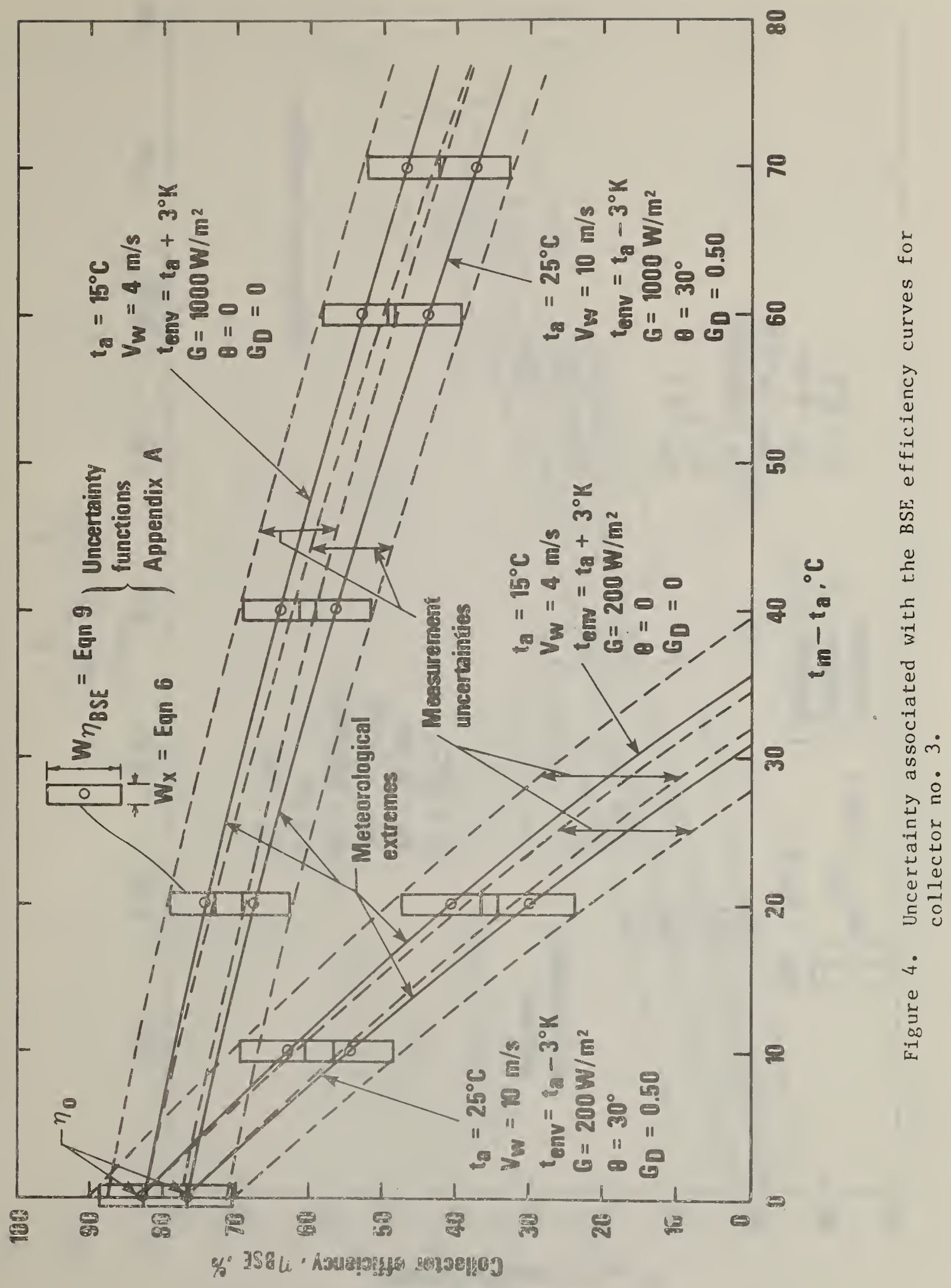




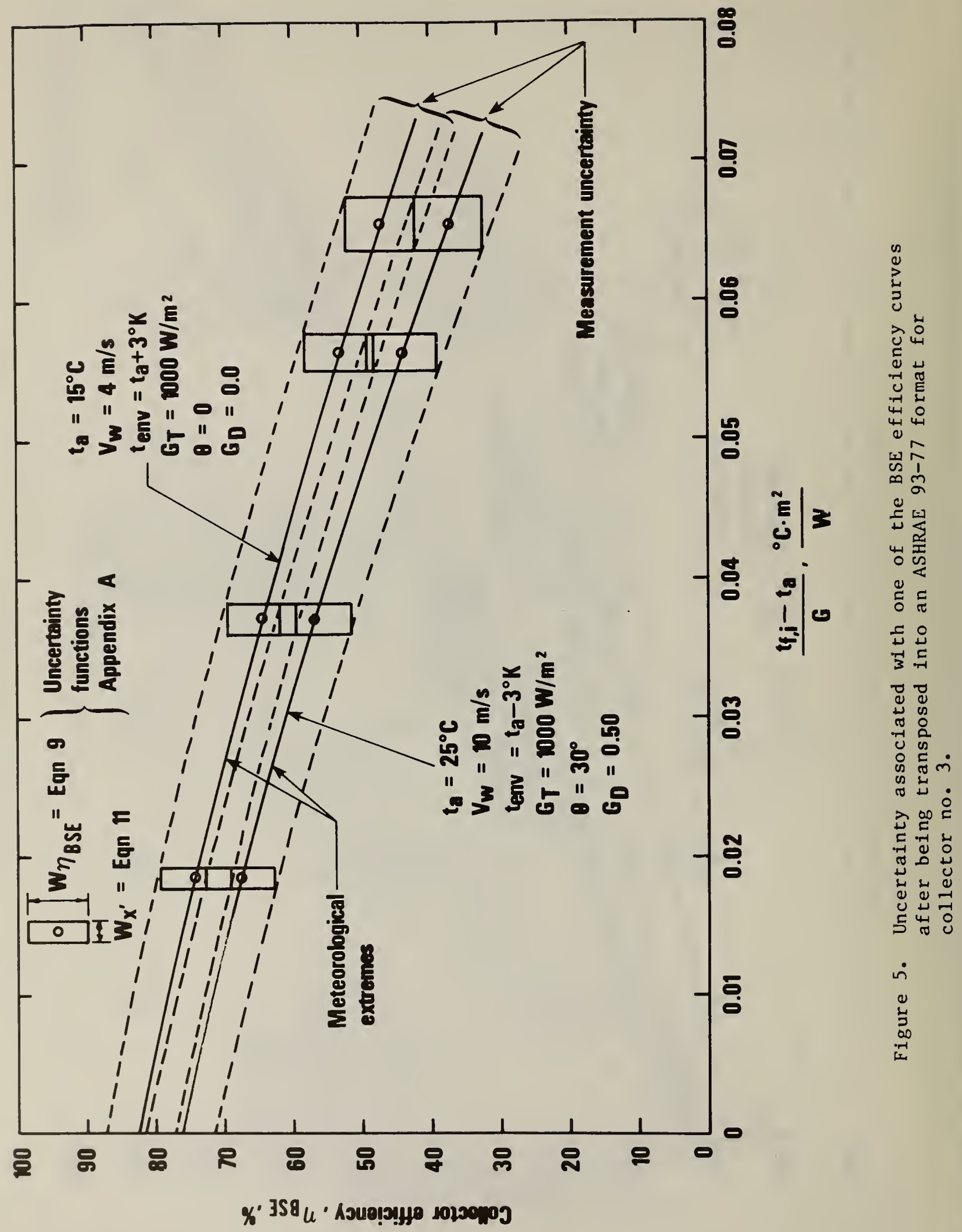




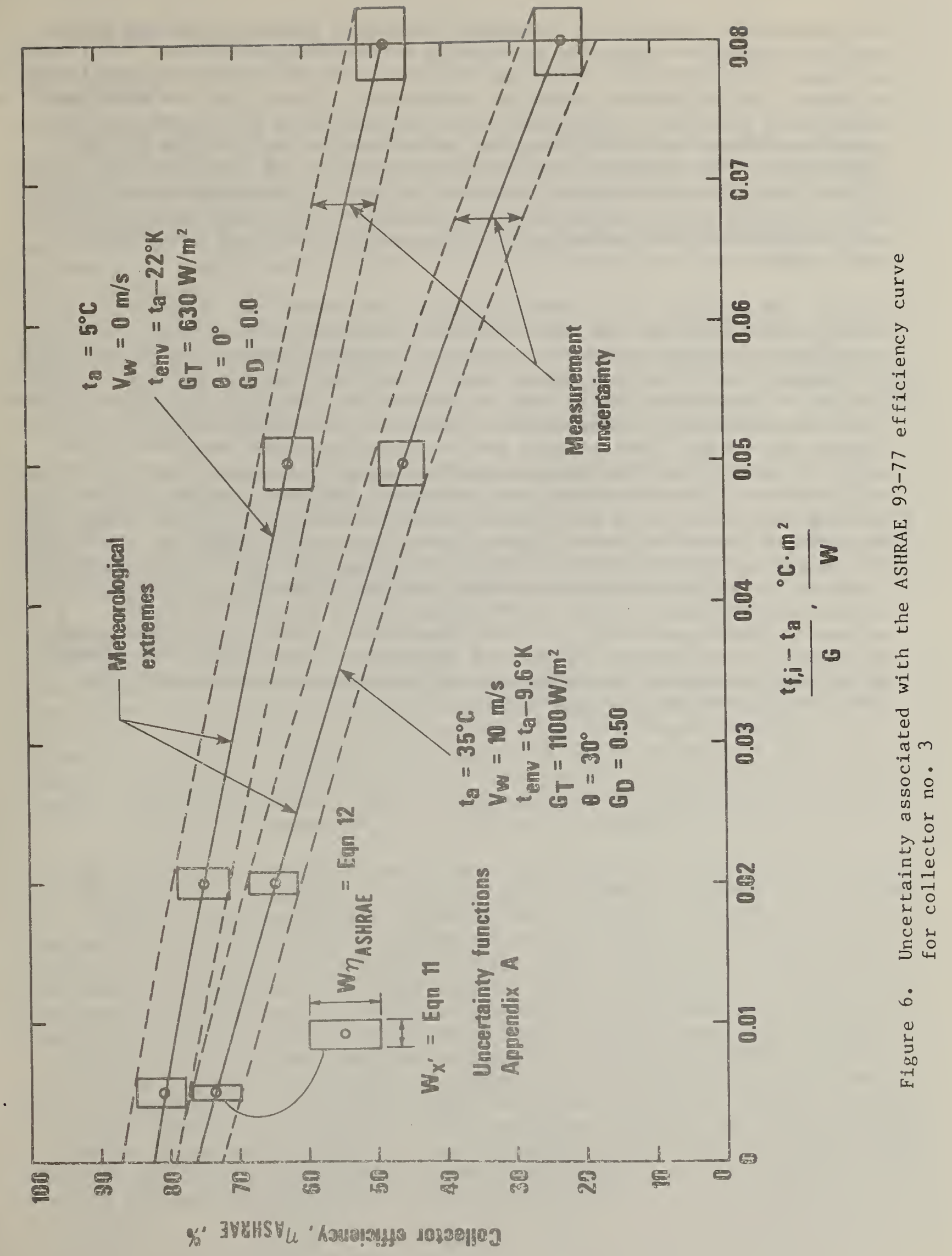


The measurement uncertainty associated with each of the curves was quantitatively determined using the propagated measurement uncertainty functions developed in Appendix A. Applying the individual measurement uncertainties of Table 2 and allowable operating conditions of Table 3 to the developed uncertainty functions of Appendix A for the collector being examined, the absolute measurement uncertainty was determined for each of the plotted parameters. The horizontal and vertical dimensions of the rectangles superimposed upon the meterological extremes reflect the measurement uncertainty of the plotted $x$ and $y$ parameters, respectively. The uncertainty functions used to generate the rectangles are referenced on enlarged rectangles on each figure.

Several observations can be made regarding the comparison of overall uncertainty associated with the BSE and ASHRAE collector test results. The BSE and ASHRAE collector efficiency curves with related uncertainties are shown in Figures 5 and 6 using a format consistent with Standard 93-77 for collector no. 3. An obvious difference is the smaller spread in the BSE efficiency curve meteorological extremes when compared to the ASHRAE efficiency curve. The smaller spread, reflecting a smaller meteorological uncertainty, is expected considering the tighter control over meteorological test conditions as a result of indoor testing. For practical purposes, outdoor collector testing must allow for a wider range of environmental test conditions. The measurement uncertainties on Figure 5 and 6 are nearly identical (nominally +5 percentage points) because of the near identical individual measurement inaccuracies allowed within the ASHRAE and BSE documents. The dominating factor contributing to the \pm 5 percentage points is the uncertainty of $\pm 3 \%$ related to the measurement of solar irradiance. Overall, the compounded uncertainty (both meteorological and measurement) associated with ASHRAE efficiency curve will always be greater than for the corresponding BSE efficiency curve for the same collector. 


\section{EXPERIMENTAL EQUIPMENT AND INSTRUMENTATION}

Test Facility

The collector testing loops designed, built, and used in the experiments described in this report are housed at an former NIKE Missile Site adjacent to the NBS Laboratories in Gaithersburg, Maryland. One of the underground bunkers built originally for storing of missiles is used as the solar laboratory with the test loops mounted on an elevator used originally for transporting the missiles up to ground level. This unique facility allows NBS personnel to conduct outdoor tests as well as indoor heat losses tests using the same test equipment.

Figure 7 shows the elevator door closed over the underground bunker occupied by the NBS collector testing group. Figure 8 shows the equipment on the elevator just after the doors have opened. Figure 9 shows the equipment in the outdoor testing configuration with the two liquid collector test loops in the foreground, and the adjacent room containing the data acquisition system.

The primary equipment used during all of the experimentation included the collector test loops, the axial fan wind simulators, and the environmental simulators. The collector test loops provided the proper collector operating conditions and equipment to monitor collector thermal performance. Both the axial fan wind simulators and the environmental simulators were used to control the environmental test conditions during indoor testing.

\section{Collector Test Loops}

Two separate test loops were built for the water-heating collectors. Both test loops are essentially identical and consist of a portable supporting frame for a test collector with the entire flow loop housed underneath the collector within the framework. The collector can be adjusted over a wide range of tilt angles $\left(0-70^{\circ}\right)$ and orientation $\left(0-360^{\circ}\right)$ and easily added to or removed from the structure. All the instrumentation (except sensors mounted in the flow loop) is housed in the adjoining instrumentation room.

Figure 10 shows a close-up of one of the test loops with a flat-plate collector (collector no. 4) mounted to the top of the frame. Figure 11 is a schematic drawing of the test loop. As can be seen, the loop is closed and was designed to be able to control and stabilize the collector fluid inlet temperature to within $\pm 0.5^{\circ} \mathrm{C}\left( \pm 1.0^{\circ} \mathrm{F}\right)$ and the fluid flow rate to within $\pm 1 \%$. Pure water was use $\bar{d}$ as the working fluid in order to eliminate uncertainities and possible errors associated with not knowing the working fluid properties. Figure 12 shows the loops from the north and, as can be seen, all equipment is sufficiently protected from the environment by having it enclosed within the housing. Plumbing and hardware within the test stand base are encased with $1.2 \mathrm{~cm}(0.5 \mathrm{in}$.) thick foam rubber insulation while all exposed plumbing is wrapped with $3.8 \mathrm{~cm}$ (1.5 in.) thick foam rubber insulation. The following paragraphs describe the details of the equipment used in the flow loops starting with the collector and moving clockwise in Figure 1l. The specifications for the equipment and sensors are given in Table 4. 
(14)

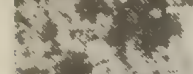

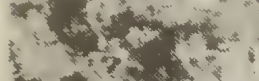

$x^{2}+2+2 k$ \&

$4+2$.

$n+10$

$k+1-x+2$

ay $y=3$

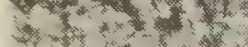

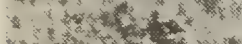

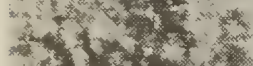

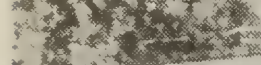

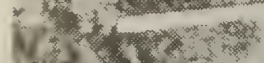

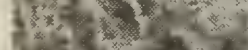

1.

k.t.

atas

is $2,12 \times$

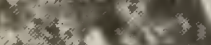

3. 10

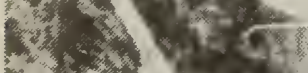

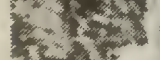

Tw.

(1) $2 x$

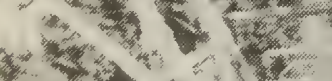

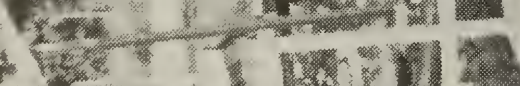

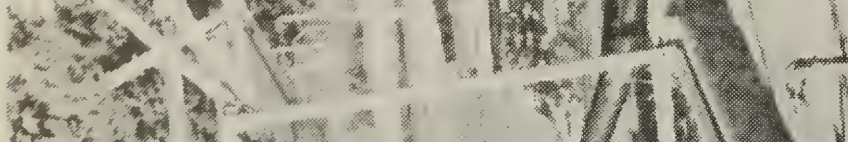

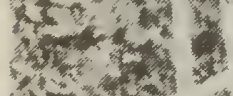

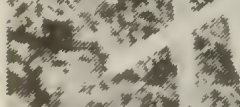

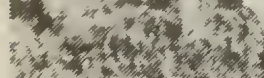

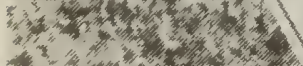

tron

,

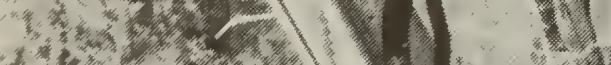
(n)

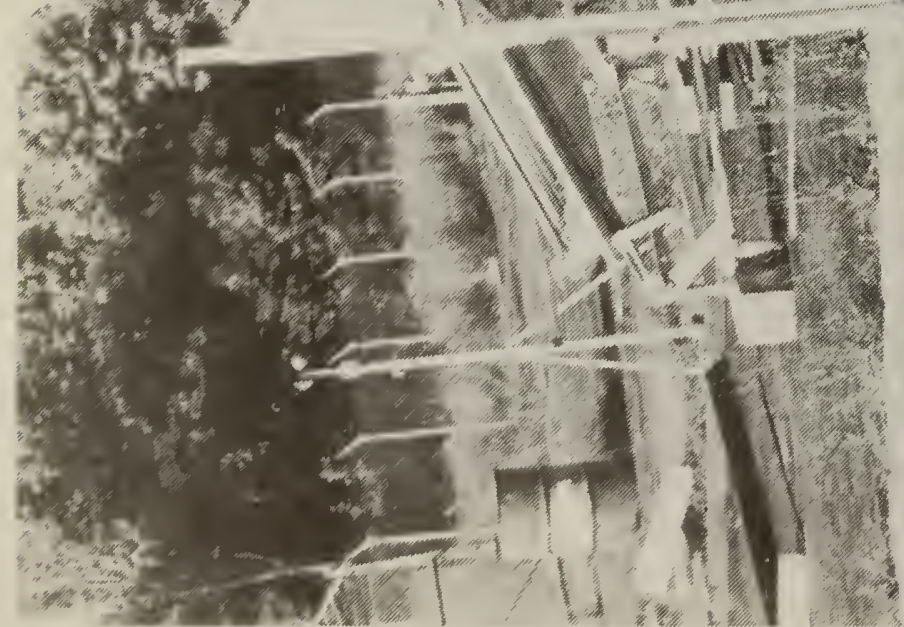

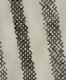

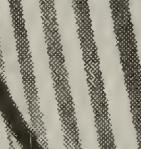

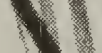
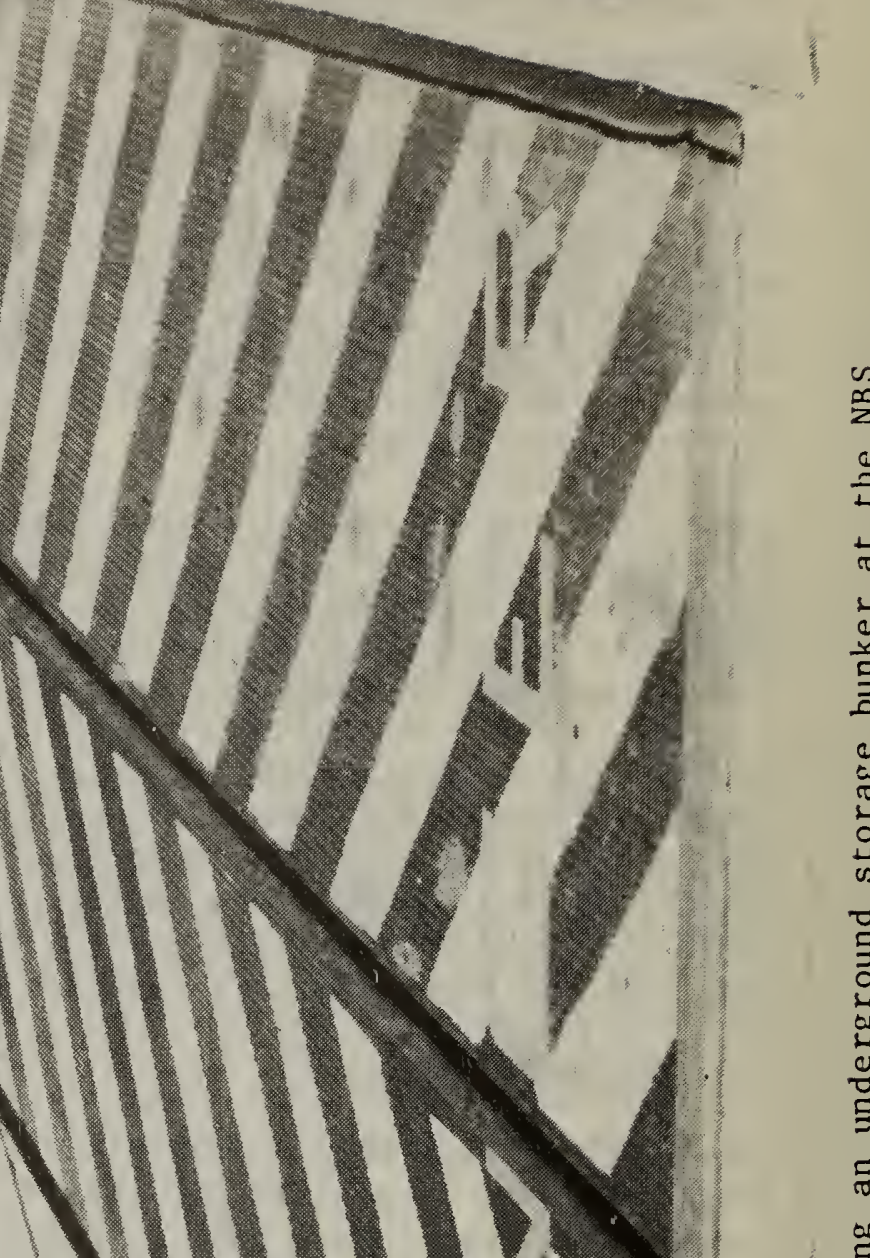

$\stackrel{\infty}{2}$

㫕

苞

0
0
0
0
0
0
0

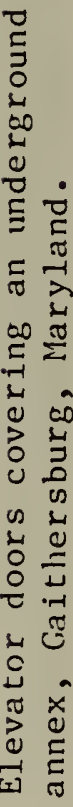

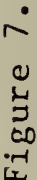




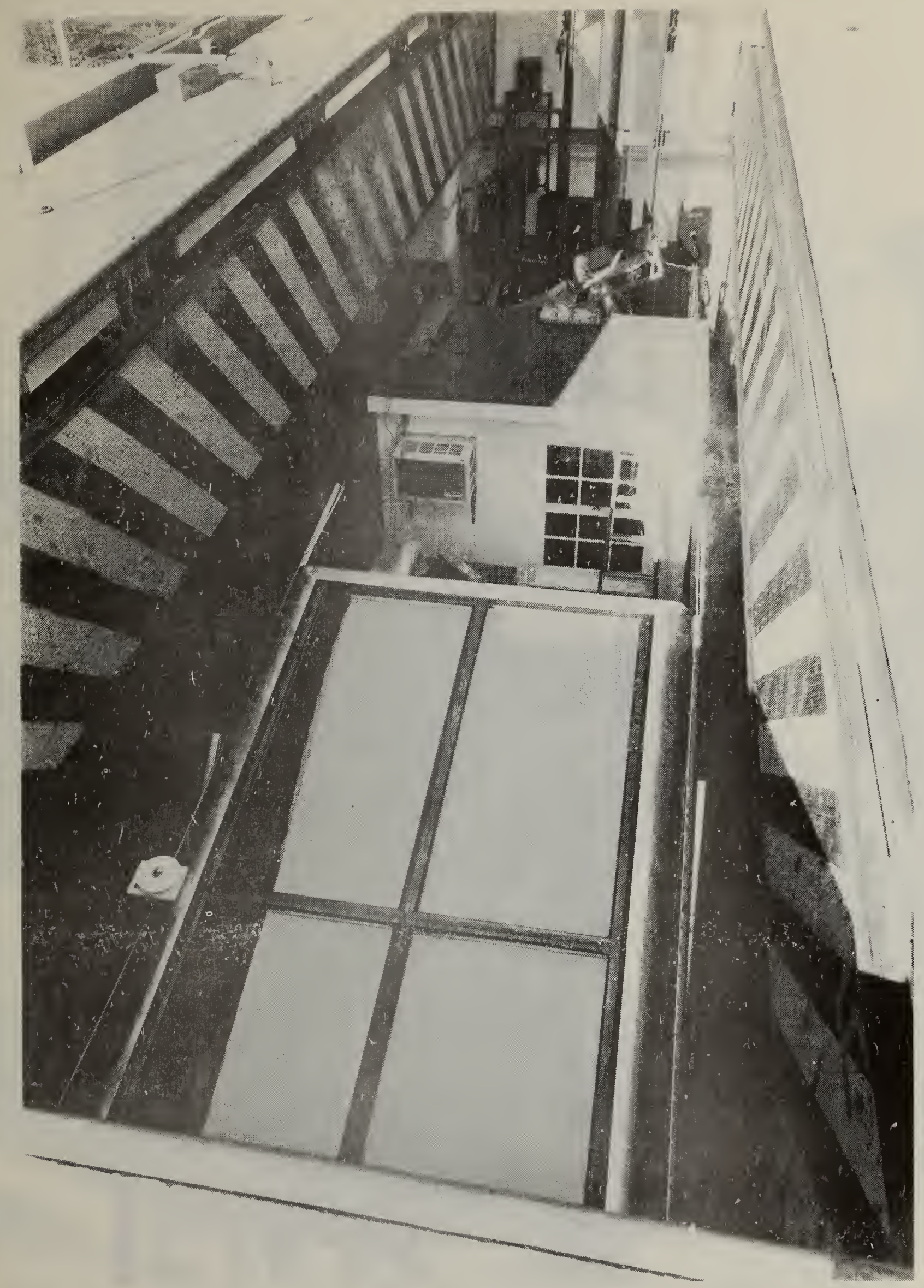

Figure 8. Solar collector testing equipment mounted on the elevator and lowered to the floor of the underground storage bunker at the NBS annex, Gaithersburg, Maryland. 


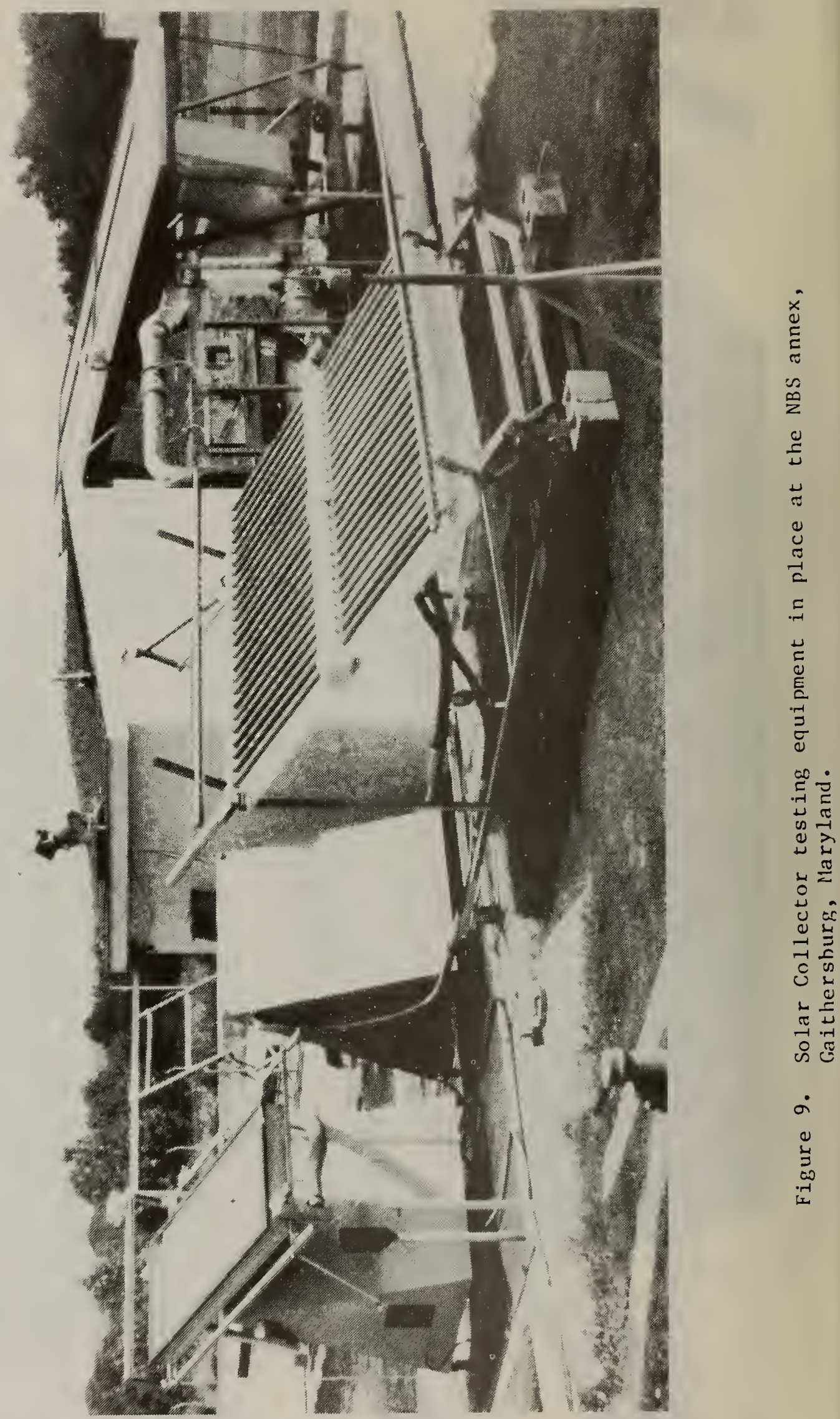




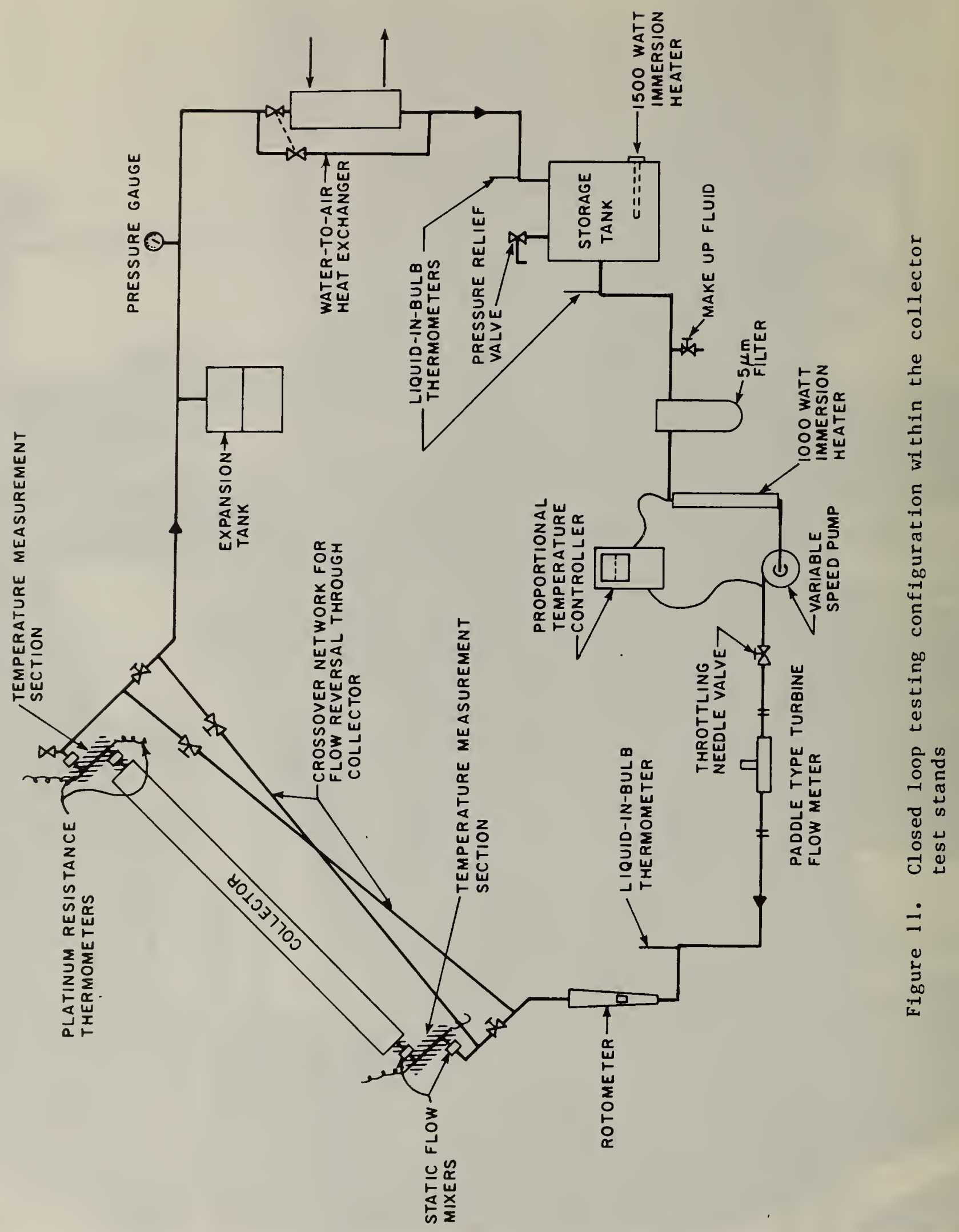


The temperature measurement sections are located immediately upstream and downstream of the collector. Both inlet and outlet sections are located as close as possible to the connection of the collector and are insulated with $3.8 \mathrm{~cm}$ ( $1.5 \mathrm{in}$.) thick foam rubber insulation in order to minimize thermal heat losses and to ensure a temperature change of less than $0.05^{\circ} \mathrm{C}$ $\left(0.1^{\circ} \mathrm{F}\right)$ between the sections and the collector. Proper thermal homogeneity is provided by insuring a Reynolds number of at least 5000 and allowing the fluid to pass through at least one right angle bend or static screen flow mixers immediately before entering the measurement section. The sections are constructed so that two temperature sensors can be inserted simultaneously through compression fittings. To provide proper bleeding of trapped air from the entire system, air bleed valves are located immediately adjacent to the wells. Sheathed platinum resistance thermometers (PRT) and linear bridge amplifiers are used to determine the inlet and outlet absolute temperature across a collector. Two separate PRT's are inserted within each of the inlet and out let temperature measurement sections in order to ensure a check on temperature measurement. The PRT's were calibrated in two matched sets to insure an absolute temperature measurement to within $+0.05^{\circ} \mathrm{C}\left(0.09^{\circ} \mathrm{F}\right)$ and a temperature difference resolution of $+0.1^{\circ} \mathrm{C}\left(0.18^{\circ} \mathrm{F}\right)$. The $\mathrm{X}$ crossover network connected between the inlet and outlet of the collector outside of the temperature measurement sections is utilized for fluid flow reversal through the collector. During indoor thermal loss tests, the flow is reversed so that the fluid flows down through the collector.

A 11.3 liter ( 3 gal) expansion tank is in the closed flow loop to allow for full expansion of the working fluid and to dampen pressure fluctuations.

A water-to-air heat exchanger is used to dump the collected energy during outdoor testing. The water-to-air heat exchanger is a $36 \mathrm{~cm}$ (14 in) square by $2.5 \mathrm{~cm}(1.0 \mathrm{in})$ deep fluid radiator. For adjustment purposes, the water-to-air heat exchanger uses ganged ball valves to serve as a bypass and modulate the heat dump. The ganged bypass valves produce a constant back pressure and consequently a steady flow rate over the full range of ad justment.

Although not shown in the schematic drawing of Figure 11, the flow loop can be opened in order to provide a means of periodically calibrating the flow meters in place against a weigh tank and stopwatch. In addition, the flow meters can also be easily removed for cleaning, checking, and additional calibration.

Further downstream are the storage and recovery tanks including a pressure relief valve. The 38 liter (10 gal) water storage tank can be seen in Figure 11 and is incorporated in the flow loop to act as a buffer and eliminate thermal cycling which tends to occur within a closed system. In addition, the storage tank contains a $1.5 \mathrm{~kW}$ immersion heater which can be used to increase the overall flow loop temperature. 


\section{Table 4}

Specifications For The Equipment And Sensors Used In The Collector Test Loops

Equipment/Sensor

Specifications

Temperature measurement section

Water-to-air heat
exchanger

Storage tank

Pressure relief valve

Filter

Electric Heater

Temperature Controller
Outer shell assembly is constructed from $1.27 \mathrm{~cm}(0.5 \mathrm{in.})$ i.d., $0.317 \mathrm{~cm}(0.125$ in.) wall hard-drawn copper tubing and fittings; Compression fitting with Polytetrafluoroethylene ferrule allow for insertion of sheathed temperature probes; flow rate and flow configuration produces turbulent flow and fluid swirling after passing through one right angle bend and static screen flow mixers. (See Figure 15.)

Automative radiator; effective surface area of $1.85 \mathrm{~m}^{2}\left(20 \mathrm{ft}^{2}\right)$; $U_{A}$ yalue of $181.5 \mathrm{~W} /\left(\mathrm{m}^{2} \cdot{ }^{\circ} \mathrm{C}\right)\left(32 \mathrm{Btu} /\left(\mathrm{h} \cdot \mathrm{ft}^{2} \cdot{ }^{\circ} \mathrm{F}\right)\right)$

37.8 \& (10 gal.) glass-1ined domestic hot water tank; $1500 \mathrm{~W}(5118 \mathrm{Btu} / \mathrm{h})$ immersion heater

$2.06 \mathrm{kPa}$ (30 psi) spring-loaded valve

5 micron cartridge filter for hot water applications

$1000 \mathrm{~W}(3410 \mathrm{Btu} / \mathrm{h})$, cartridge resistance immersion heater

Adjustable proportional set point controller; $1000 \mathrm{~W}\left(3410 \mathrm{Btu} / \mathrm{h}_{1}\right)$ load capability using a triac assembly and a type-T thermocouple sensor 
Specifications For The Equipment And Sensors Used In The

Collectors Test Loops

Equipment/Sensor

Specifications

Pump

Flow meters

Temperature sensors

Temperature difference sensors

Pressure drop sensor
Self-priming, eccentric-disc positivedisplacement pump; variable pumping capacity of $0-3.45 \times 10^{-4} \mathrm{~m}^{3} / \mathrm{s}(0-5 \mathrm{gal} . /$ min.), forward or reverse and a static pressure head of $3.44 \times 10^{4} \mathrm{~Pa}$ (50 psi)

Turbine meter; Paddle-wheel type incorporating an orifice upstream and downstream providing a linear span of $0-6.3 \times 10^{-5} \mathrm{~m}^{3} / \mathrm{sec}(0-1 \mathrm{gal} . / \mathrm{min}$. using ball bearings and a magnetic pickup; specially linearized to within $+0.9 \%$ over the intended ranges of temperature and flow rates

$100 \mathrm{ohm}, 3$ wire platinum resistance thermometers interfaced with linear bridge amplifiers for a $1 \mathrm{mv} /{ }^{\circ} \mathrm{C}$ output

ThermocoupleS, type-T, 24 gauge incorporating stainless steel or copper sheathing with and without grounded the rmocouple junctions

Platinum resistance thermometers - same as for absolute temperature measurement

Inverted U-tube manometer; $0.635 \mathrm{~cm}$ ( 0.25 in.) i.d. and $25.4 \mathrm{~cm}$ (10 in.) long, filled with water and allowing the upper $U$ to be trapped with air 
Mercury-in-glass thermmeters calibrated from $0-100^{\circ} \mathrm{C}\left(32-212^{\circ} \mathrm{F}\right)$ and accurate to $+1^{\circ} \mathrm{C}\left(+2^{\circ} \mathrm{F}\right)$ are inserted into oil filled $0.93 \mathrm{~cm}(3 / 8 \mathrm{in})$ diameter copper wells in line with the inlet and outlet to the storage tank in order to monitor the respective temperatures. The inlet and outlet temperatures are required for adjusting the heat exchanger bypass in order to properly maintain steady-state conditions in the flow loop. To obtain steady-state conditions, the heat exchanger bypass is adjusted so that the storage tank inlet and outlet temperatures are equal to within $2^{\circ} \mathrm{C}\left(4^{\circ} \mathrm{F}\right)$.

A provision for make-up fluid in the flow loop serves several purposes. It can be used for filling or draining the loop or for pressurizing the entire system. Make-up water is obtained from a demineralized water storage tank.

A $0-0.4 \mathrm{l} / \mathrm{sec}(0-6 \mathrm{gal} / \mathrm{min}) 5-\mathrm{micron}$ particulate fluid filter is incorporated within the loop in order to protect the system from foreign particles. The filter is located upstream of the pump and flow meter since they are both very susceptible to damage by particulate matter.

The controlled $1 \mathrm{~kW}$ heater downstream of the filter serves to stabilize the inlet fluid temperature to the collector. Likewise the heater provides make up energy into the loop to offset the energy losses during the collector indoor heat loss tests. The input power to the heater is adjusted so that the fluid temperature downstream of the pump is held constant to within \pm $0.1^{\circ} \mathrm{C}\left( \pm 0.2^{\circ} \mathrm{F}\right)$. The heater power is controlled by a proportional temperature controller which senses the temperature downstream of the heater immediately after the pump with a type-T thermocouple and then proportionally controls the heater power in response to the sensor's deviation from a set point temperature. The proportionality of power output to set point deviation is adjustable in order to minimize temperature cycling within the flow loop.

The flow rates encountered within the loop are very low $(0-0.063 \mathrm{l} / \mathrm{s}(0-1 \mathrm{gal} /$ min)) requiring a stability of $\pm 1 \%$ while operating against high back pressures. For such circumstances, a low-flow 0-0.32 l/s (0-5 gal/min) positivedisplacement eccentric-disc pump capable of operating against back pressures of up to $340 \mathrm{kPa}$ ( 50 psi) was selected over several centrifugal pumps. Most typical centrifugal pumps are limited to higher flow rates and lower working pressures. This pump is further capable of adjusting the flow rate to within $\pm 0.0013 \mathrm{l} / \mathrm{s}( \pm 0.02 \mathrm{gal} / \mathrm{min})$ while a $1.3 \mathrm{~cm}(0.5 \mathrm{in}$.$) diameter needle valve$ downstream of the pump allows for fine adjustment.

A low flow paddle type turbine meter with a passive magnetic transducer is used to measure flow rate. The flow meter produces a digital output proportional to volumetric flow.

During this test program, the flow meter was always calibrated in-situ with a typical open-loop weight tank arrangement and in conjunction with any related electronic displays or readouts.

The low flow turbine meter and electronic display were initially calibrated over a flow and temperature range of $0-0.063 \mathrm{l} / \mathrm{s}(0-1 \mathrm{gal} / \mathrm{min}$. $)$ and $20-$ $100^{\circ} \mathrm{C}\left(68-212^{\circ} \mathrm{F}\right)$ respectively to an uncertainity of $\pm 0.9 \%$. 
A visual flow meter is located immediately downstream of the electronic flow meter in each loop. Functioning as a coarse flow indicator, the visual flow meter also serves as a sight glass for determining whether air is trapped within the system. Because the flow meter is only used to make coarse adjustments in the flow rate, the accuracy and resolution could be quite low. The flow meter used, a rotameter, is capable of measuring flows of $0-0.07 \mathrm{l} / \mathrm{s}(0-1.1 \mathrm{gal} / \mathrm{min})$ with an uncertainity of $\pm 2 \%$ of full scale.

For safety purposes, a $0.210 \mathrm{kPa}$ (0-30 psi) static pressure gauge is connected at the solar collector inlet. The purpose is to visually indicate the system pressure and warn of collector and system overpressurization.

Axial Fan Wind Simulator

The axial fan wind simulator used during indoor testing is comprised of two $68.5 \mathrm{~cm}$ (27 in) floor circulation fans. The fans provide a simulated wind across the collector surface as in Figure 13 and during this test program were either directed horizontally at the collector midsection or directed longitudinaly along the collector plane as illustrated in Figure 14. The fan speed and likewise wind speed can be stepwise controlled by use of a speed switch. Average wind speeds as high as $7.1 \mathrm{~m} / \mathrm{s}(15.8 \mathrm{mi} / \mathrm{h})$ can be simulated.

\section{Environmental Simulators}

Two environmental simulators, ES1 and ES2, were fabricated during this test program in order to provide a more uniform wind velocity across the collector than possible with the axial fan wind simulator and to investigate the effect of low "sky" temperature during indoor testing for collector thermal loss. Environmental simulator 1 (ESI) was the initial prototype. The experience obtained from ESI lead to subsequent development of environmental simulator 2 (ES2). Within each simulator, wind speeds were produced ranging from 0 to $6.4 \mathrm{~m} / \mathrm{s}$ ( 0 to $14.3 \mathrm{mi} / \mathrm{h}$ ) and apparent environmental radiance temperatures, $t_{\text {env }}$, equal to the ambient air temperature, $t_{a}$, and as low as $t_{a}-19^{\circ} \mathrm{K}$ $\left(\mathrm{t}_{\mathrm{a}}-34.2^{\mathrm{\delta}} \mathrm{R}\right)$.

ES1 is illustrated in Figure 15 and 16 and shown in Figure 17 with a collector under test. In use, it formed a rectangular duct enclosure typically $10 \mathrm{~cm} \times 91 \mathrm{~cm}$ ( 4 in $\times 36 \mathrm{in}$ ) in cross-section over the glazing surface of the collector under test. In cross-section, the bottom side of the duct enclosure was formed by the collector glazing, the sides using wood framing, and the top with a $0.05 \mathrm{~mm}$ (0.002 in) polyethylene plastic film. In operation, room air was pulled or pushed through the air duct to simulate a wind across the surface of the collector. The air was transported through the duct enclosure using a blower rated at $0.471 \mathrm{~m}^{3} / \mathrm{sec}\left(1000 \mathrm{ft}^{3} / \mathrm{min}\right)$ at 25.4 $\mathrm{cm}$ (10 in) of $\mathrm{H}_{2} \mathrm{O}$ and regulated by butterfly or bayonet dampers upstream or downstream of the blower.

To effectively simulate a low apparent environmental radiance temperature, a chilled tube and fin plate backed by insulation was suspended $1 \mathrm{~cm}(0.39$ in.) over and parallel to the polyethylene surface of the duct enclosure. 


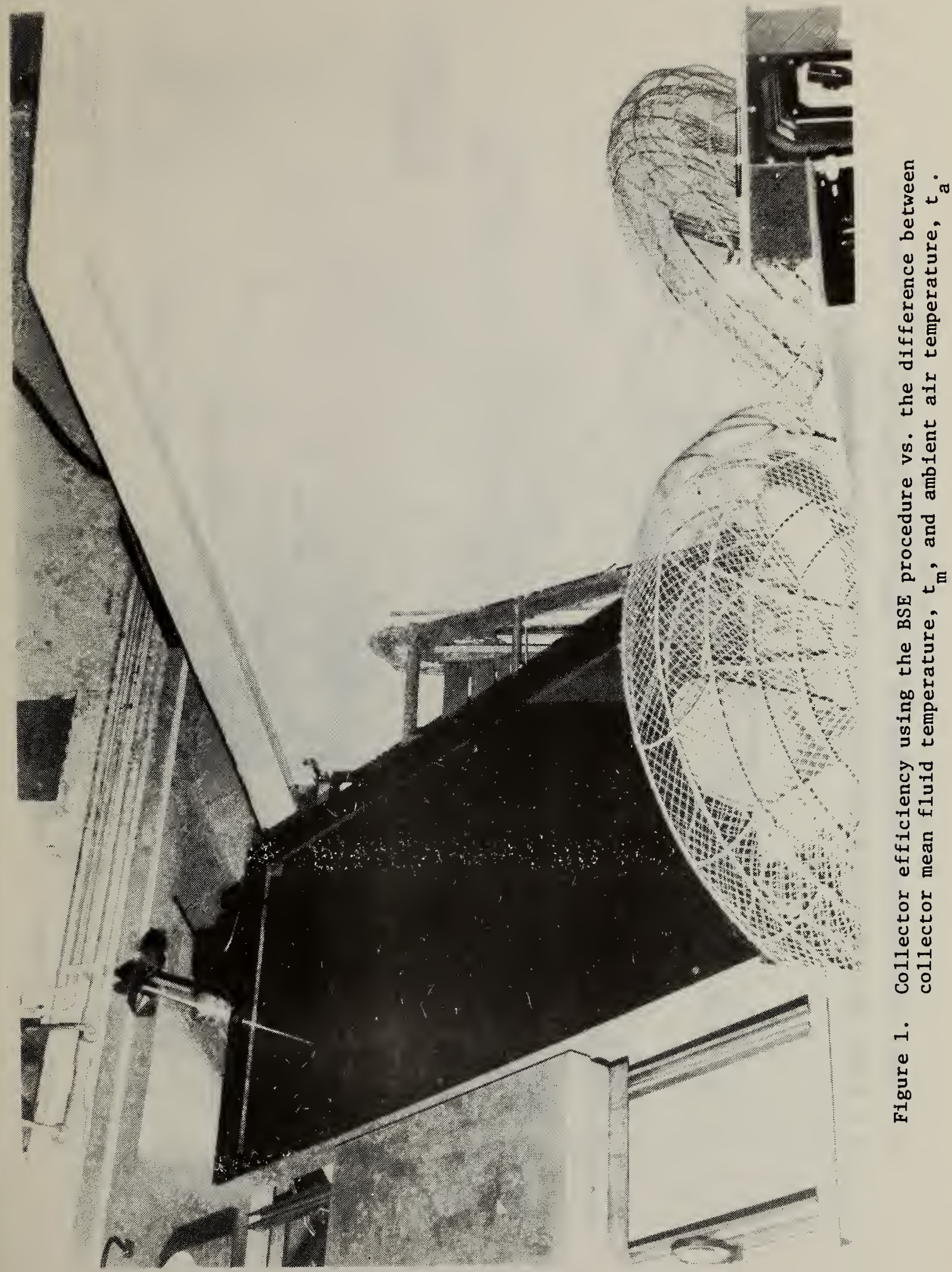



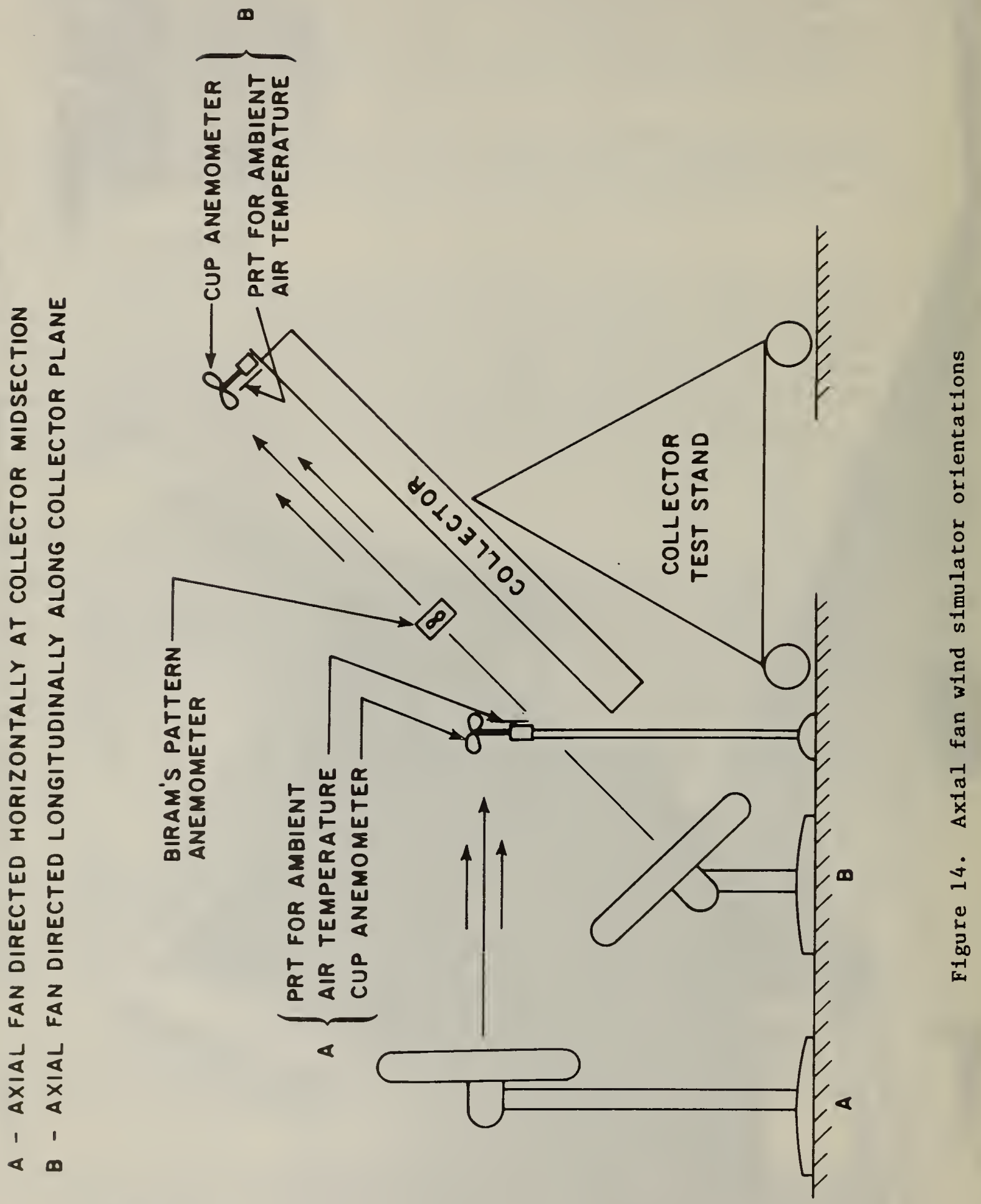


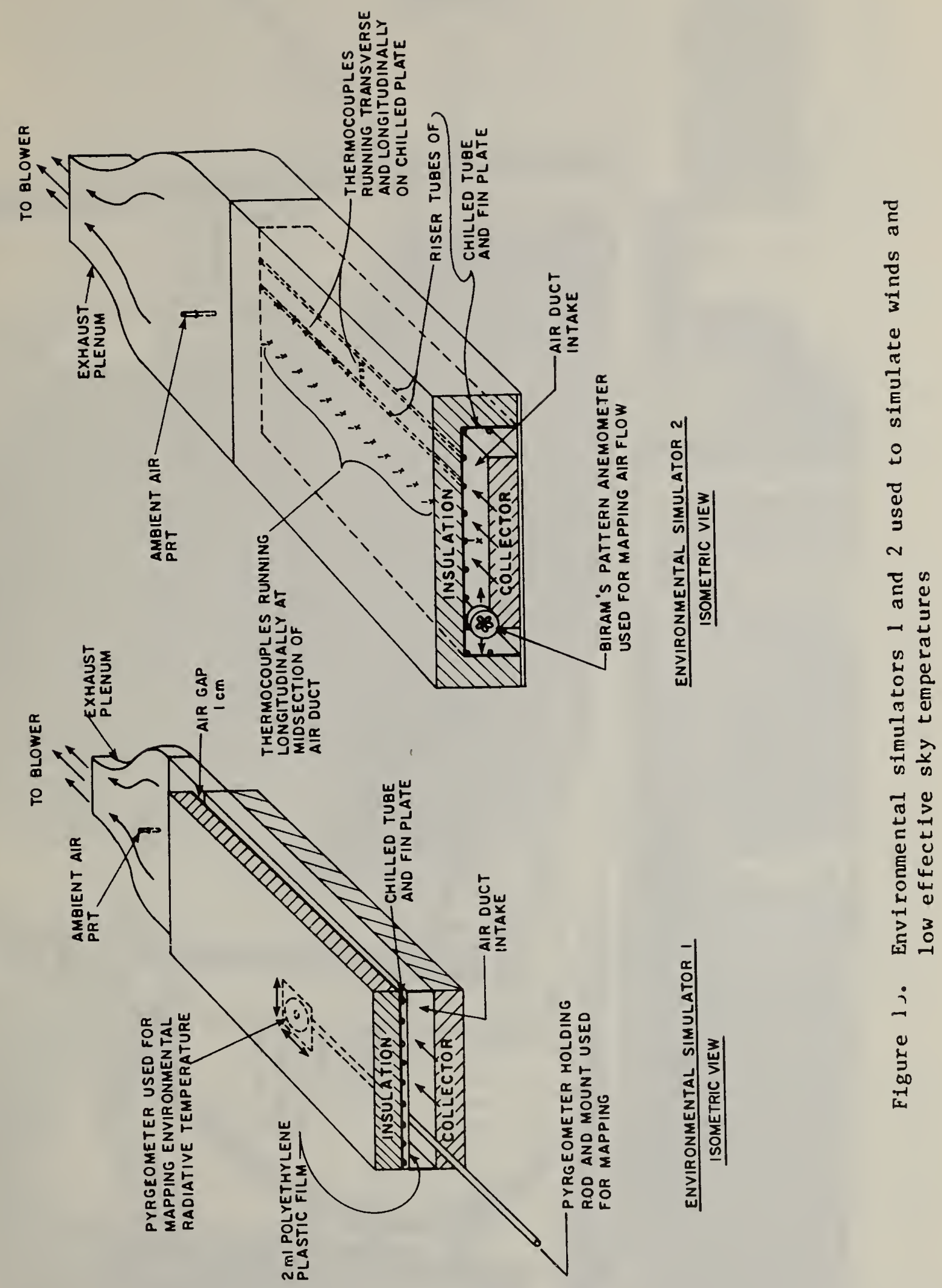




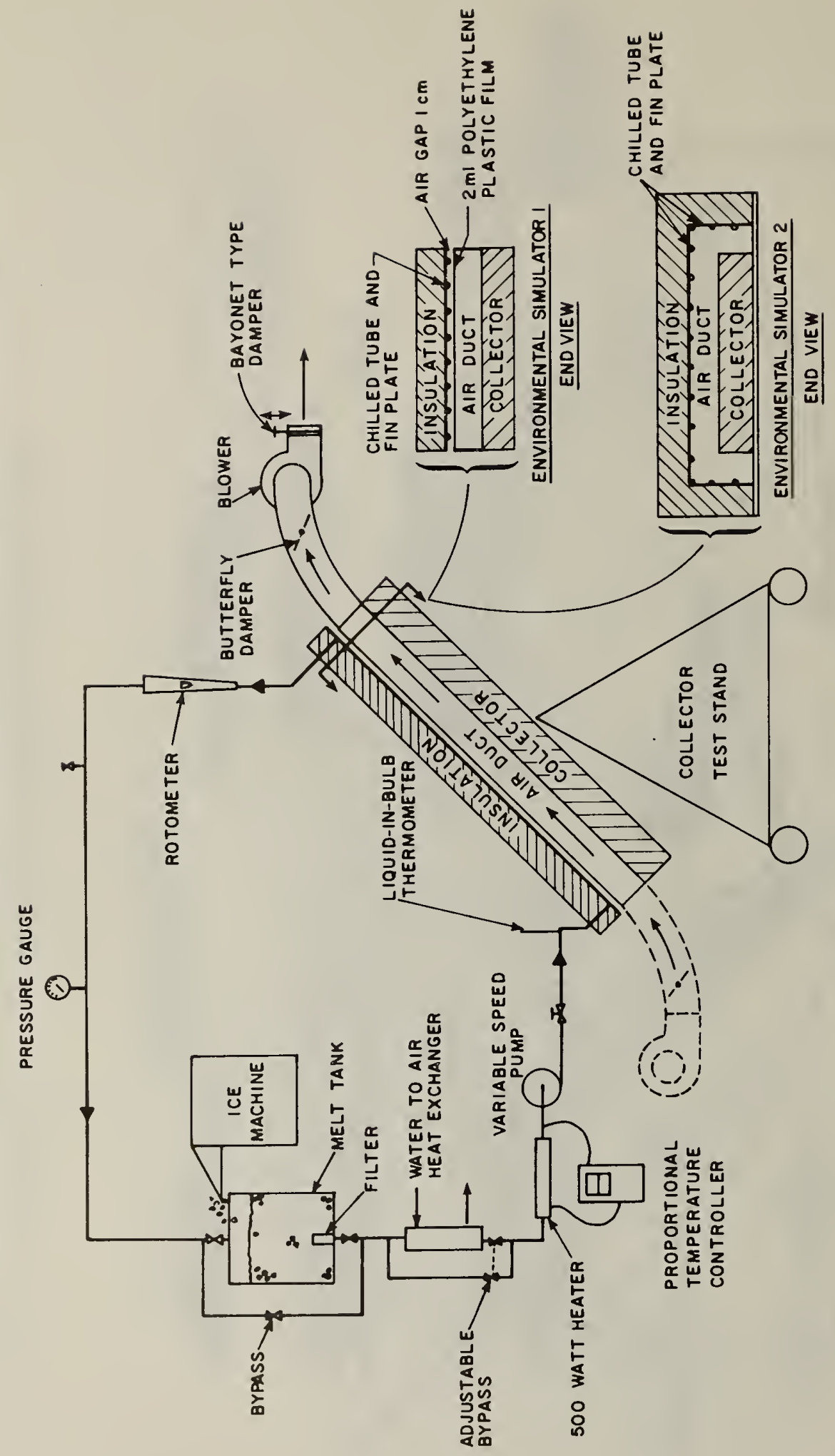

ป 


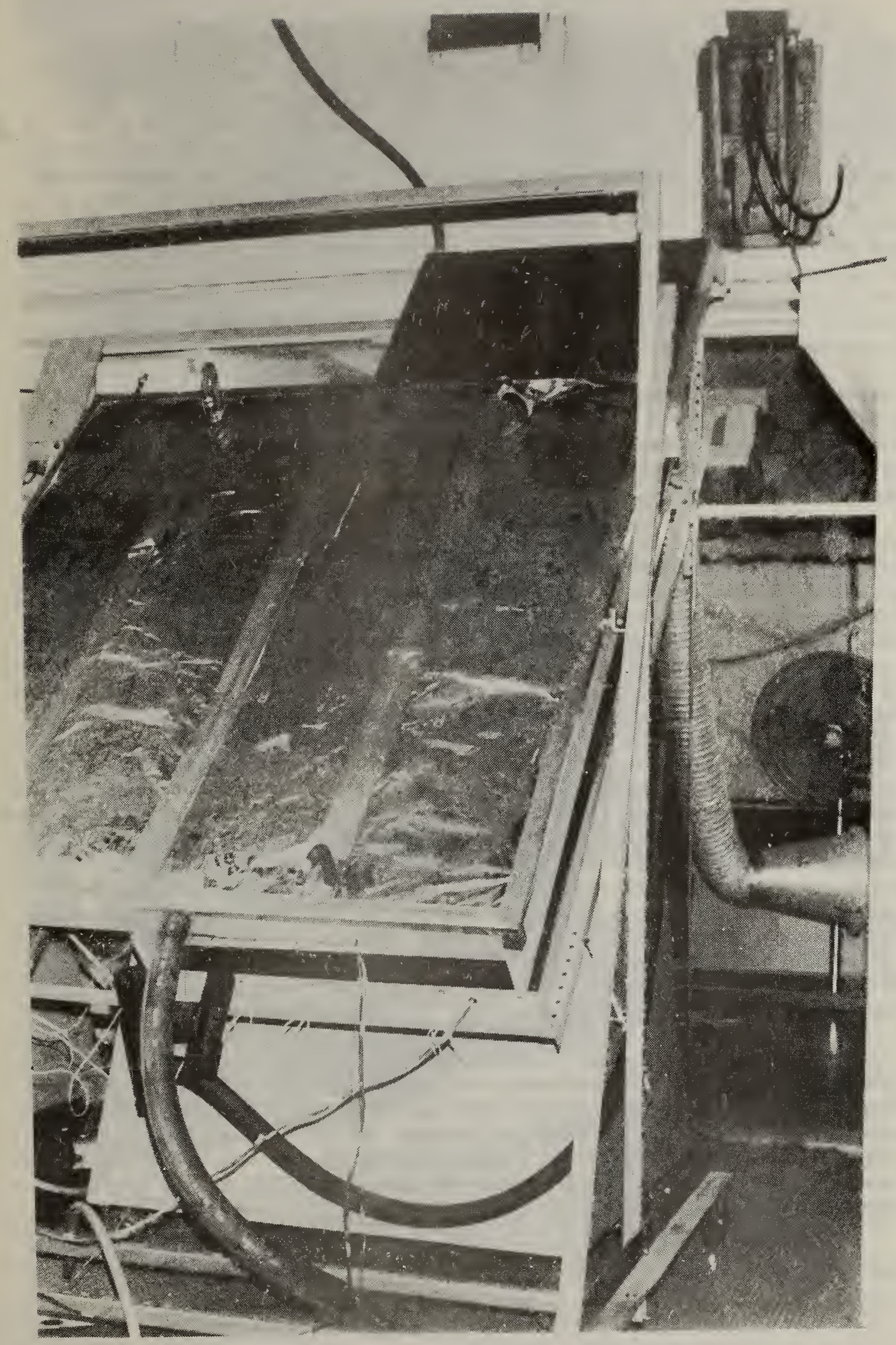

Figure 17. Environmental simulator 1 in operation with collector no. 4 
The chilled plate completely blanketed the polyethylene surface and viewed the collector through the plastic film with a view factor of 0.85 (based upon plate and collector dimensions and spacing). As a result of the high IR transmittance of the polyethylene $(80-83 \% *)$, the chilled plate and collector glazing could exchange energy by radiation. The polyethylene film was to isolate the air flow within the duct from the chilled plate to ensure as much uniformity as possible of surface temperature over the chilled plate (typically $1-2^{\circ} \mathrm{C}\left(2-4^{\circ} \mathrm{F}\right)$ ) and eliminate any convective cooling effects upon the air within the enclosed duct.

The chiller-loop in Figure 16 was used to provide a refrigerated working fluid, water, to the tube and fin chilled plate.

The chilled water was provided by melting ice within the melt tank which was continuously fed by a process ice machine. The ice water was then circulated through a water-to-air heat exchanger and past a $500 \mathrm{~W}$ in line immersion heater to elevate and control the inlet temperature of the chilled plate to within $\pm 1^{\circ} \mathrm{C}\left( \pm 2^{\circ} \mathrm{F}\right)$ of a setpoint.

Environmental simulator 2 (ES2) is also illustrated in Figures 15 and 16 and is shown in operation during collector testing in Figure 18. It was similar in design to ESl but included two modifications used to improve the stability and uniformity of environmental control during testing. First, the duct enclosure was altered to provide air flow along the collector edges and improve the view factor between the simulator and collector. For ESI, air passed only along the collector top glazing. Secondiy, the $0.05 \mathrm{~mm}(0.002 \mathrm{in})$ polyethylene plastic used in ESI was not included. It was originally felt that with the chilled plate in direct contact with the airstream, hot and cold spots would appear upon the chilled plate surface and result in excessive cooling of the airstream. But by ensuring good thermal coupling between the refrigerated fluid and the chilled plate, the surface temperature extremes were minimized and normally ranged only $4^{\circ} \mathrm{C}\left(9^{\circ} \mathrm{F}\right)$. Good thermal coupling was provided by utilizing a tube and fin plate with a high fin efficiency (0.97) and maintaining a high flow rate of $220 \mathrm{ml} / \mathrm{sec}(3.5 \mathrm{gal} / \mathrm{min})$ through the chilled plate. In operation, room air was pulled through the U-shaped duct enclosure longitudinally along the collector surface and edges. Likewise a refrigerated fluid was circulated through the U-shaped tube and fin plate to reduce the plate surface temperature and effectively create a low apparent environmental radiance temperature.

As a result of both the improved view factor and not including the polyethylene plastic within ES2, the necessity of mapping the apparent environmental radiance temperature was eliminated. The apparent environmental radiance temperature was determined knowing the average surface temperature and optical properties of the tube and fin plate. To verify the calculated apparent environmental radiance temperatures ES2 was mapped similar to ES1 during the initial stages of simulation.

* Based upon sample measurements at NBS using a spectrophotometer. 


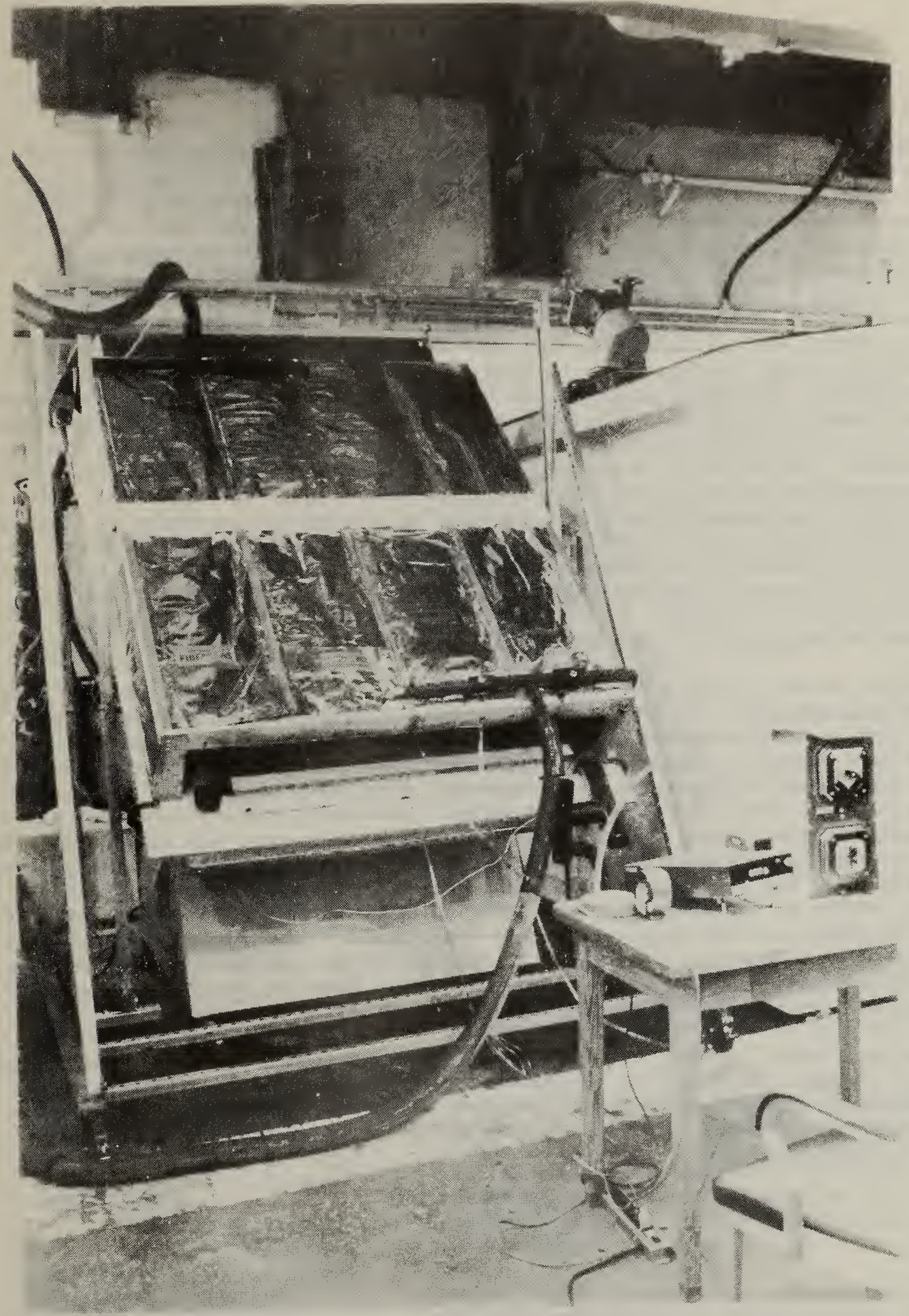

Figure 18. Environmental simulator 2 in operation with collector no. 5 
The specifications concerning the instrumentation used to monitor environmental conditions are given in Table 5. During outdoor testing, two types of ambient air temperature sensors were used in conjunction with a standard calibrated total-immersion ASTM liquid-filled thermometer. One was a type-T calibrated thermocouple and the other an industrial platinum resistance thermometer. The liquid-filled and resistance thermometer were accurate to within $+0.1^{\circ} \mathrm{C}\left(+0.2^{\circ} \mathrm{F}\right)$ while the calibrated thermocouple uncertainity was $\pm 0.2^{\circ} \overline{\mathrm{C}}\left( \pm 0.4^{\circ} \overline{\mathrm{F}}\right)$. All were housed within a well ventilated small instrument shelter located $1.25 \mathrm{~m}(4.1 \mathrm{ft})$ above the ground with its door facing north. During indoor testing with the axial fan wind simulator, a resistance thermometer was located immediately adjacent to the cup anemoneter as shown in Figure 13. For the environmental simulators, the air temperature within the enclosed duct was determined using three methods. First, the exit exhaust temperature from the simulator was monitored by a platinum resistance thermometer located within the exhaust plenum as shown in Figure 15 . Secondly, a resistance thermometer attached to a probe was periodically inserted within the air duct to spacially "map" the air temperature. Thirdly, an array of thermocouples shown in Figure 15 were located at $15.2 \mathrm{~cm}$ ( 6 in) intervals running longitudinally along the midsection of the enclosed duct. The platinum resistance thermometer and thermocouples had an associated uncertainty of $\pm 0.1^{\circ} \mathrm{C}$ and $\pm 0.2^{\circ} \mathrm{C}$, respectively.

During outdoor testing and indoor testing with the axial fans, the wind speed was measured by a cup anemometer delivering a direct current output proportional to the wind speed. Being portable, the wind anemometer could be located close to any tested collector and adjusted in height. As a result of a wind tunnel calibration, the resulting uncertainty of the wind velocity measurement was $\pm 0.35 \mathrm{~m} / \mathrm{s}( \pm 0.8 \mathrm{mi} / \mathrm{h})$. When using the environmental simulators during indoor testing, a Birams pattern anemometer was used to map the air velocity profile across the enclosed air ducts. During the mapping, the anemometer was sequentially positioned at $10 \mathrm{~cm}$ (4 in) increments along the air intake or exhaust of the simulator as shown in Figure 15. Positioned at each location, air velocity readings were obtained after integrating the air flow over a 30 second interval. As many as 16 readings were sometimes taken during a single run in order to average the results and determine an equally weighted average wind speed through the simulator.

During outdoor testing, the wind direction was recorded by visual observation of a directional wind vane during each test interval for the first part of the test program. Later in the program, a weather vane producing an analog output proportional to wind direction was installed to continuously monitor wind direction. 
Specifications For The Instrumentation Used To Make The Meteorological Measurements

Ambient air temperature

Wind speed

Wind direction

Total solar radiation incident on the collector tilted surface

Diffuse component of the solar radiation incident on the collector tilted surface

Direct beam solar radiation

Apparent environmental radiance temperature

Collector IR radiative losses
Calibrated type-T, 24 gauge thermocouple or precision platinum resistance thermometer housed within a vented weather shelter

Standard 3-cup wind anemometer incorporating a d.c. generator; output of 0.0581 volts $/ \mathrm{m} / \mathrm{s}(0.026 \mathrm{volts} / \mathrm{mph}) \operatorname{directly}$ proportional to wind velocity

Biram's Pattern Anemometer with jeweled movement, disconnector, automatic zero setting, $10 \mathrm{~cm}$ ( $4 \mathrm{in}$ ) in diameter for measuring air velocities from 1 to $15.3 \mathrm{~m} / \mathrm{s}$ (200 to $3000 \mathrm{ft} / \mathrm{min}$ )

Direction vane with a two-wiper potentiometer $\left(0-540^{\circ}\right)$

Precision spectral pyranometer utilizing an all black thermopile detector and temperature compensation; class 1 pyranometer as classified by the World Meteorological Organization

$10 \mathrm{~cm}$ (3.93 in) shadow disc attached to a $1 \mathrm{~m}(3.28 \mathrm{ft})$ long support rod

Normal incidence pyrheliometer with a collimated view of $5.7^{\circ}$ and an automatic tracker

Pyrgeometer; precision infrared radiometer capable of undirectional measurement of either incoming or outgoing long wave terrestrial radiation; a modification of the precision spectral pyranometer using a silicon hemisphere with a transmittance of 0.50 from 0.35 to $50 \mu \mathrm{m}$

Thermographic camera with a black and white and color display. The camera spectral sensitivity is from 6-15 $\mu \mathrm{m}$ by incorporating germanium optics with a minimum temperature difference resolution of $0.2^{\circ} \mathrm{C}$ $\left(0.4^{\circ} \mathrm{F}\right)$ at an object temperature of $30^{\circ} \mathrm{C}$ $\left(86^{\circ} \mathrm{F}\right)$ 
For measuring total solar irradiance incident on the solar collector, two types of pyranometers were used. Initially, a "black-and-white" mode1 8-48* pyranometer was used and was later replaced with an "a11-black" Model PSP*. Both pyranometers have a thermopile sensing element and similar protective dome glazings but differ in the recelver optical coatings and patterns. The pyranometer was mounted on an adjacent surface parallel to the collector in such a manner that it did not cast any shadow onto the collector. Care was taken to ensure that the pyranometer was at the same tilt as the solar collector and to minimize reflected and reradiated energy from the solar collector onto the pyranometer. The typical mounting scheme used is shown in Figure 10. The diffuse component of the incident solar radiation was determined for each efficiency test point by shading the pyranometer following the recommended technique of reference [11]. In addition to monitoring the total solar radiation, the direct normal radiation was measured using a pyrheliometer. The pyrheliometer tracked the sun and thereby measured the direct normal incident solar radiation throughout the day.

The apparent environmental radiance temperature occurring within ESI was determined by use of a commercially available infrared radiometer (pyrgeometer). Based on a calibration against a blackbody source, the pyrgeometer was capable of determining the absolute incoming long wave irradiance to within $\pm 3 \%$ integrated over the spectrum 3.5 to $50 \mu \mathrm{m}$. As a result, the apparent environmental radiance temperature could be determined to within $\pm 0.75^{\circ} \mathrm{C}\left( \pm 1.35^{\circ} \mathrm{F}\right)$. When mapping, the pyrgeometer was inserted into the duct enclosure through the air intake. The pyrgeometer was oriented with the radiometer base flat against the collector glazing with the infrared detector viewing in a direction away from the collector. The intent was for the radiometer to sense the same radiative environment as seen by the collector. The pyrgeometer was translated across the length and width of the collector surface forming a matrix of $20 \mathrm{~cm}$ ( 8 in) squares. In practice, the pyrgeometer was attached to a support rod as in Figure 15 and physically positioned at each point within the matrix. During a normal mapping run, as many as 44 readings were sometimes necessary to adequately map the entire collector surface. The average apparent environmental radiance temperature for a particular mapping run was calculated by averaging all of the various matrix segments equally.

The apparent environmental radiance temperature occurring within ES2 was determined from knowing the average surface temperature and optical properties of the tube and fin plate. The average surface temperature of the plate was determined using a matrix of thermocouples soldered to the blackened surface. To verify the calculated apparent environmental radiance temperatures, ES2 was mapped similarly as with ESl during the initial stages of use.

The collector overall radiative losses were qualitatively observed and documented using the thermographic equipment in Table 5. The equipment was com-

\footnotetext{
*Eppley Laboratories, Newport, Rhode Island. Identification of commercial instruments does not imply recommendation or endorsement by the National Bureau of Standards.
} 
prised of two CRT displays, black and white and color, and a thermographic camera sensitive to $I R$ radiation over the spectral range of 6-15 $\mu \mathrm{m}$.

\section{Data Acquisition}

A variety of data taken during this test program was monitored and recorded by a data acquisition system and other recorders. Data such as flow rates and temperatures from the liquid collector test loops, as well as meteorological data, were fed into one central instrumentation room. The room is a permanent part of the facility and is environmentally controlled and located adjacent to the test loops as shown in Figure 9.

The input signals from the various test loop transducers consist of analog voltage, digital voltage, or variable resistance. Analog signals are produced by thermopiles, pyranometers, anemometers, digital signals by liquid flow meters; and variable resistance from resistance thermometers. The digital and variable resistance signals are converted into analog signals before input to the data acquisition system. A flow rate monitor converts the flow transducer digital signals into analog form while separate individually matched and calibrated bridge amplifiers convert the resistance thermometer signals into analog form before entering the data aquisition system.

After conditioning the input data the information is fed into the equipment shown in Figure 19. The equipment is comprised of a combination of strip chart recorders and electronic integrators connected in parallel with a data logger. The purpose of the strip chart recorders is to monitor pertinent specific information on a continuous basis while the data logger scans and records all the input data on a periodic basis. Information such as irradiance, flow rates, and inlet-outlet temperature differences are continuously recorded on strip chart recorders in order to readily observe any transients. Electronic integrators are sometimes used to integrate quantities such as solar radiation or fluid temperature rise across a solar collector. The data logger scan interval was most often one minute during this test program. The data logger is capable of calculating and recording the arithmetic average of up to 16 inputs over a specific time interval; thus, the scan rate can be once per minute, whereas the average of the inputs can be automatically calculated and printed every five-minutes. Both the scan rate and the averager time interval are independent and adjustable. Typically input quantities such as wind speed, air temperature, and collector fluid flow rate are averaged using the built-in averager and printed on paper tape for later analysis. Approximately half-way through the experimental study described in this report, a magnetic tape drive recording system was interfaced with the data logger system to expedite the data reduction on the NBS central computer facility.

During a specific test, the collector absorber temperature as well as the simulator air and chilled plate temperatures were manually recorded separately from the automatic data acquisition system. The required thermocouples were interfaced through a selector switch into a thermocouple reader.

Table 6 includes the specifications for the strip chart recorders, integrators, and data logger. 


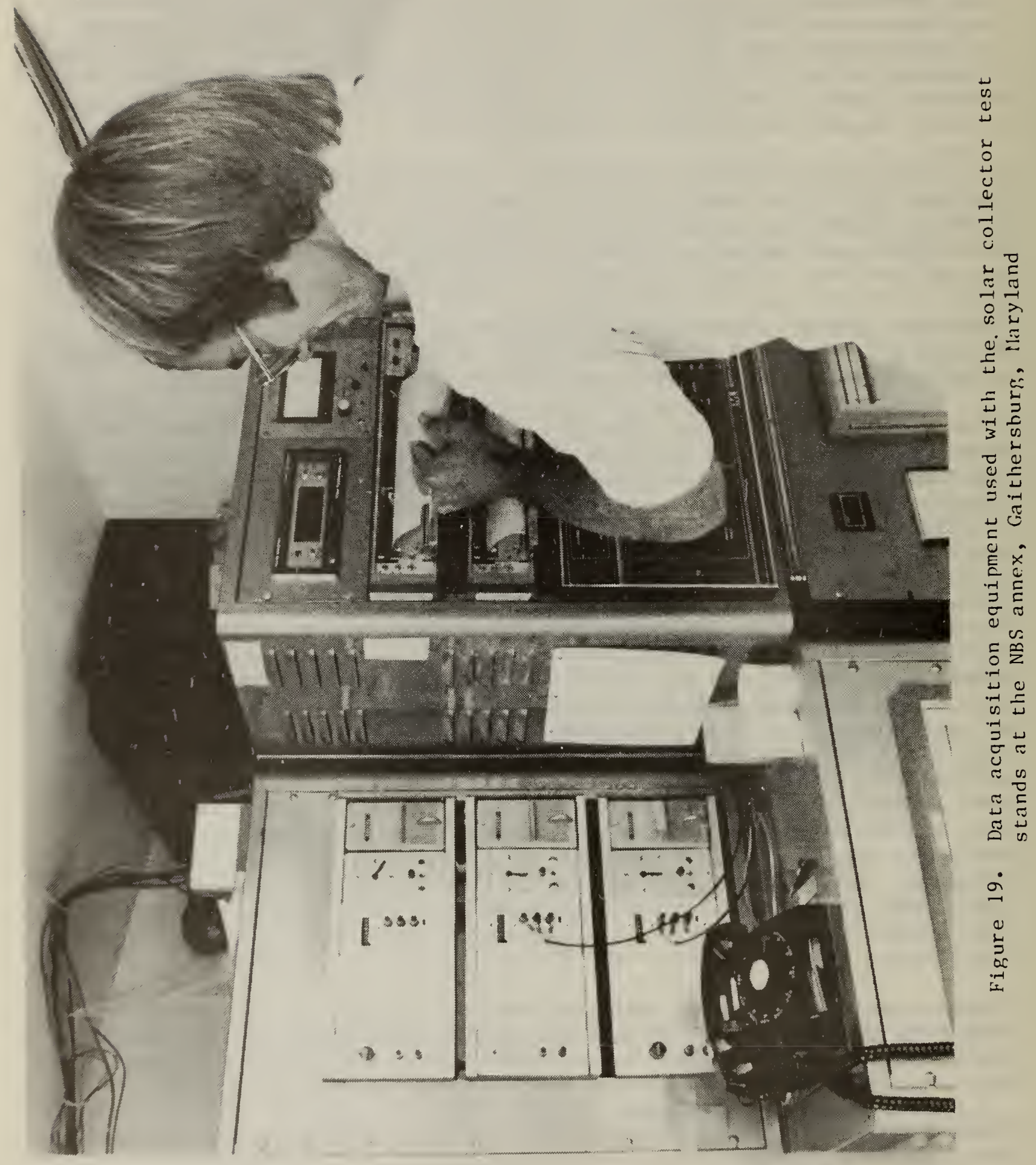


Table 6

Specifications For Strip-Chart Recorders, Integrators, and The Data Logger

\section{Strip-Chart Recorders}

2 Pen - Multi Range Input Span

Uncertainty: $\pm 0.25 \%$ of span

Input Impedance: $0-5 \mathrm{~V}, 30$ mega ohms; $5 \mathrm{~V}-10 \mathrm{~V}, 2.5$ mega ohms Time Constant: $0.5 \mathrm{~s}$

Input Spans: $0.1 \mathrm{mV}-10 \mathrm{~V}$, multiple range

Type Inputs Monitored: thermopiles, pyranometers, flow rates

2 Pen - Fixed Input Span

Uncertainty: $\pm 0.05 \%$ of reading

Input Impedance: 5 mega ohms

Time Constant: $0.75 \mathrm{~s}$

Input Span: $0-5 \mathrm{mV}$

Type Inputs Monitored: referenced thermocouples

3 Pen - Fixed Input Spans

Uncertainty: $+0.5 \%$ of span

Input Impedancé: 5 mega ohms

Time Constant: 1 s

Input Spans: $0-5 \mathrm{mV}, 0-100 \mathrm{mV}, 0-5 \mathrm{~V}$

Type Inputs Monitored: thermopiles, flow rates, resistance

thermometers

\section{Integrators}

Uncertainty: $\pm 0.5 \%$ of reading, \pm 2 digits $/ \mathrm{h}$

Input Impedancē: 1 mega ohm

Input Span: $0-30 \mathrm{mV}$

Type Inputs Monitored: thermopiles, pyranometers

\section{Data Logger}

Uncertainty: $\pm 0.01 \mathrm{mV}$, Max Error: $0.005 \%$ full scale, $\pm 0.2^{\circ} \mathrm{C}$

Input Imedance $\bar{T} 100$ mega ohms

Input Ranges: 0 - $400 \mathrm{mV}$; type-T thermocouples

Type Inputs Monitored: All input data thermocouples, $0-100^{\circ} \mathrm{C}$; analog signals, $0-400 \mathrm{mV}$

Special Features: 16-channel arithmetic averager with separate averaging time base

Magnetic Tape Drive: Incremental tape drive, 800 bpi, 9 track with

a DTL/TTL plus voltage true interface 


\section{EXPERIMENTAL TESTS}

Five flat-plate liquid heating solar collectors were experimentally tested according to both the BSE procedure and ASHRAE Standard 93-77. The collectors are described in Table 7 and were representative of various generic types of commercially available collectors. The collector parameters $F_{R}(\tau \alpha)_{e}$ and $F_{R} U_{L}$ were determined from the intercept and slope of the ASHRAE efficiency curve, respectively. The Hottel, Whillier, and Bliss analytical formlation for $(\tau \alpha)_{e}$ and $F^{\prime \prime}$ using the collector geometry and thermophysical properties $[12,13]$ were used to calculate $F^{\prime}$ and $U_{L}$.

Collector no. 3 had the highest overall thermal performance and collector no. 5 the poorest. The overall performance of the remaining three collectors tended to fall between the extremes of collectors no. 3 and no. 5 . Collectors no. 1 and 5 were identical in construction except for their types of glazing. Both exhibited poor thermal coupling between the working fluid and collector absorber due to a low fin efficiency and bond conductance resulting from a thin foil copper absorber that was mechanically clamped to the fluid risers as shown 1n Figure 20. Collectors no. 1 and 5 were selected to accentuate the differences between collector thermal losses measured indoors and experienced outdoors. In particular, collector no. 5 should have experienced the largest difference because of its high overall heat loss coefficient, $\left(U_{L}\right)$, and low collector efficiency factor, $\left(F^{\prime}\right)$.

Al1 five collectors were tested in direct conformance with both the ASHRAE and BSE collector test procedures.* Table 8 summarizes the environmental control configurations for all five collectors during the indoor testing. Each of the five collectors were tested using the axial fan wind simulators which were elther directed horizontally at the collector midsection (configuration A) or longltudinally along the collector aperture plane (configuration B) as 1llustrated in Figure 14. Axial fan configuration B was an improvement over A because more uniform wind speeds resulted but was only used with collectors no. 4 and 5. Collectors no. 3, 4 and 5 were also tested with the environmental simulators, ES1 and ES2.

Pulling the air through elther simulator resulted in better uniformity in wind speed compared with pushing it through. The air was pulled through the environmental simulators for collectors no. 4 and 5 only.

Various indoor environmental test conditions were simulated using each of the environmental control configurations. Using the axial fans, the wind speed across a collector was normally step controlled at $0,3.5$ and $6 \mathrm{~m} / \mathrm{s}(0,7.8$, $13.4 \mathrm{mi} / \mathrm{h}$ ) while the apparent environmental radiance temperature was allowed to float around room temperature $\left(t a \pm 3^{\circ} \mathrm{K}\right)$. Using the envorinmental simulators, three different wind speeds were simulated for each of two different

* When testing outdoors in accordance with the ASHRAE procedure, some data. points on the efficiency curves for collectors no. 1, 2, and 3 were obtained when the wind speed exceeded $4.5 \mathrm{~m} / \mathrm{s}(10 \mathrm{mi} / \mathrm{h})$. The average wind speed for all the points for collectors no. 1 and 3 was less than $4.5 \mathrm{~m} / \mathrm{s}(10 \mathrm{mi} / \mathrm{h})$. 
Table 7

Description of Collectors Tested

$\begin{array}{ccccc}\text { Collector } & \text { Collector } & \text { Collector } & \text { Collector } & \text { Collector } \\ \text { No. } 1 & \text { No. } 2 & \text { No. } 3 & \text { No. } 4 & \text { No. } 5\end{array}$

\begin{tabular}{|c|c|c|c|c|c|}
\hline Manufacturer & $\begin{array}{c}\text { Commerclal Solar } \\
\text { Energy }\end{array}$ & PPG Industries & $\begin{array}{c}\text { Chamberlain Mfg. } \\
\text { Company }\end{array}$ & Lennox LMSC $18-1$ & $\begin{array}{c}\text { Commercial Solar } \\
\text { Energy }\end{array}$ \\
\hline $\begin{array}{l}\text { Gross Area }\left(m^{2}\right) \\
\text { Aperture Area }\left(m^{2}\right)\end{array}$ & $\begin{array}{l}2.47 \\
2.29\end{array}$ & $\begin{array}{l}1.65 \\
1.60\end{array}$ & $\begin{array}{l}1.96 \\
1.79\end{array}$ & $\begin{array}{l}1.53 \\
1.40\end{array}$ & $\begin{array}{l}2.47 \\
2.29\end{array}$ \\
\hline \multicolumn{6}{|l|}{ Glazing } \\
\hline Material & Plate glass & Tempered glass & $\begin{array}{l}\text { Tempered low- } \\
\text { iron glass }\end{array}$ & $\begin{array}{l}\text { Tempered low- } \\
\text { iron glass with } \\
\text { anti-reflective } \\
\text { coatings }\end{array}$ & Polyfluoroethylene \\
\hline Number & 2 & 2 & 1 & 2 & 1 \\
\hline $\begin{array}{l}\text { Solar Transmittance } \\
\text { (single glass) }\end{array}$ & 0.87 & 0.85 & 0.90 & 0.96 & 0.92 \\
\hline
\end{tabular}

\section{Absorber}

\begin{tabular}{|c|c|c|c|c|c|}
\hline Material & Copper Foll & $\begin{array}{c}\text { Aluminum Roll } \\
\text { Bond }\end{array}$ & Mild Steel & Mild Steel & Copper Foll \\
\hline $\begin{array}{l}\text { Flow } \\
\text { configuration }\end{array}$ & $10 \underset{\text { parallel }}{\text { risers }}$ & $\begin{array}{l}13 \begin{array}{l}\text { parallel } \\
\text { risers }\end{array}\end{array}$ & $\begin{array}{l}\text { Pillow absorber } \\
\text { completely wetted } \\
\text { surface }\end{array}$ & 10 parallel & $\begin{array}{l}10 \begin{array}{l}\text { parallel } \\
\text { risers }\end{array} \\
\text { fise }\end{array}$ \\
\hline Coating & Flat Lacquer & Flat Lacquer & $\begin{array}{l}\text { Black Chrome } \\
\text { Nickel Substrate }\end{array}$ & $\begin{array}{l}\text { Black Chrome } \\
\text { Nickel Substrate }\end{array}$ & Flat Lacquer \\
\hline Solar Absorptance & 0.95 & 0.94 & 0.94 & 0.94 & 0.95 \\
\hline I.R. Emittance & 0.92 & 0.92 & 0.12 & 0.10 & 0.92 \\
\hline
\end{tabular}

\section{Insulation}

\begin{tabular}{|c|c|c|c|c|c|}
\hline Material & $\begin{array}{l}\text { Low Density } \\
\text { Polyurethane }\end{array}$ & Glass fiber & Glass fiber & Fiberglass-board & $\begin{array}{l}\text { Low Density } \\
\text { Polyurethane }\end{array}$ \\
\hline Thickness $(\mathrm{cm})$ & 6.35 & 7.62 & 7.00 & 7.9 & 6.35 \\
\hline$F_{R}(\tau \alpha)_{e}$ & 0.58 & 0.74 & 0.80 & 0.72 & 0.63 \\
\hline${ }_{R} U_{L} W /\left(m^{2} \cdot{ }^{\circ} \mathrm{C}\right)$ & -4.71 & -5.14 & -4.43 & -3.62 & -6.56 \\
\hline$F^{\prime}$ & 0.74 & 0.97 & 0.95 & 0.86 & 0.75 \\
\hline $\mathrm{U}_{\mathrm{L}} \mathrm{W} /\left(\mathrm{m}^{2} \cdot{ }^{\circ} \mathrm{C}\right)$ & 6.06 & 5.44 & 4.63 & 4.24 & 9.10 \\
\hline
\end{tabular}

* Derived from slope or intercept of ASHRAE 93-77 efficlency curve

** Determined from $F_{R}(\tau \alpha)_{e}$ and $F_{R} U_{L}$ and $H W B$ analytical formulations of $(\tau \alpha)_{e}$ and $F "$ 


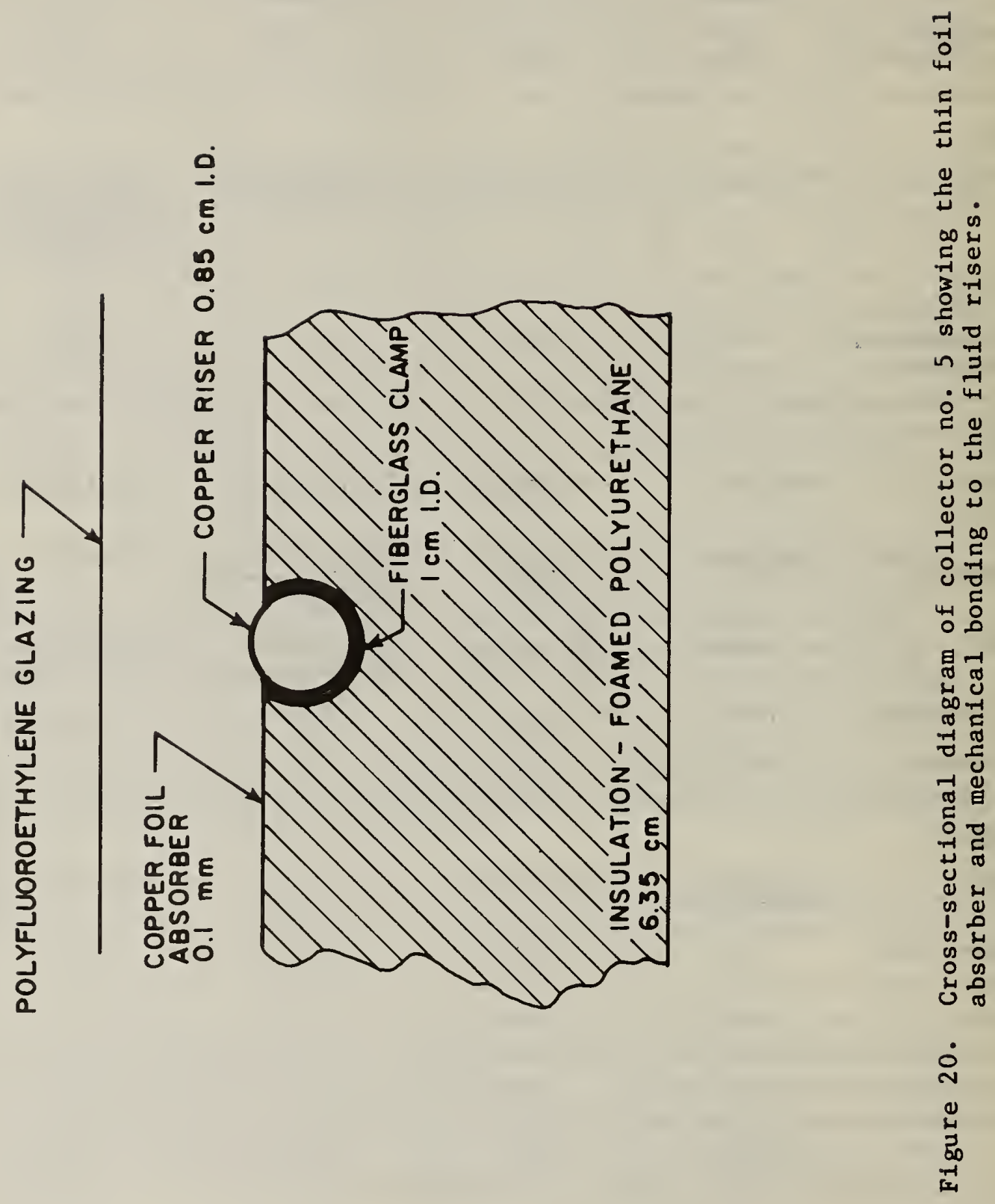


Table 7

Description of Collectors Tested

$\begin{array}{ccccc}\text { Collector } & \text { Collector } & \text { Collector } & \text { Collector } & \text { Collector } \\ \text { No. } 1 & \text { No. } 2 & \text { No. } 3 & \text { No. } 4 & \text { No. } 5\end{array}$

Manufacturer

Commercial Solar Energy
PPG Industries

$\begin{array}{ll}2.47 & 1.65 \\ 2.29 & 1.60\end{array}$

Chamberlain Mfg. Company

$\begin{array}{lll}1.96 & 1.53 & 2.47 \\ 1.79 & 1.40 & 2.29\end{array}$

Lennox LMSC 18-1

1.40
Gross Area $\left(\mathrm{m}^{2}\right)$

Aperture Area $\left(m^{2}\right)$

\section{Glazing}

Materia

Plate glass

Tempered glass

Tempered lowfron glass

2

Number

Solar Transmittance

(single glass)

\section{2}

0.87
1.65

1.79
Commercial Solar sinergy

2.47

2.29

\section{Absorber}

\begin{tabular}{|c|c|c|c|c|c|}
\hline Material & Copper Foll & $\underset{\text { Bond }}{\text { Aluminum Roll }}$ & Mild Steel & Mild Steel & Copper Fo1l \\
\hline $\begin{array}{l}\text { Flow } \\
\text { configuration }\end{array}$ & $10 \begin{array}{l}\text { parallel } \\
\text { risers }\end{array}$ & $13 \begin{array}{l}\text { parallel } \\
\text { risers }\end{array}$ & $\begin{array}{l}\text { Pillow absorber } \\
\text { completely wetted } \\
\text { surface }\end{array}$ & 10 parallel & $\begin{array}{l}10 \begin{array}{l}\text { parallel } \\
\text { risers }\end{array}\end{array}$ \\
\hline Coating & Flat Lacquer & Flat Lacquer & $\begin{array}{l}\text { Black Chrome } \\
\text { N1ckel Substrate }\end{array}$ & $\begin{array}{l}\text { Black Chrome } \\
\text { Nickel Substrate }\end{array}$ & Flat Lacquer \\
\hline I.R. Emlttance & 0.92 & 0.92 & 0.12 & 0.10 & 0.92 \\
\hline
\end{tabular}

\section{Insulation}

\begin{tabular}{|c|c|c|c|c|c|}
\hline Material & $\begin{array}{l}\text { Low Density } \\
\text { Polyurethane }\end{array}$ & Glass fiber & Glass fiber & Fiberglass-board & $\begin{array}{l}\text { Low Density } \\
\text { Polyurethane }\end{array}$ \\
\hline Thickness (cm) & 6.35 & 7.62 & 7.00 & 7.9 & 6.35 \\
\hline$F_{R}(\tau \alpha)_{e}$ & 0.58 & 0.74 & 0.80 & 0.72 & 0.63 \\
\hline$F_{R} U_{L} W /\left(m^{2} \cdot{ }^{\circ} \mathrm{C}\right)$ & -4.71 & -5.14 & -4.43 & -3.62 & -6.56 \\
\hline * $F^{\prime}$ & 0.74 & 0.97 & 0.95 & 0.86 & 0.75 \\
\hline${ }^{*} U_{L} w /\left(m^{2} \cdot{ }^{\circ} \mathrm{C}\right)$ & 6.06 & 5.44 & 4.63 & 4.24 & 9.10 \\
\hline
\end{tabular}

* Derived from slope or intercept of ASHRAE 93-77 efficiency curve

** Determined from $F_{R}(\tau \alpha)_{e}$ and $F_{R} U_{L}$ and HWB analytical formulations of $(\tau \alpha)_{e}$ and $F^{*}$ 


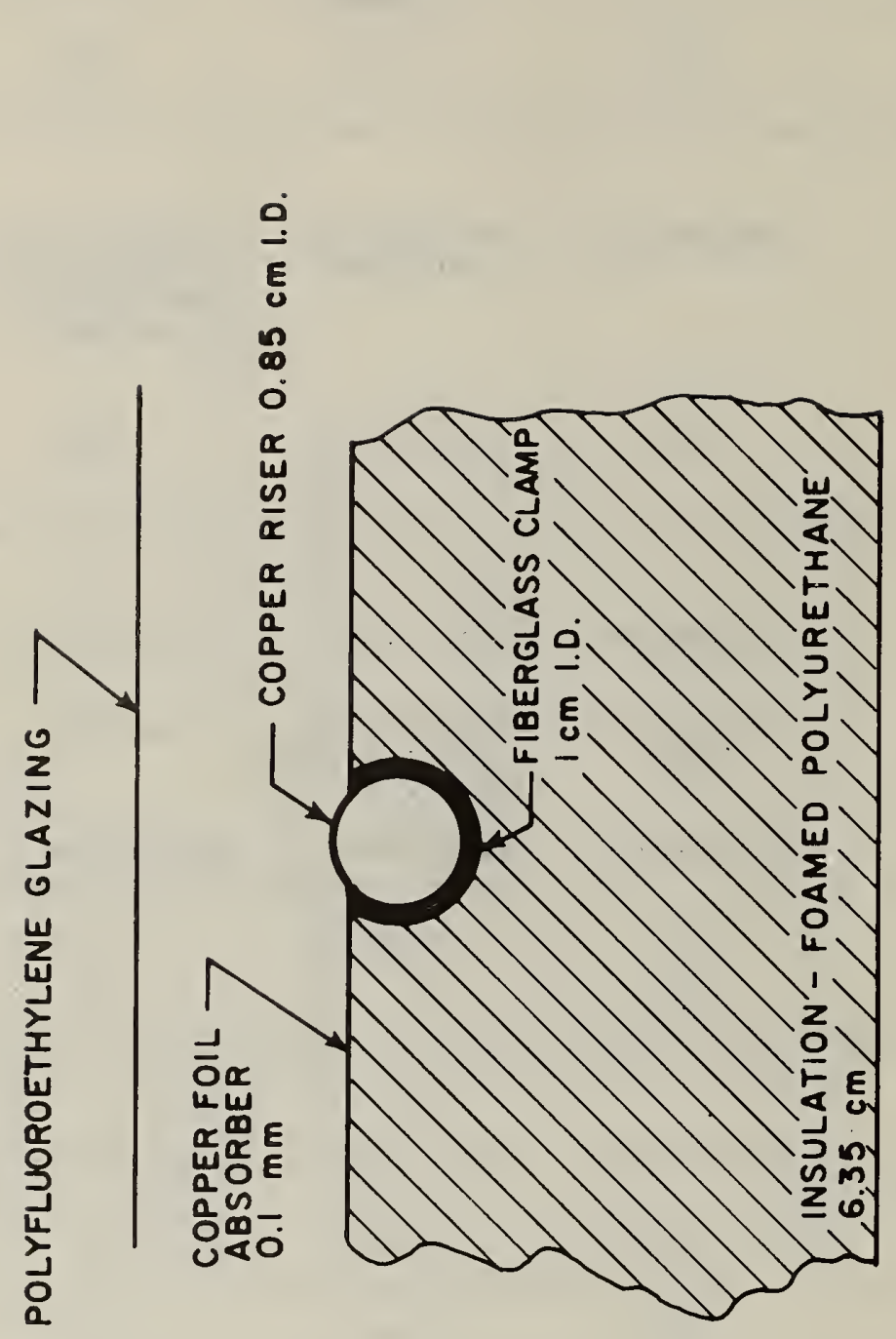

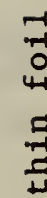


Table 8

Environmental Control Configurations Used During The Collector Thermal Loss Tests

\begin{tabular}{|c|c|c|c|}
\hline Collector & Axial Fan & $\begin{array}{l}\text { Environmental } \\
\text { Simulator } \\
1\end{array}$ & $\begin{array}{l}\text { Environmental } \\
\text { Simulator } \\
2\end{array}$ \\
\hline
\end{tabular}

No. 1

(Configuration A)

Horizontally at

collector midsection

No. 2

(Configuration A)

Horizontally at

collector midsection

No. 3 (Configuration B)

Horizontally at

collector midsection

Pushing air

through simulator

No. 4 (Configuration B)

Longitudially in

Pulling air

collector plane

through simulator

No. 5 (Configuration B)

Longitudinally in

Pulling air

configuration collector

through simulator

plane 
apparent environmental radiance temperatures. Wind speeds of $0,3.5$, and $6 \mathrm{~m} / \mathrm{s}(0,7.8$, and $13.4 \mathrm{mi} / \mathrm{h})$ were simulated for apparent environmental radiance temperatures equal to room temperatures $t_{a}$, and $t_{a}-19^{\circ} \mathrm{K}$. 


\section{TEST RESULTS AND DISCUSSION}

The results of testing the five collectors according to the BSE and ASHRAE test procedures are presented in Figures 21-31. The efficiency has been plotted based on the Standard 93-77 format. The heat loss curves and family of collector efficiency curves recommended in the BSE procedure are not included. The solid curves on each figure are test results using the BSE procedure and the dashed curve, results from testing in accordance with Standard 93-77. Only the solid curves which represent test conditions with wind speeds above $4 \mathrm{~m} / \mathrm{s}(9 \mathrm{mi} / \mathrm{h})$ and apparent environmental radiance temperatures of $t_{a} \pm 3^{\circ} \mathrm{K}$ are in strict conformance with the BSE procedure. The additional curves are included to show the effect of other environmental conditions. The ASHRAE Standard 93-77 curves were constructed from a linear least squares fit to the test data whereas the BSE curves were constructed from utilizing the indoor measured collector thermal losses which were nonlinear and thus a second order efficiency curve resulted. Each figure contains a summary of the applicable outdoor and indoor test conditions. In every case, the efficiency curves from the BSE tests are based on the average outdoor solar irradiance experienced during the Standard 93-77 test on the same collector.

The results are discussed below in four parts. First, a comparison is made between the BSE efficiency curves generated for all five collectors using the axial fan wind simulators and the corresponding ASHRAE 93-77 curves. Secondly, the BSE efficiency curves resulting from testing collectors no. 3 and 4 using environmental simulator 1 and for collector no. 5 using environmental simulator 2 are compared against the Standard 93-77 curves for the same collector. Thirdly, a comparison is made between the BSE efficiency curves determined using the axial fan wind simulator and using the environmental simulators. Finally, experimental results are shown and discussed concerning the control of environmental test conditions using the various simulators during indoor testing.

\section{Collector Efficiency Curves Using Axial Fan Wind Simulators}

Figures 21 through 25 give the experimental results for testing each of the five collectors strictly according to the currently adopted BSE and ASHRAE Standard 93-77 collector test procedures.* During all of the indoor testing, axial fans were used to simulate various wind speeds. Either fan configurations $A$ or $B$ of Figure 14 were used and are specified in each figure. The apparent environmental radiance temperature was not regulated but was allowed to float at or near room temperature $\left(t a \pm 2^{\circ} \mathrm{K}\right)$.

In general, the agreement between the Standard 93-77 collector efficiency curves and the BSE curves (wind speed $>4 \mathrm{~m} / \mathrm{s}$ ) $(9 \mathrm{mi} / \mathrm{h})$ for all five collectors is equal to or less than the measurement uncertainty associated with the Standard 93-77 curve of 4-5 efficiency points. The only exception is for collector no. 3 where the curves differ greatly in slope. However, the

*except as noted above 


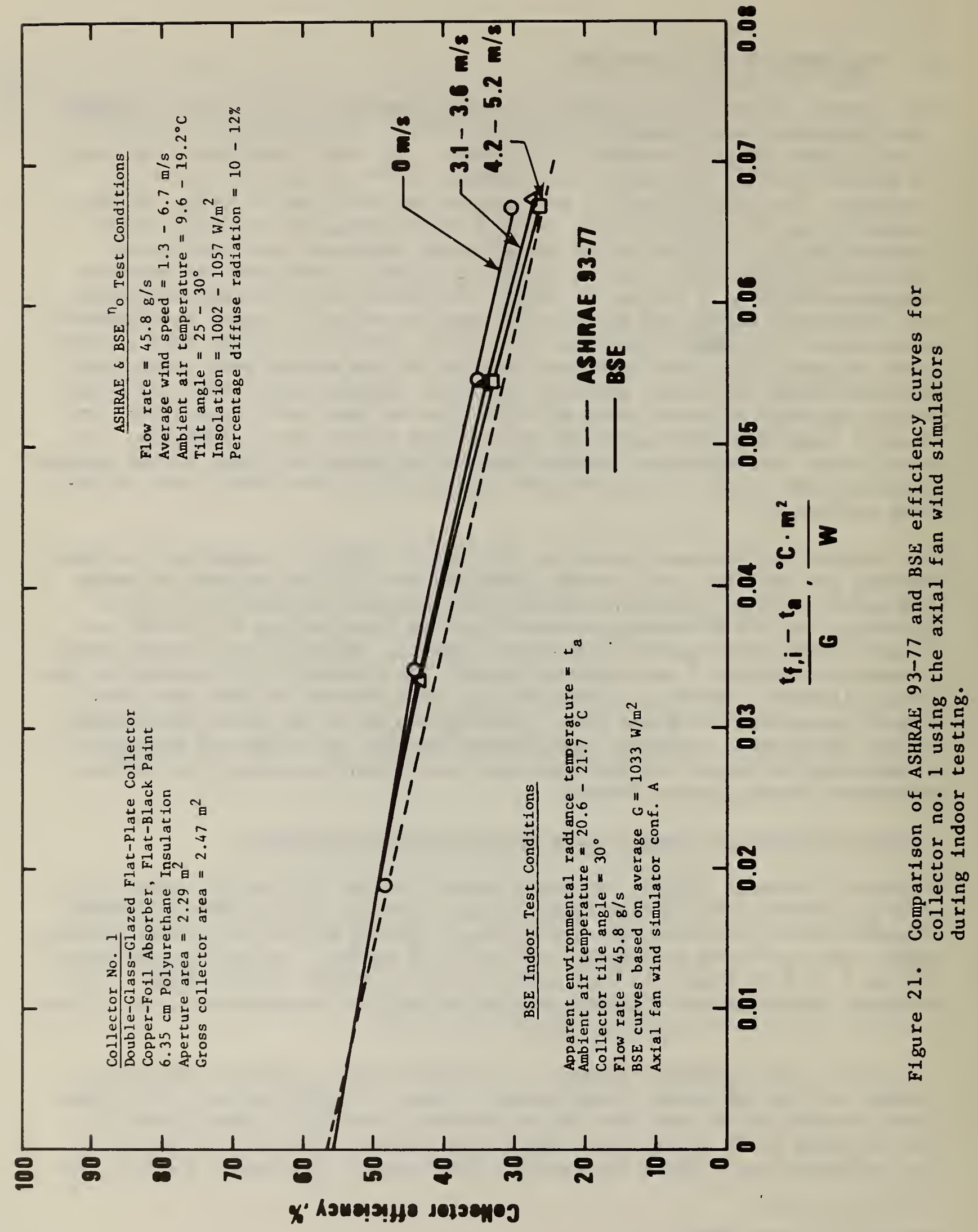




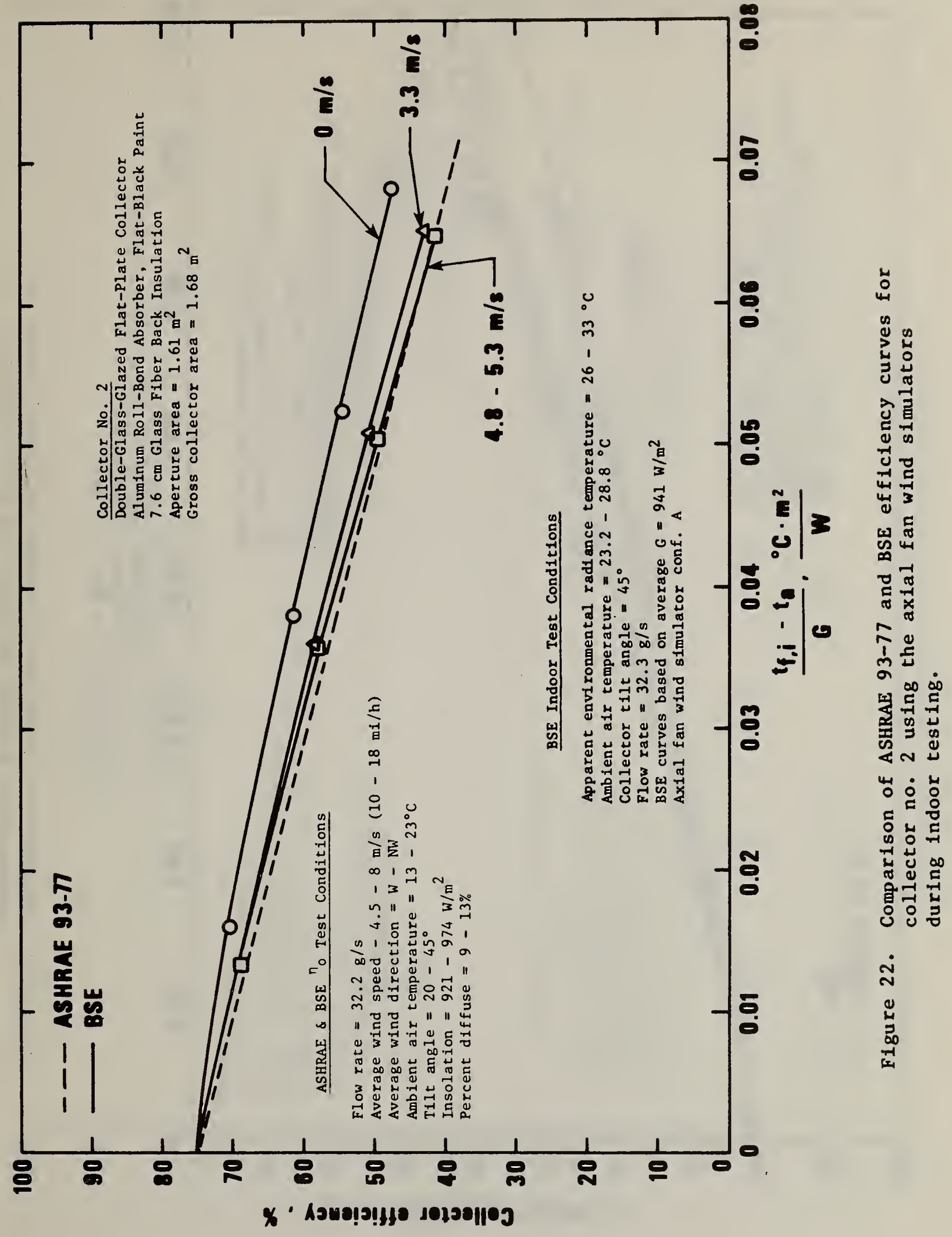




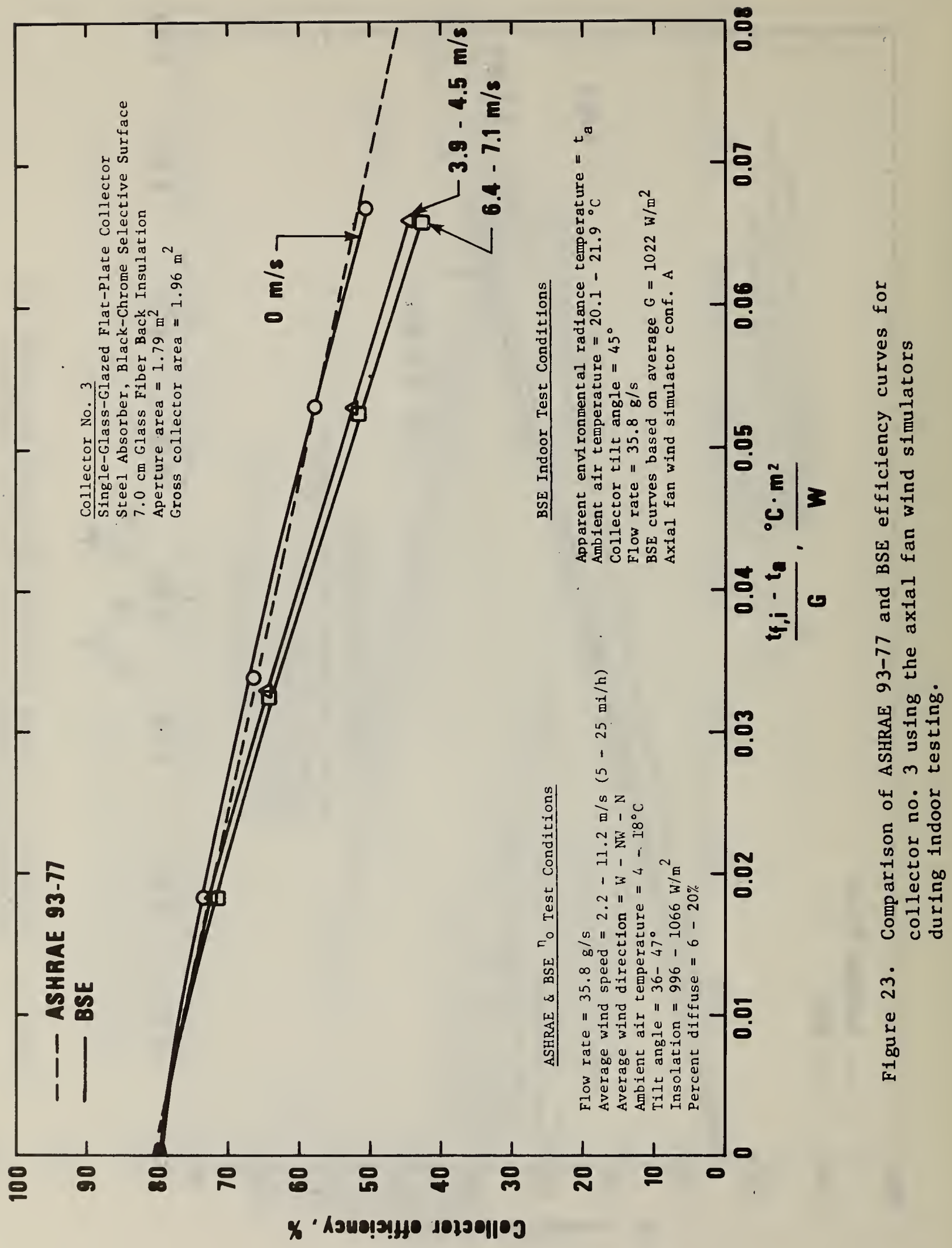




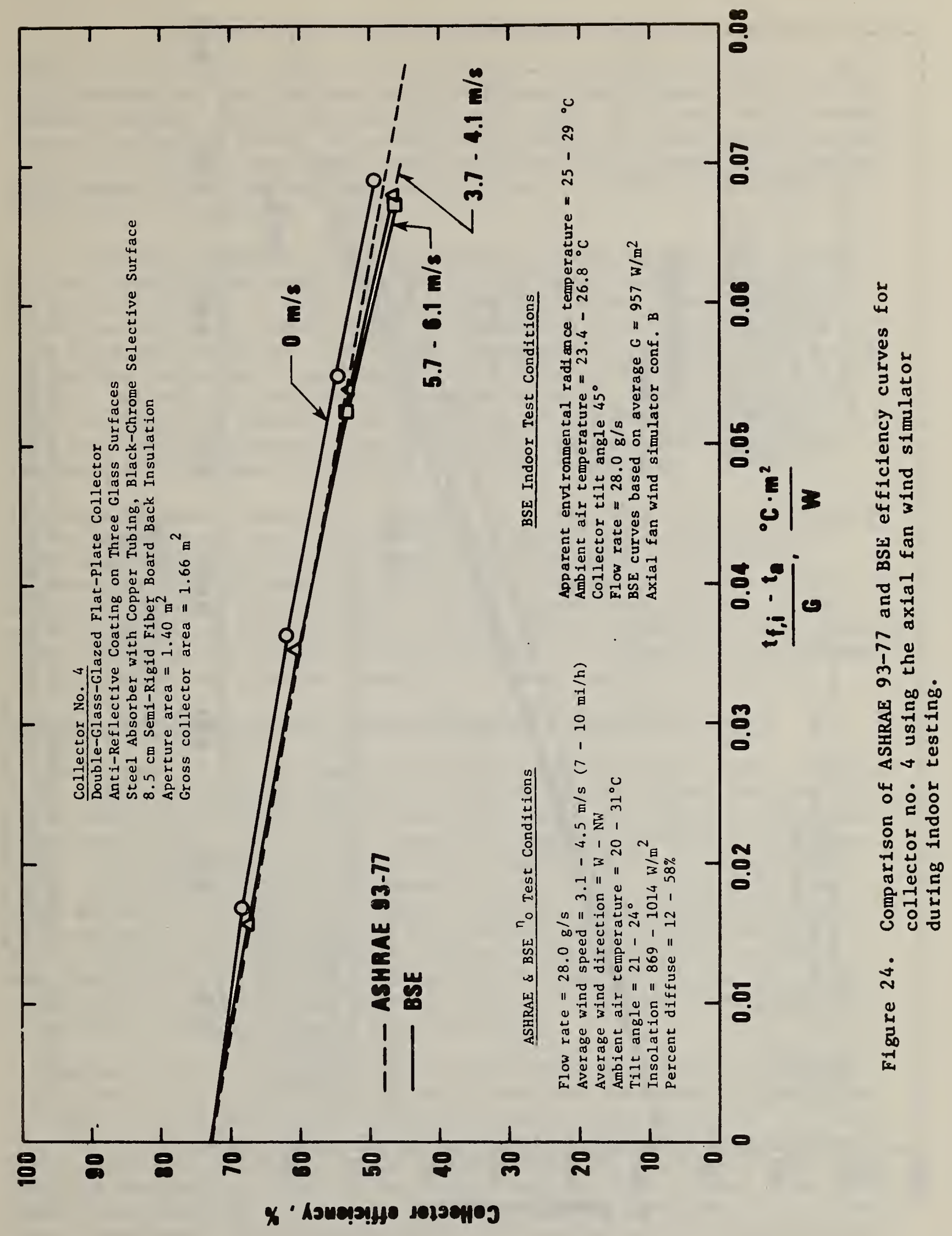




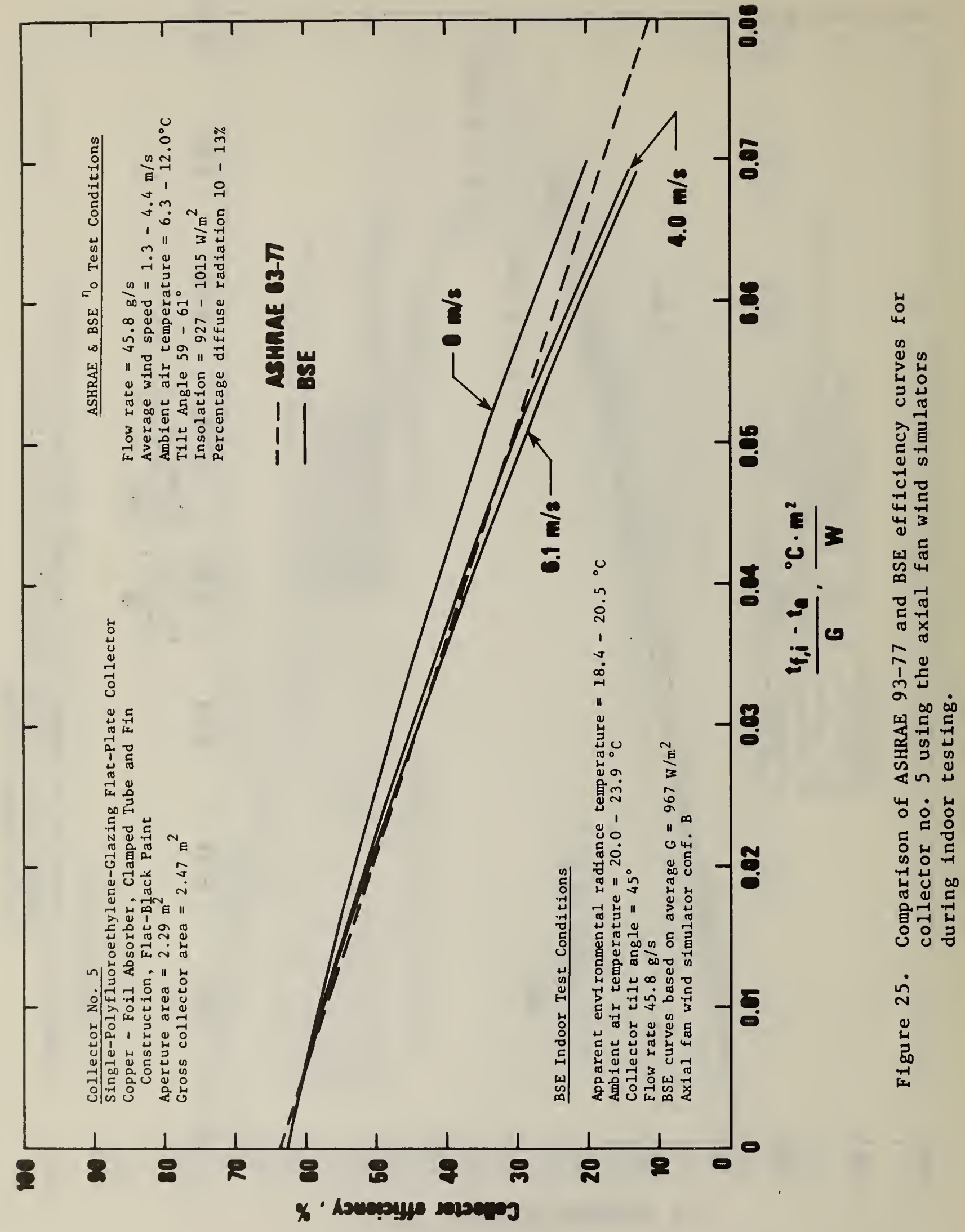


efficiency curve discrepancies for collector no. 3 are still less than the total uncertainty (both meteorological and measurement) associated with the companion ASHRAE curve. For each collector except no. 3, the best agreement between the BSE and ASHRAE efficiency curves occurs for wind velocities above $3.7 \mathrm{~m} / \mathrm{s}(8.2 \mathrm{mi} / \mathrm{h})$. The ASHRAE efficiency curve for collector no. 3 may be high because of the low air temperature (around $4^{\circ} \mathrm{C}\left(40^{\circ} \mathrm{F}\right)$ ) encountered during most of the outdoor testing.

It was generally expected, based upon collector construction, that collector no. 5 would be the most sensitive to wind speed followed in order by collectors no. $3,2,1$, and 4. The collectors followed this trend except for collector no. 2. Collector no. 2 exhibited a larger sensitivity to wind speed than expected. After using thermographic equipment on it during the various indoor heat loss tests, several thermal short circuits were observed between the absorber plate and collector glazing or casing. The short circuits were caused by direct contact of the collector absorber with the outer edge flashing and the absorber buckling against the inner glazing due to inadequate allowance for thermal expansion.

The close agreement between the Standard 93-77 and BSE collector efficiency curves for collector no. 5 in Figure 25 is significant. Collector no. 5 had a high overall thermal loss coefficient $\left(9.1 \mathrm{~W} /\left(\mathrm{m}^{2}{ }^{\circ} \mathrm{C}\right)\right.$ ) and a low collector efficiency factor $(0.75)$. Both factors should tend to accentuate the differences between thermal losses indoors and outdoors. Consequently, of all the five collectors, the agreement between the two procedures should have been the poorest for collector no. 5. In reality, the agreement is quite good, less than the Standard 93-77 measurement uncertainty.

Collector Efficiency Curves Using Environmental Simulators 1 and 2

Figures 26 and 27 are the result of testing collectors no. 3 and 4, respectively using environmental simulator 1 (ES1) during the indoor testing. Likewise, Figure 28 is the result of testing collector no. 5 with environmental simulator 2 (ES2). For the BSE curves the apparent environmental radiance temperature ranged from near ambient air temperature, $t_{a}$, to $t_{a}-$ ( 15 to $\left.19^{\circ} \mathrm{k}\right)$. This range of radiance temperature, $t_{a}$, to $t_{a}-\left(15\right.$ to $\left.19^{\circ} \mathrm{k}\right)$ typically reflects the extremes of outdoor effective sky temperatures. Due to the construction of ESI (allowing air flow only across the collector glaz ing), the BSE efficiency curves of Figures 26 and 27 reflect the collector sensitivity to wind only across the glazing. Since ES2 provided air flow along both the collector top and edges, Figure 28 includes wind sensitivity of collector no. 5 to both top and edge losses.

In figures 26-28, the agreement between the ASHRAE Standard 93-77 and BSE efficiency curves over the full range of simulated environmental conditions is better than or equal to the measurement uncertainty associated with the Standard 93-77 curve. Collector no. 4 was very insensitive to variations in both apparent environmental radiance temperatures and wind speed. This was expected considering collector no. 4 had a very low overall heat loss coefficient and because ESI used during the indoor testing accounted for top losses only. Based upon these experimental results, no definitive conclusions can 


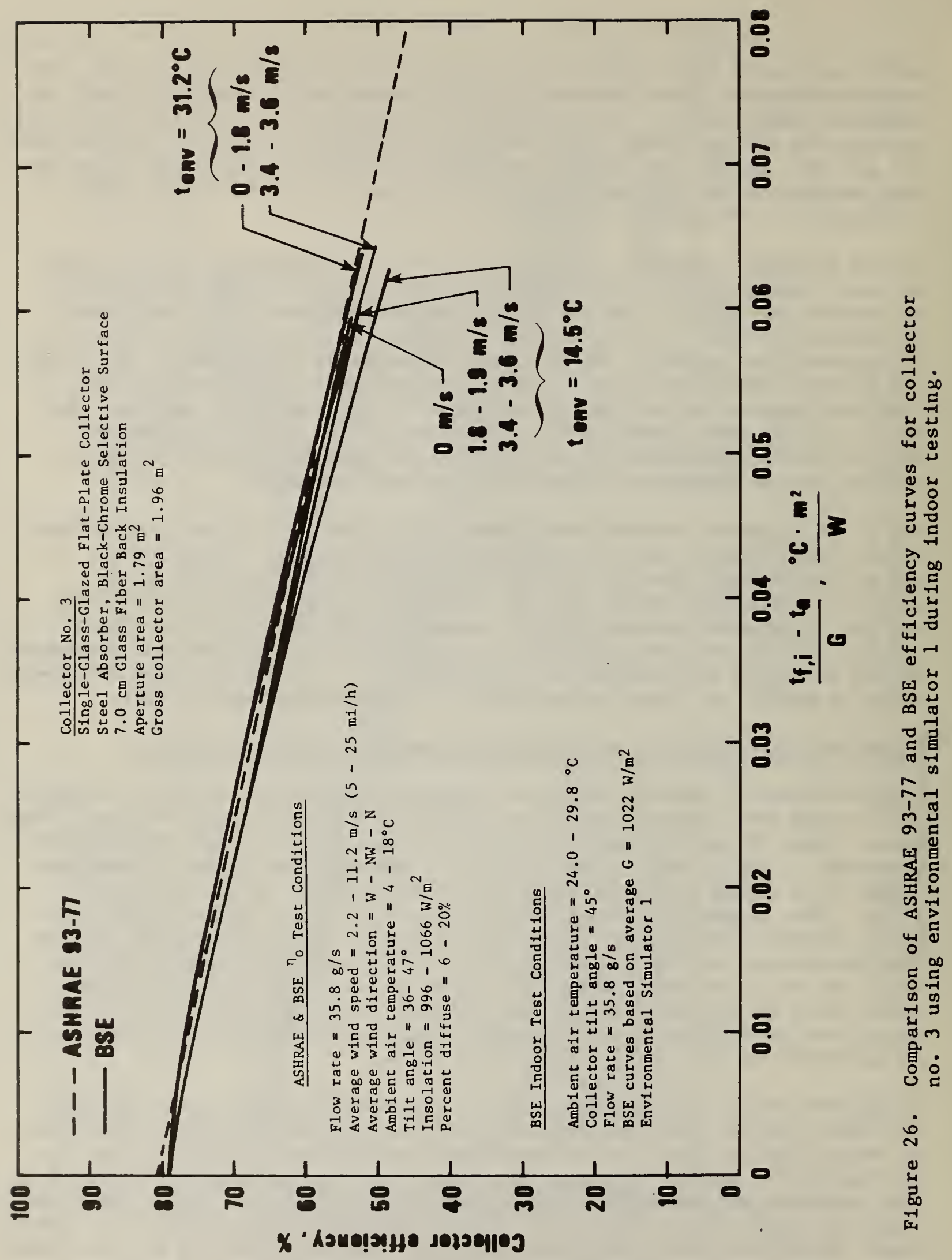




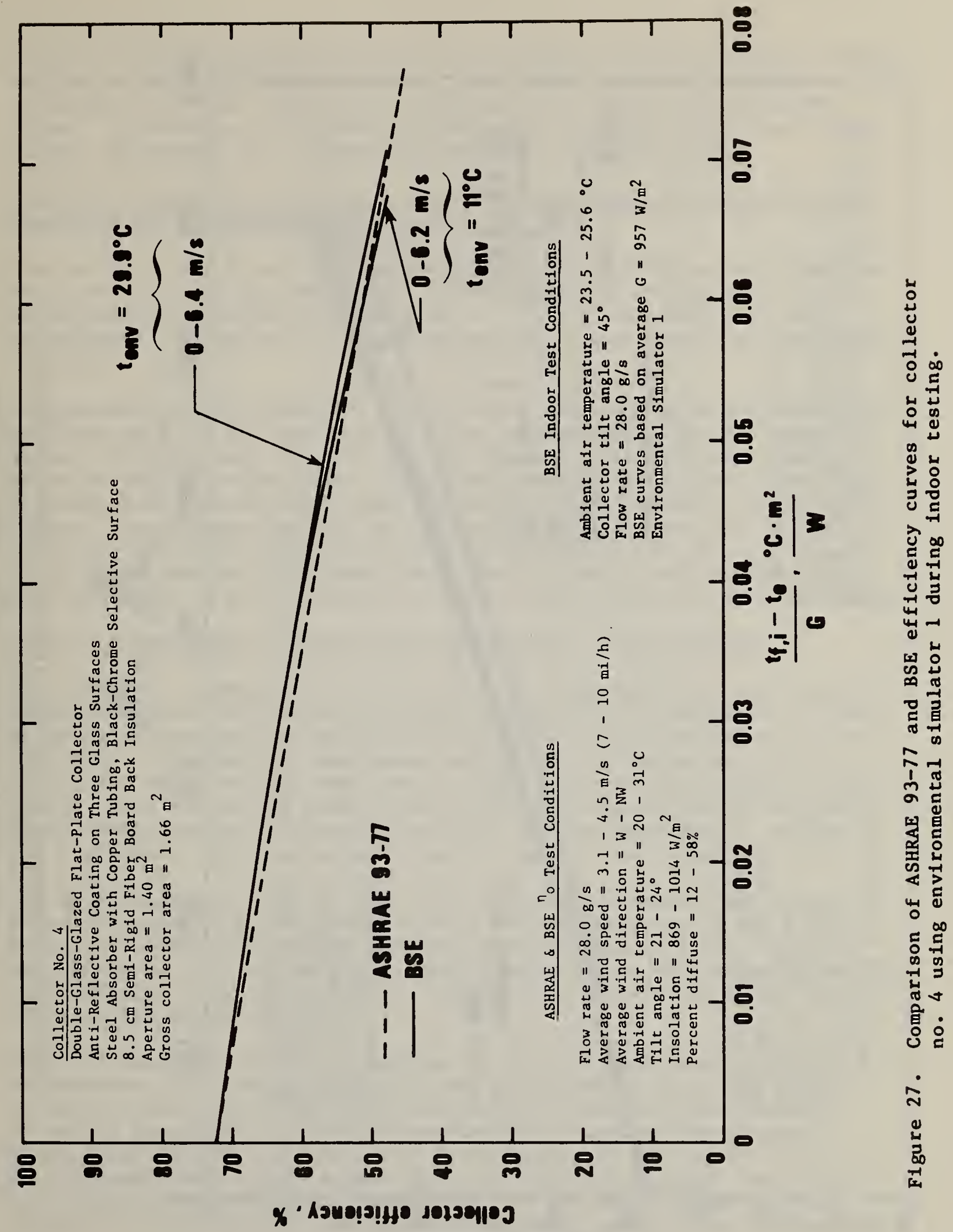




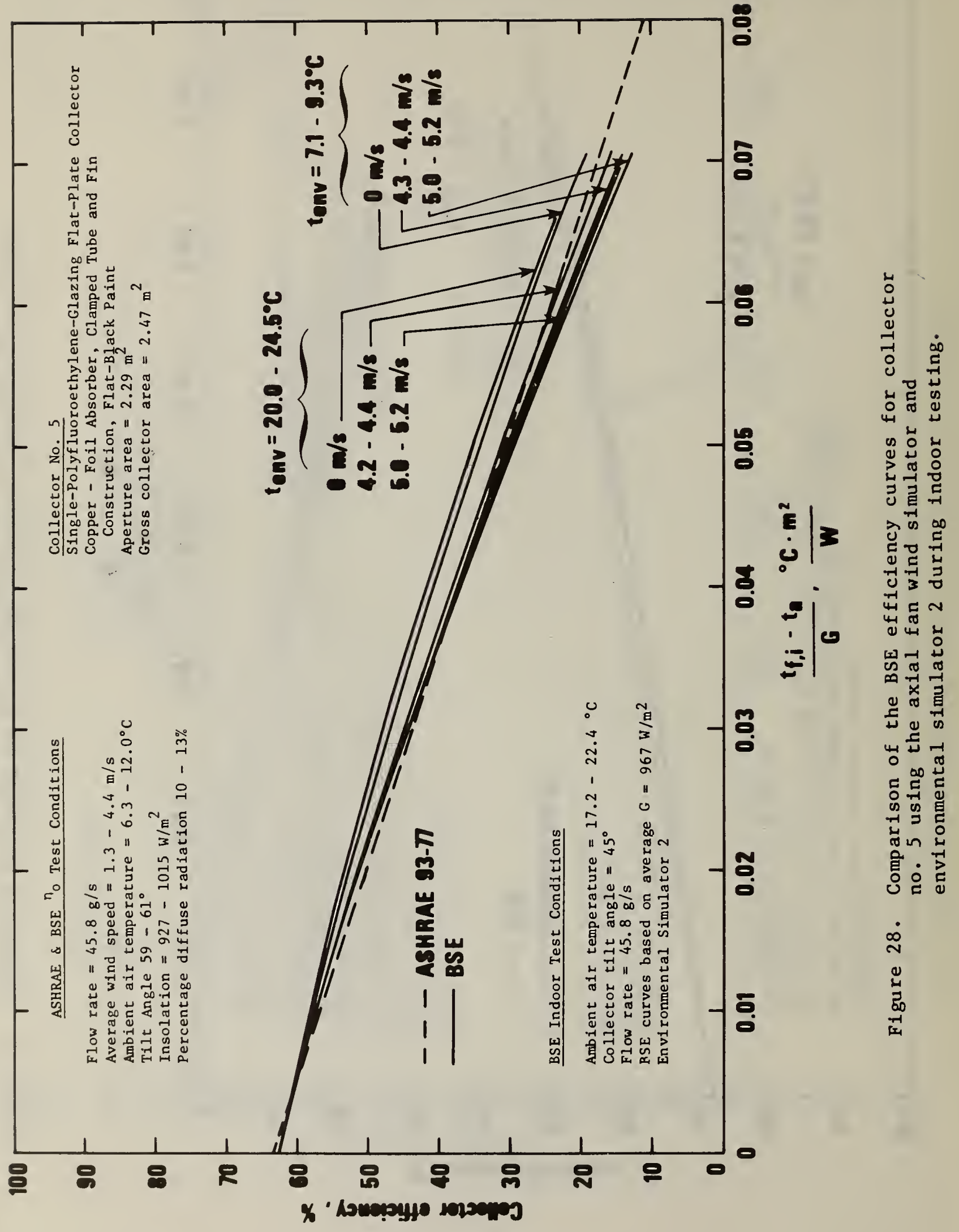


be made about which indoor test conditions produce the best agreement between the BSE and ASHRAE efficiency curves. This should have been expected considering the total uncertainty associated with each of the efficiency curves. In addition, the indoor environmental conditions which best reflect outdoor performance will depend upon individual collector design.

Comparison Between BSE Efficiency Curves Obtained Using the Axial Fan Wind Simulators and Environmental Simulators 1 and 2

Figures 29,30 and 31 are the results of comparing the BSE curves determined using the axial fan wind simulators and environmental simulators 1 and 2 during indoor testing of collectors no. 3, 4 and 5, respectively. The envi ronmental simulators are summarized on each figure under BSE Indoor Test Conditions.

The agreement between using ESI and the axial fans in Figures 29 and 30 are excellent at $0 \mathrm{~m} / \mathrm{s}$ but very poor at higher wind speeds. This is due to the curves reflecting only the collector top thermal losses and not overall losses as with the axial fans. The effect is higher efficiency curves for wind speeds above $0 \mathrm{~m} / \mathrm{s}$ when using ESI because of the lower collector heat losses. The agreement between the curves in Figure 31 where ES2 is compared with the axial fan wind simulator is extremely good. The development of ES2 to include air flow along the collector edges as well as the top glazing results in more realistic collector thermal losses to the environment.

Regulation and Control of BSE Indoor Environmental Test Conditions

The sequential implementation of the axial fan wind simulator, environmental simulator 1 , and environmental simulator 2 was part of a progressive effort to refine and improve the control of experimental indoor environmental test conditions. A variety of measurement and mapping techniques were used to monitor the indoor wind velocity and apparent environmental radiance temperatures. As a result, any improvements in control and uniformity of environmental conditions due to altering the axial fan configuration or environmental simulator construction were readily apparent and documented.

Figure 32 illustrates typical wind velocity profiles mapped transversely to the air flow across a collector for axial fan configurations $A$ and $B$ while pushing or pulling air through environmental simulators 1 or 2 . Definite improvement in air flow uniformity resulted when the axial fans were directed longitudinally along the collector plane and when the air was pulled through either environmental simulator.

Figure 33 shows the results of mapping the apparent environmental radiance temperatures using the pyrgeometer within environmental simulator 1 . The results are also typical of conditions within environmental simulator 2 . The matrix represents the spacial distribution of apparent environmental radiance temperatures longitudinally and transversely as viewed out from the collector surface. As a result of the collector-simulator view factor and likewise increasing fluid temperature from bottom to top within the simulator, higher apparent environmental radiance temperatures were observed 


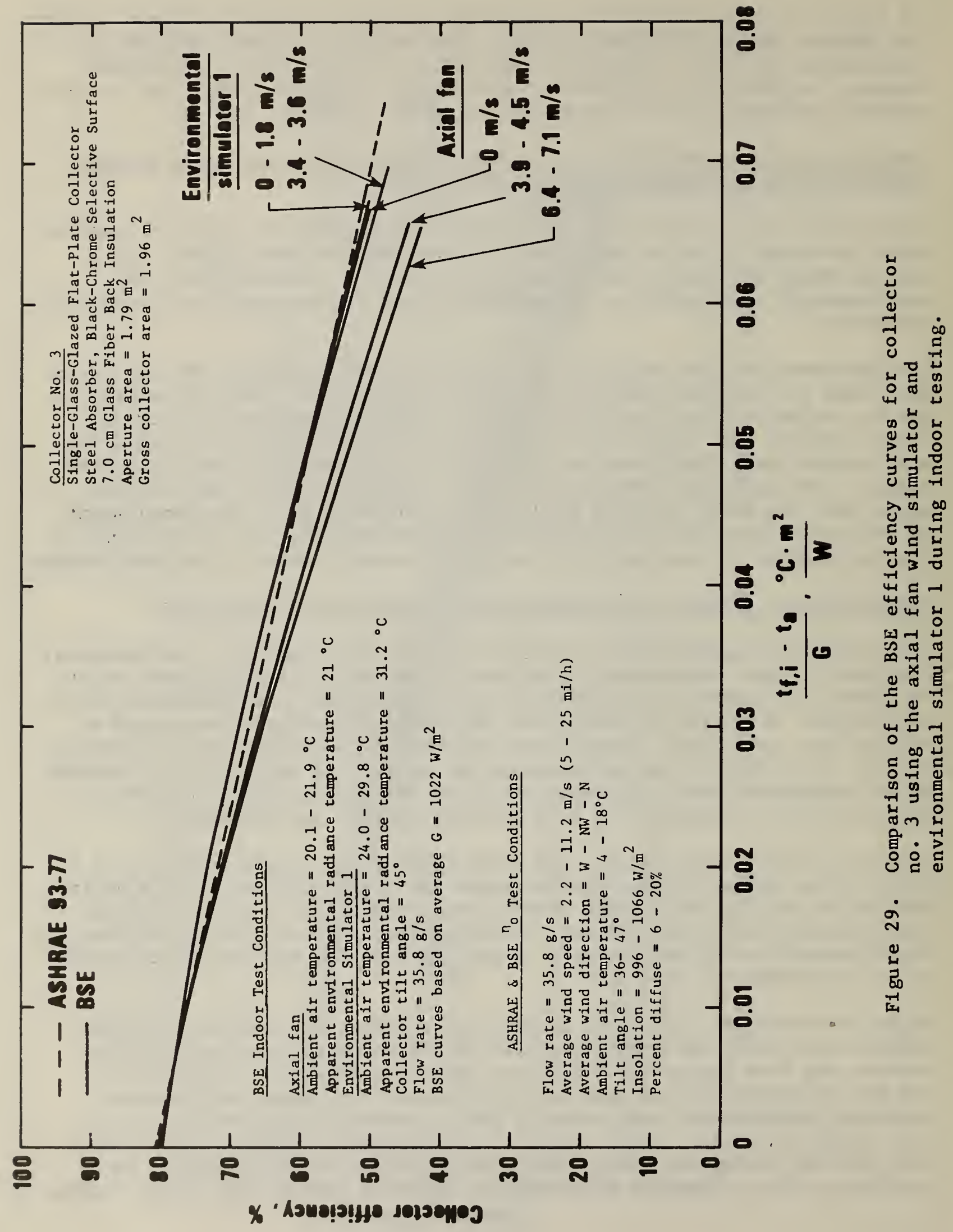




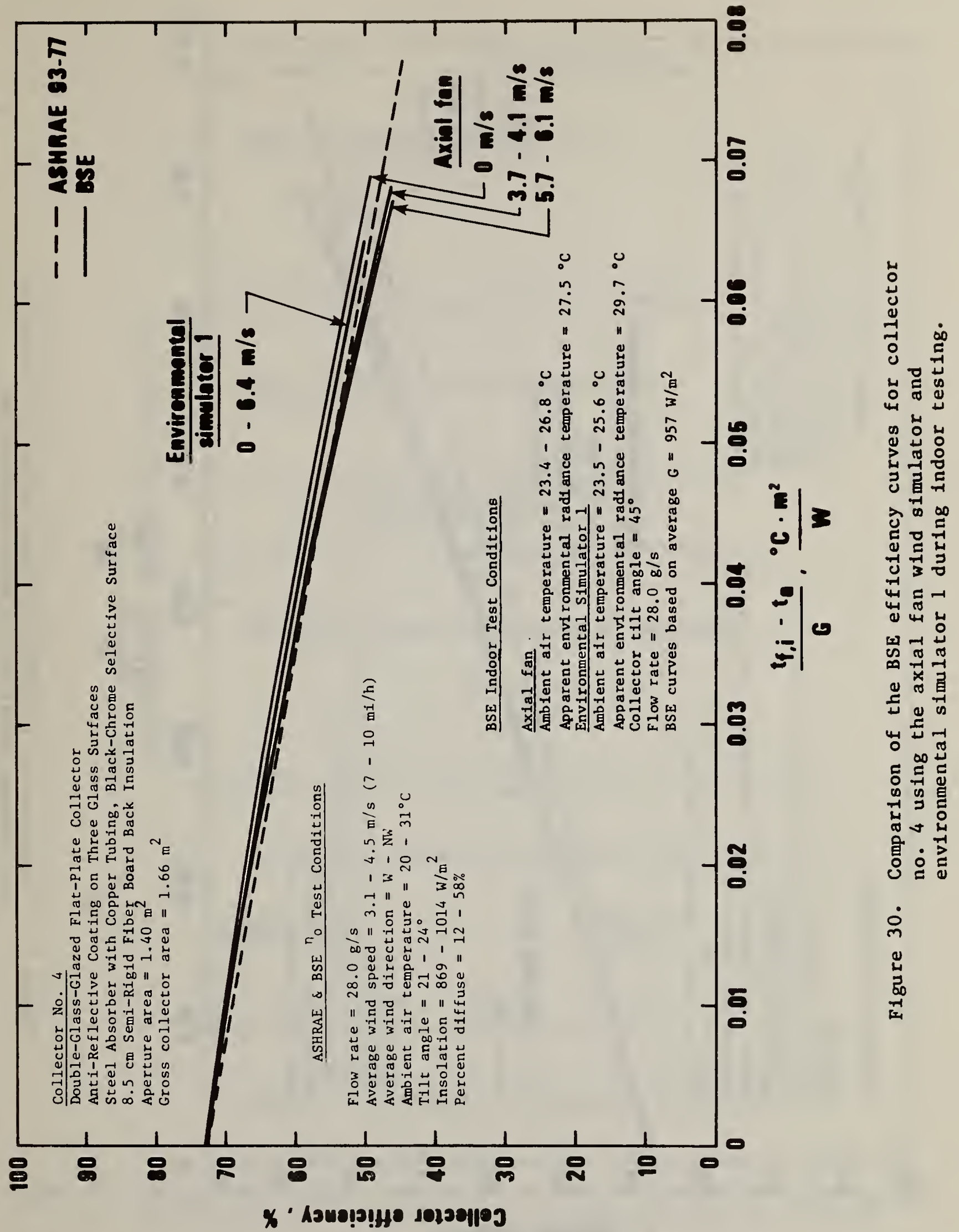




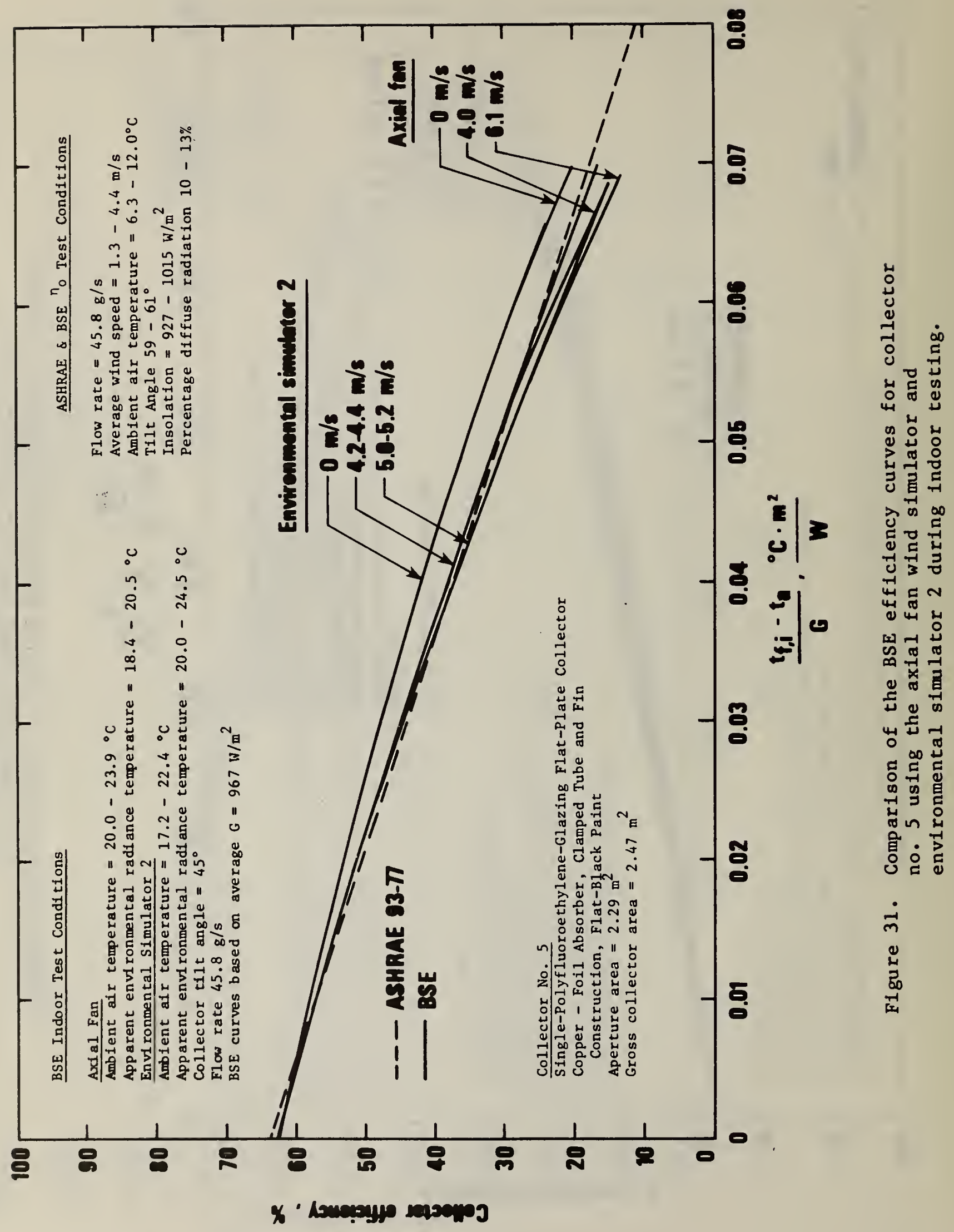



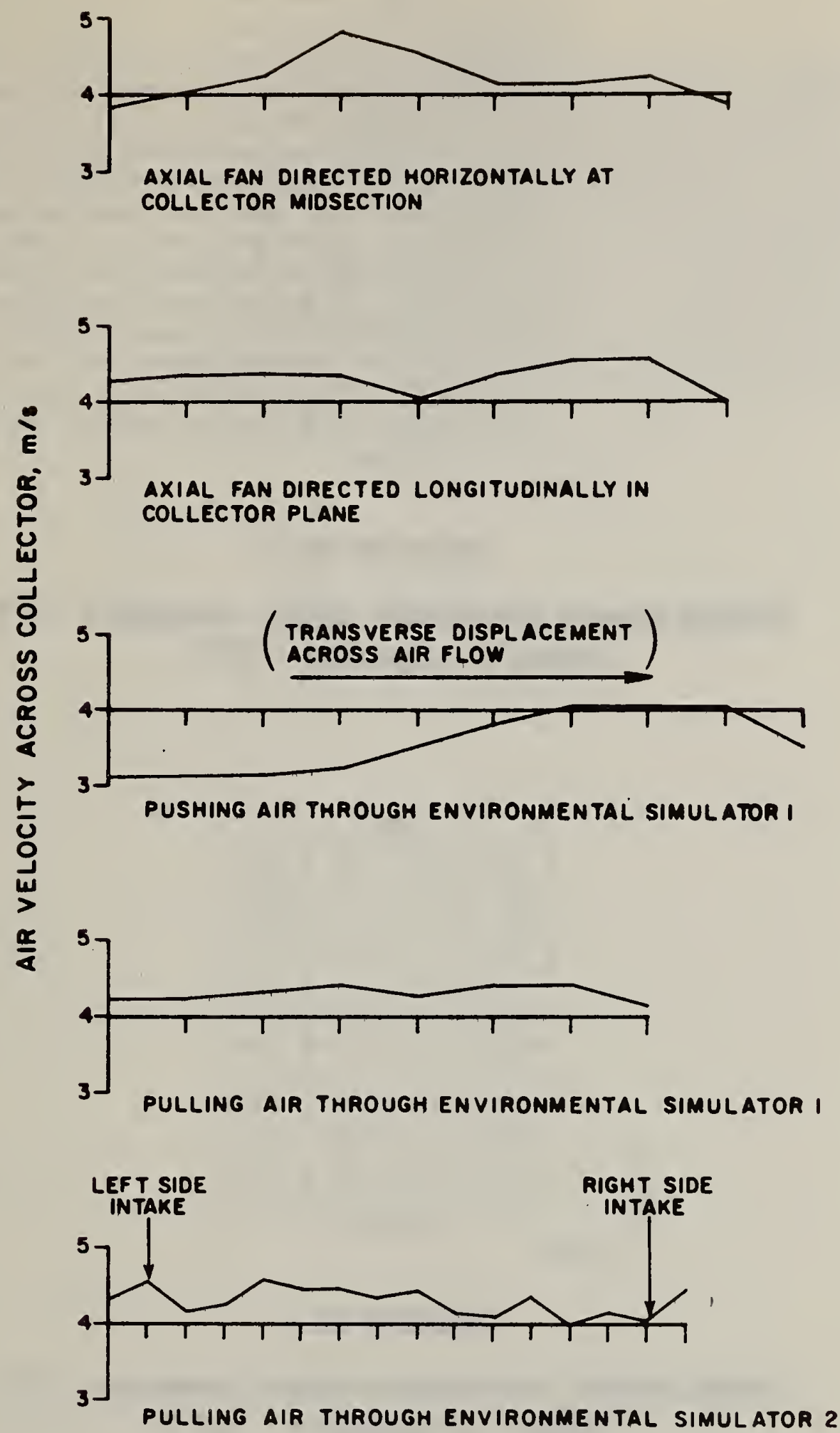

F1gure 32. Typical wind speed transverse flow profiles mapped while using the axial fan wind simulators and environmental simulators 1 and 2 . 


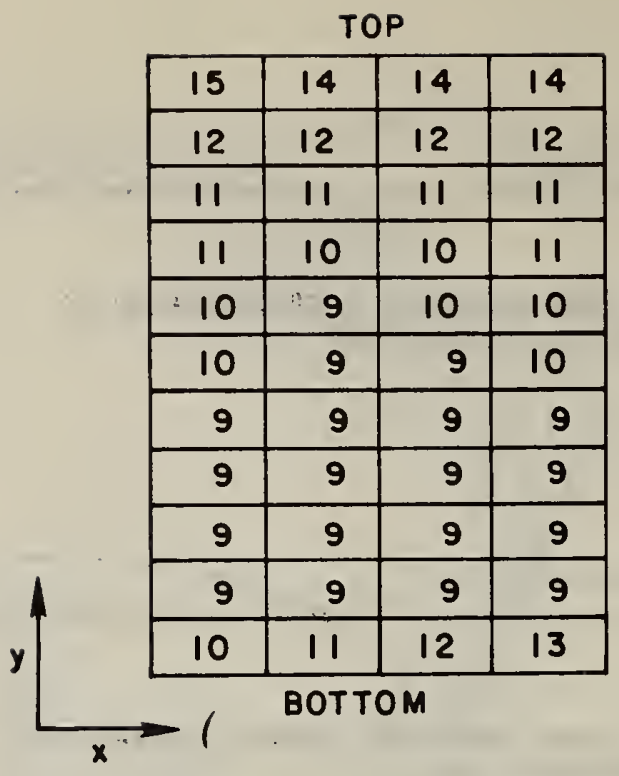

COUECTOR NO. 3

Average apparent envirormental radiance temperature $=11^{\circ} \mathrm{C}$ Ambient air temperature $=23.1^{\circ} \mathrm{C}$

\begin{tabular}{|c|c|c|c|}
\hline 12 & 12 & 12 & 12 \\
\hline 12 & 11 & 11 & 12 \\
\hline 12 & 11 & 11 & 11 \\
\hline 11 & 11 & 11 & 11 \\
\hline 11 & 11 & 11 & 11 \\
\hline 11 & 11 & 11 & 11 \\
\hline 11 & 11 & 11 & 11 \\
\hline 11 & 11 & 10 & 11 \\
\hline 11 & 11 & 11 & 11 \\
\hline
\end{tabular}

COLECTOR M. 4

Average apparent environmental radiance temperature $=11^{\circ} \mathrm{C}$ Ambient air temperature $=24.2^{\circ} \mathrm{C}$

Figure 33. Typical apparent environmental radiance temperatures mapped within environmental simulators 1 and 2 . 
around the matrix perimeter and from bottom to top. The increased uniformity of apparent environmental radiance temperature as viewed by collector no. 4 was primarily the result of increasing the fluid flow through the tube and fin plate of the environmental simulator. The increased flow rate decreased the fluid temperature rise and consequently the temperature extremes from top to bottom along the tube and fin sheet. The edge effects around the matrix perimeter were essentially eliminated by using environmental simulator 2 which had a view factor near unity. Air temperature within the environmental simulators under zero wind conditions would stratify by as much as $30^{\circ} \mathrm{C}\left(54^{\circ} \mathrm{F}\right)$ because of the stagnant enclosed air space. Consequently during $0 \mathrm{~m} / \mathrm{s}$ test conditions, a very low air flow $(<0.05 \mathrm{~m} / \mathrm{s}(0.11 \mathrm{mi} / \mathrm{h}))$ was maintained to minimize stratification. The temperature stratification was normally reduced to less than $5^{\circ} \mathrm{C}\left(9^{\circ} \mathrm{F}\right)$. 


\section{SUMMARY AND CONCLUSIONS}

This report has briefly described the BSE solar collector test procedure. A test facility has been fabricated at NBS in compliance with the BSE test procedure in addition to existing test facilities capable of collector testing in accordance with ASHRAE Standard 93-77. A variety of five different flat-plate liquid heating solar collectors were tested in accordance with both procedures and the results compared. Slight refinements in the control of the BSE indoor environmental test conditions were also investigated. The main conclusions of the study are:

1. For all five flat-plate liquid heating collectors tested in this program, the differences between the efficiency curves determined strictly using the BSE and the ASHRAE collector test procedures were less than the total uncertainty, measurement and meteorological, associated with the ASHRAE Standard 93-77 curve. For four of the collectors, the agreement was better than $+4-5$ efficiency points which is typically less than or equal to the measurement uncertainty assoclated with the ASHRAE 93-77 curve.

2. The overall uncertainty in determining collector thermal efficiency is reduced and repeatability improved when using the BSE collector test procedure compared to the ASHRAE procedure. The uncertainty in determining the collector optical efficiency is identical between the procedures but the uncertainty associated with the variation in meteorological test conditions is reduced when determining collector thermal losses under the BSE procedure.

3. For flat-plate liquid-heating collectors, the determination of the near-normal-incidence instantaneous collector efficiency using the BSE procedure can be completed in two days, one for outdoor testing, and one for indoor testing. Only one day is dependent upon outdoor environmental conditions in contrast to 4 days of outdoor testing normally required by ASHRAE Standard 93-77 when using a fixed orientation test stand.

4. The following are conclusions regarding the control of indoor environmental test conditions which give results that best reflect actual collector thermal performance outdoors for flat-plate liquid-heating collectors:

a. The simulated wind velocity across the collector surface should be maintained at or above $3.7 \mathrm{~m} / \mathrm{s}(8.2 \mathrm{mi} / \mathrm{h})$.

b. The apparent environmental radiance temperature can be allowed to range from room temperature to as low as $16-19^{\circ} \mathrm{K}\left(28-32^{\circ} \mathrm{R}\right)$ below room temperature, and the statement in conclusion 1 above will still be satisfied. 
c. The axial fan wind simulators are sufficient for simulating controlled indoor wind conditions. In order to maintain a uniformity in wind speed of \pm 9 percent, directing the axial fans longitudinally along the collector aperture plane is preferred over directing the fans horizontally at the collector midsection.

d. Environmental simulators 1 and 2 were successful in increasing unfformity of indoor environmental test conditions in order to parametrically examine collector thermal performance as a function of both wind speed and apparent environmental radiance temperatures. Environmental simulator 2 is preferred because it provided simulated wind along both the collector top and edges. Both simulators were capable of simulating wind speeds from 0 to $6 \mathrm{~m} / \mathrm{s}$ ( 0 to $13.4 \mathrm{mi} / \mathrm{h}$ ) with a transverse flow uniformity of \pm 4 percent and apparent environmental radiance temperatures ranging from amblent air temperature to $16-19^{\circ} \mathrm{K}\left(28-32^{\circ} \mathrm{R}\right)$ below ambient air temperature with a uniformity of $\pm 2^{\circ} \mathrm{K}\left(3.6^{\circ} \mathrm{R}\right)$ as viewed by the collector. 


\section{RECOMMENDATIONS}

1. The BSE collector test procedure is recommended as an alternative to ASHRAE Standard 93-77 for testing flat-plate water heating solar collectors. Based upon the results of this study, the procedure improves repeatability and reduces the time and overall uncertainty associated with determining collector thermal performance.

2. The BSE procedure should be evaluated for possible use in testing unglazed collectors. Considering that the thermal performance of unglazed collectors is extremely sensitive to variations in environmental conditions, the BSE procedure should provide tighter regulation of the environmental test conditions to both ensure quasi-steadystate conditions and minimize the overall test result uncertainty.

3. An evaluation of the BSE procedure should be extended to include nonflat-plate collectors. Possible problems asociated with measuring low collector thermal losses may prevent the application of the procedure to evacuated tubular or concentrating collectors.

4. The following are recommended modifications or additions to the present BSE procedure:

a. During the indoor test, the wind speed across the collector surface should be a setpoint value of $4 \mathrm{~m} / \mathrm{s}(8.9 \mathrm{mi} / \mathrm{h})$ with a specified uncertainty and uniformity.

b. A standard procedure should be adopted for the measurement of indoor simulated wind speeds. Likewise, a standard technique should be included for calculating the average wind speed.

c. The thermophysical properties of the collector working fluid should be known to within $\pm 0.5 \%$ and not vary by more than $0.5 \%$ over the operating temperature range within a test period. Presently, the BSE procedure lacks any requirement for fluid density and prescribes that the specific heat not vary by more than $5 \%$ over the operating temperature range between the collector inlet and outlet.

d. The stability requirements for the collector inlet fluid temperature during the indoor testing should be tightened to $+0.2^{\circ} \mathrm{C}$ from the present $+0.5^{\circ} \mathrm{C}$. Also, an inlet fluid temperature cycle rate of less than $0.1^{\circ} \mathrm{C} / \mathrm{min}$ should be specified. In practice, the tighter control of the inlet temperature is not any more difficult under stable laboratory conditions. The result will be less uncertainty associated with the low temperature difference measurements. 


\section{REFERENCES}

1. BSE Guidelines and Directions for Determining the Usability of Solar Collectors, A. Solar Collector Efficiency Test, BSE, Kruppstrasse 5, 4300 Essen 1, Federal Republic of Germany, May, 1978.

2. "Method of Testing to Determine the Thermal Performance of Solar Collectors," ASHRAE Standard 93-77, ASHRAE, 345 East 47 th Street, New York, New York, 10017, 1977.

3. Symons, J.G., "The Direct measurement of Heat Loss from Flat-Plate Solar Collectors on an Indoor Testing Facility", CSIRO, Division of Mechanical Engineering, Technical Report No. TR7, 1976.

4. Christie, E.A., "A Method of Measuring the Performance Characteristics of Flat-Plate Solar Collectors", CSIRO, Divison of Mechanical Engineering, Technical Report No. TR6, 1976.

5. Smith, C.C., and T.A. Weiss, Design Application of the Hotte1-WhillierBliss Equation", Solar Energy, Vo1. 19, No. 2, pp. 109-114, 1977.

6. Whillier, A., "The Thermal Performance of Solar Water Heaters", Solar Energy, Vol. 9, No. 1, 1965.

7. Reed, K. A., "Solar Collector Test Plan", Argonne National Laboratory, 9700 South Cass Avenue, Argonne, Illinois 60439, 1977.

8. Streed, E.R., and Thomas, W.C., "Results and Analysis of a Round-Robin Test Program for Liquid-Heating Flat-Plate Solar Collectors", NBS Technical Note 975 , August 1978 .

9. Streed, E.R., Thomas, W.C., Dawson, III A.G., Wood, B.D., and J.E. Hill "Results and Analysis of Round Robin Test Program for Liquid-Heating Flat-Plate Solar Collector," Solar Energy, Vo1. 22, pp. 235-249, 1979.

10. Duffie, J.A., and W.A., Beckman, Solar Energy Thermal Processes, John Wiley and Sons, New York, 1974.

11. Guide to Meteorological Instrumentation and Observing Practices, Secretariet of the World Meteorological Organization, Geneva, Switzerland, 4th Edition, 1971.

12. Bliss, R.W., "The Derivation of Several Plate Efficiency Factors Useful in the Design of Flate-Plate Solar Heat Collectors", Solar Energy, Vo1. 3, No. 4, December, 1959.

13. Whillier, A., "Prediction of Performance of Solar Collectors", App1ications of Solar Energy for Heating and Cooling of Buildings, ASHRAE GRP 170, ASHRAE, 345 East 47th Street, New York, 10017, 1977: 
14. Hill, J.E., Jenkins, J. P., and D.E., Jones, "Experimental Verification of Standard Test Procedure for Solar Collectors", NBS Building Science Series 117, January, 1979. 
10. NOMENCLATURE

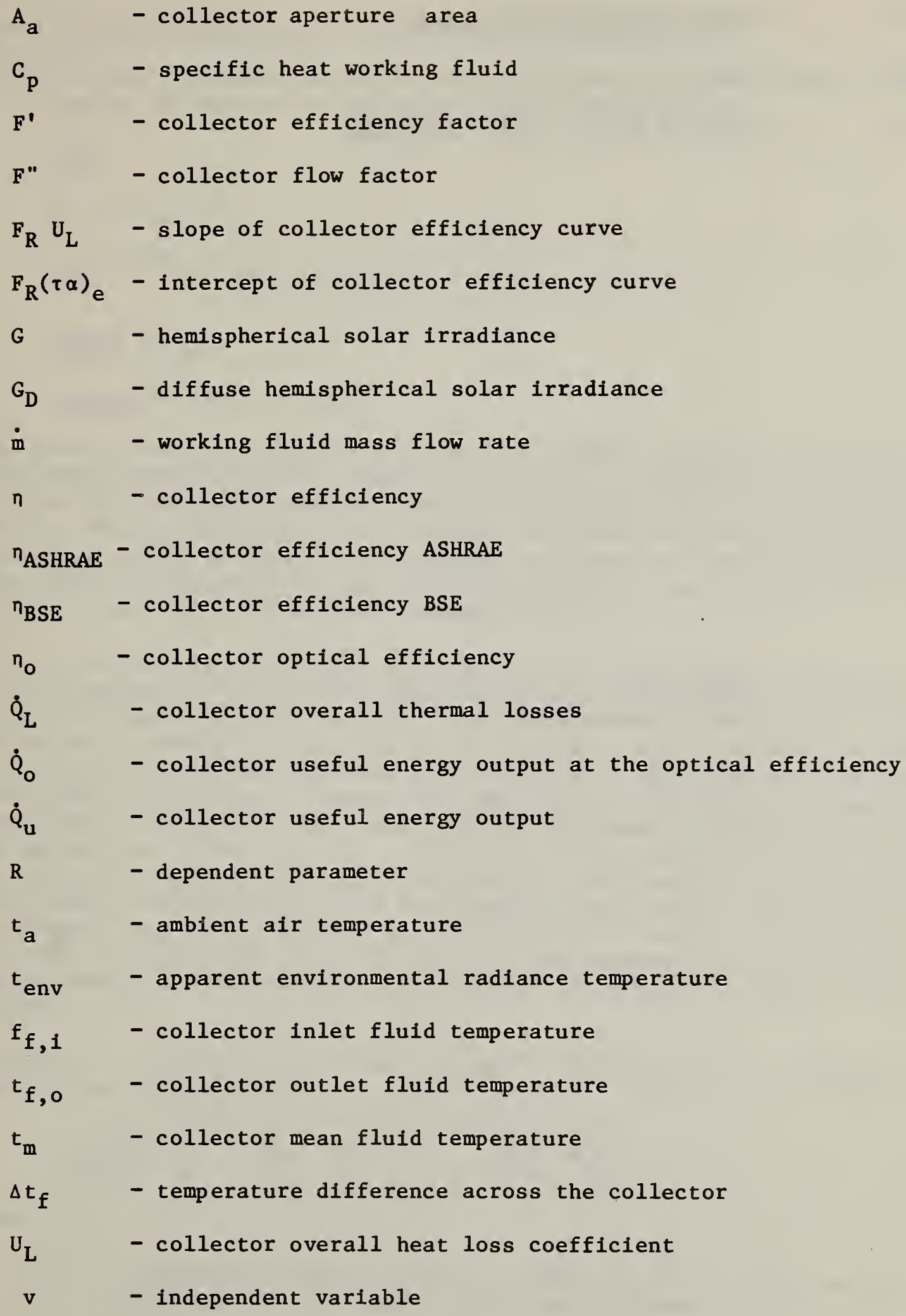




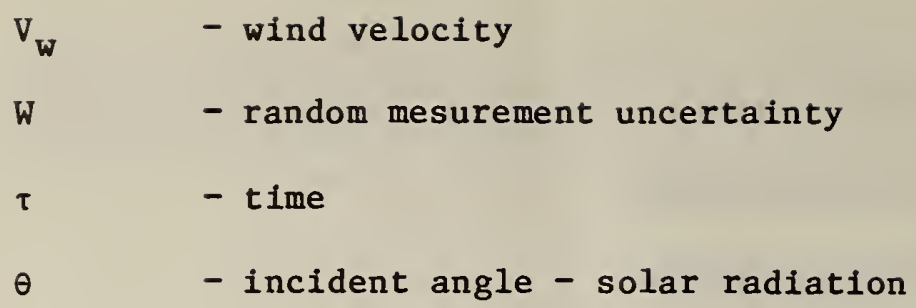




\section{APPENDIX A}

Analysis of Propagating Random Measurement Uncertainties

From the data recorded during the BSE and ASHRAE collector tests, the results are reduced and plotted to formulate the following curves:

BSE

$\dot{Q}_{L}$ vs $\left(t_{m}-t_{2}\right)$

$\eta_{B S E}$ vs $\left(t_{m}-t_{a}\right)$

ASHRAE $93-77$

$\eta_{\text {ASHRAE }}$ vs $\left(t_{f, 1}-t_{a}\right) / G$

The above parameters used to plot each curve have a random and systematic uncertainty associated with their determination. Systematic errors serve to bias the plotted curves and produce a relative shift in the absolute result, whereas random errors are responsible for the observed data scatter. Considering that systematic errors will be assumed correctible and do not contribute to the observed data scatter, the subsequent analysis will only address random errors and their propagation.

Each of the plotted parameters $\dot{Q}_{L},\left(t_{m}-t_{a}\right), n_{B S E}, n_{A S H R A E}$ and $\left(t_{f,}-t_{a}\right) / G$ are determined from individual measurements of temperature, fluid flow rates, solar irradiance, and the working fluid thermophysical properties. The random uncertainty associated with each of the individual measurements when combined to calculate a plotted parameter will result in compounding the parameter uncertainty. In order to assess the magnitude of the parameter uncertainty, measurement uncertainty functions must be developed for each of the plotted parameters as a function of the individual measurements and their allowable inaccuracies. The uncertainty functions are based upon a root-mean-square (RMS) uncertainty propagation and the measurement inaccuracies allowed within the BSE and ASHRAE procedures in Table 2. The results of testing collector no. 3 will be used to demonstrate the utilization of the uncertainty functions to obtain the parameter uncertainty and to illustrate the expected scatter on the plotted curves.

In general, the relation for RMS propagated uncertainty due to random independent uncertainties is

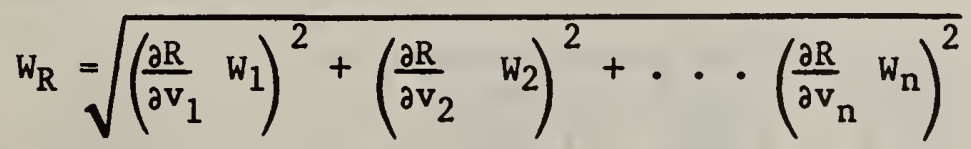

where

$\mathrm{W}=$ random measurement uncertainty which could be either positive or negative. The sign of $W$ is indeterminant. 


$$
\begin{aligned}
& \mathbf{R}=\text { dependent parameter } \\
& \mathbf{v}=\text { independent variable }
\end{aligned}
$$

or

$$
\frac{W_{R}}{R}= \pm \sqrt{\left(\frac{W_{1}}{v_{1}}\right)^{2}+\left(\frac{W_{2}}{v_{2}}\right)^{2}+\cdots \cdot\left(\frac{W_{n}}{v_{n}}\right)^{2}}
$$

$\underline{\text { Propagated Measurement Uncertainty Functions for } \dot{Q}_{L},{ }^{n} \text {, and }\left(t_{m}-t_{a}\right)}$

The corresponding formulations for each parameter are

$$
\begin{aligned}
& \dot{Q}_{L}=\dot{\mathrm{m}} C_{p}\left(\Delta t_{f}\right) \\
& n_{o}=\dot{m} c_{p}\left(\Delta t_{f}\right) / G \\
& t_{m}-t_{a}=x
\end{aligned}
$$

where

$$
\begin{aligned}
\dot{m} & =\text { mass flow rate through the collector } \\
C_{p} & =\text { specific heat of the working fluid } \\
\Delta t_{f} & =\text { temperature difference across the collector } \\
G & =\text { solar irradiance within the plane of the collector } \\
t_{m} & =\text { arithmetic mean temperature between collector inlet and } \\
t_{a} & =\text { autlet fluid temperatures }
\end{aligned}
$$

The RMS uncertainty functions are

$$
\begin{aligned}
& \frac{\mathrm{W}_{\mathrm{Q}_{\mathrm{I}}}}{\dot{\mathrm{Q}}_{\mathrm{L}}}= \pm \sqrt{\left(\frac{\mathrm{W}_{\dot{m}}}{\mathrm{~m}}\right)^{2}+\left(\frac{{ }_{\mathrm{C}_{\mathrm{p}}}}{\mathrm{C}_{\mathrm{p}}}\right)^{2}+\left(\frac{\mathrm{W}_{\Delta \mathrm{t}_{f}}}{\Delta \mathrm{t}_{\mathrm{f}}}\right)^{2}} \\
& \frac{w_{n_{0}}}{n_{o}}= \pm \sqrt{\left(\frac{w_{m}}{m}\right)^{2}+\left(\frac{W_{C}}{C_{p}}\right)^{2}+\left(\frac{W_{G}}{G}\right)^{2}+\left(\frac{W_{\Delta t_{f}}}{\Delta t_{f}}\right)^{2}}
\end{aligned}
$$




$$
\frac{w_{x}}{x}= \pm \sqrt{\left(W_{t_{m}}\right)^{2}+\left(W_{t_{a}}\right)^{2}} /\left(t_{m}-t_{a}\right)
$$

From Table 2 the allowable measurement uncertainties or inaccuracies spectfied within the BSE procedure are

$$
\frac{W_{\mathrm{m}}}{\mathrm{m}}= \pm 0.01
$$

$$
\begin{aligned}
& \frac{W_{C_{p}}}{C_{p}}= \pm 0.005 \text { assumed considering that the thermophysical properties } \\
& \text { of the working fluid are well known } \\
& \frac{W_{G}}{G}= \pm 0.03 \\
& W_{t_{m}}= \pm 0.5^{\circ} \mathrm{C} \\
& W_{t_{a}}= \pm 0.5^{\circ} \mathrm{C} \\
& W_{\Delta t_{f}}= \pm 0.1^{\circ} \mathrm{C}
\end{aligned}
$$

When determining $\dot{\mathrm{Q}}_{\mathrm{L}}$

$$
\Delta t_{f}=\dot{Q}_{L} /\left(\dot{m} c_{p}\right)
$$

when determining $n_{0}$

$$
\Delta t_{f}=\eta_{0}(G) A_{a} /\left(\dot{m} C_{p}\right)
$$

where

$$
A_{a}=\text { aperture area of collector }
$$

Then, after substituting the individual terms into the uncertainty functions

$$
\frac{{ }^{W} \dot{Q}_{L}}{\dot{Q}_{L}}= \pm \sqrt{0.000125+\left(\frac{0.1 \dot{m}{ }_{p}}{\dot{Q}_{L}}\right)^{2}}
$$




$$
\begin{aligned}
& \frac{w_{n_{0}}}{n_{0}}= \pm \sqrt{0.001025+\left(\frac{0.1(\dot{m}) C_{p}}{n_{0}(G) A_{a}}\right)^{2}} \\
& \frac{w_{x}}{x}= \pm \frac{0.707}{t_{m}-t_{a}}
\end{aligned}
$$

For collector no. 3, the following are typical conditions.

$$
\begin{aligned}
A_{a} & =1.79 \mathrm{~m}^{2} \\
\dot{m} & =0.0358 \mathrm{~kg} / \mathrm{s} \\
C_{p} & =4.187 \mathrm{~kJ} /\left(\mathrm{kg}^{\left.\circ{ }^{\circ} \mathrm{C}\right)}\right. \\
\mathrm{G} & \geq 200 \mathrm{~W} / \mathrm{m}^{2}
\end{aligned}
$$

Substituting the conditions into equations (1), (2), and (3)

$$
\begin{aligned}
& \frac{w_{Q_{L}}}{\dot{Q}_{L}}= \pm \sqrt{0.000125+\left(\frac{14.9}{\dot{Q}_{L}}\right)^{2}} \\
& \frac{w_{\eta_{0}}}{n_{0}} \leq \pm \sqrt{0.001025+\left(\frac{0.0416}{n_{0}}\right)^{2}} \\
& \frac{w_{x}}{x}= \pm \frac{0.707}{t_{m}-t_{a}}
\end{aligned}
$$

\section{Propagated Measurement Uncertainty Function for ${ }^{n}$ BSE}

The relation for $\eta_{\mathrm{BSE}}$ is

$$
\eta_{B S E}=\eta_{0}-\dot{Q}_{L} / A_{a} G
$$

Consequently the uncertainty function is

$$
w_{\eta_{B S E}}= \pm \sqrt{\left(w_{\eta_{0}}\right)^{2}+\left(w_{Q_{L} / A_{a} G}\right)^{2}}
$$




$$
\begin{aligned}
& W_{n_{0}} \leq\left(\begin{array}{c}
W_{\eta_{0}} \\
\frac{\eta_{b}}{b}
\end{array}\right){ }_{b} \\
& W_{\dot{Q}_{L} / A_{a} G}=\left(\frac{W_{Q_{L}}}{\dot{Q}_{L}}\right)\left(\frac{\dot{Q}_{L}}{A_{a} G}\right)
\end{aligned}
$$

Substituting equation (1) and (2) into eqns. (7)

$$
w_{\eta_{B S E}} \leq \pm\left[\begin{array}{l}
\eta_{0}^{2}\left[0.001025+\left(\frac{0.1(\dot{m}) c_{p}}{\dot{Q}_{L}}\right)^{2}\right] \\
+\left(\frac{\dot{Q}_{L}}{A_{a} G}\right)^{2}\left[0.00125+\left(\frac{0.1 \dot{m} c_{p}}{\eta_{b} G A_{a}}\right)^{2}\right]
\end{array}\right] \frac{1}{\frac{1}{2}}
$$

Applying the appropriate conditions for collector no. 3, equation (8) becomes

$$
W_{B S E} \leq \pm\left((0.00102) n_{0}{ }^{2}+\frac{0.0000390\left(\dot{Q}_{L}\right)^{2}+69.2}{G^{2}}+0.00174\right)^{\frac{1}{2}}
$$

Propagated Measurement Uncertainty Functions for ${ }^{n}$ ASHRAE and $\left(t_{f, i}-t_{a}\right) / G$

Realizing that the allowable measurement uncertainties with the ASHRAE procedure are identical to the BSE requirements for outdoor testing the equations for determining $\eta_{A S H R A E}$ and $\eta_{0}$ are identical, therefore

$$
\begin{aligned}
& \frac{w_{n_{\text {ASHRAE }}}}{n_{\text {ASHRAE }}}=\frac{w_{n_{0}}}{n_{0}} \\
& \frac{w_{n_{\text {ASHRAE }}}}{n_{\text {ASHRAE }}}= \pm \sqrt{0.001025+\frac{0.1(\dot{m}) c_{p}}{n_{0}(G) A_{a}}}
\end{aligned}
$$

Defining $x^{\prime}=\left(t_{f, 1}-t_{a}\right) / G$ 


$$
\frac{w_{x^{\prime}}}{x^{\prime}}= \pm \sqrt{\frac{\left(w_{t_{f, i}}\right)^{2}+\left(w_{t_{a}}\right)^{2}}{\left(t_{f, i}-t_{a}\right)^{2}}+\left(\frac{w_{G}}{G}\right)^{2}}
$$

Using the allowable ASHRAE measurement uncertainties from Table 2.

$$
\frac{W_{x^{\prime}}}{x^{\prime}}= \pm \sqrt{\frac{0.5}{\left(t_{f, i}-t_{a}\right)^{2}}+0.0009}
$$

Applying the typical conditions for collector no. 3 to equation (10) with $\mathrm{G} \geq 630 \mathrm{w} / \mathrm{m}^{2}$,

$$
\frac{w_{\eta_{\text {ASHRAE }}}}{n_{\text {ASH RAE }}} \leq \pm \sqrt{0.000125+\left(\frac{0.0132}{n_{\text {ASHRAE }}}\right)^{2}}
$$




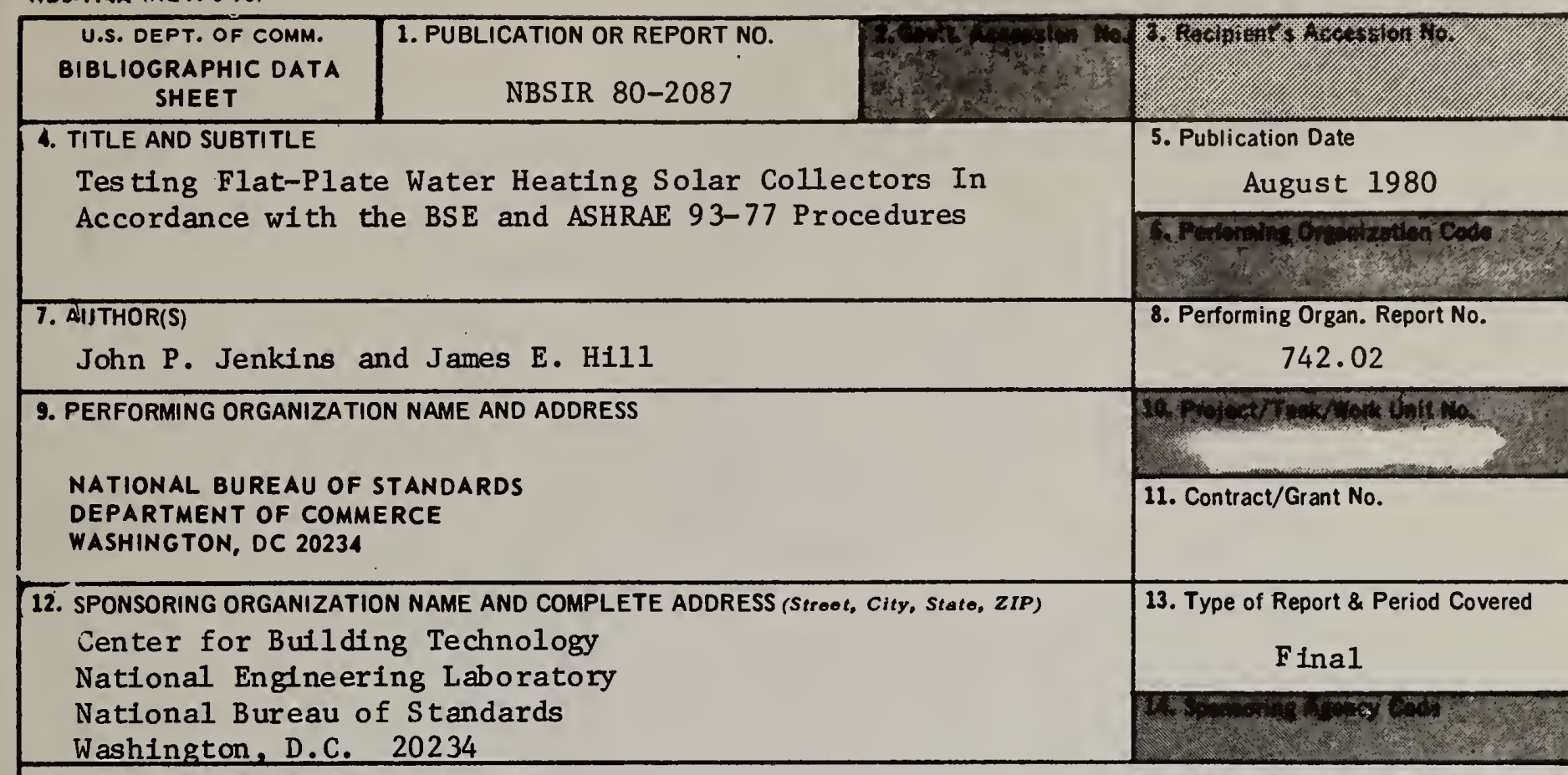

15. SUPPLEMENTARY NOTES

$\square$ Document describes a computer program; SF-185, FIPS Software Summary, is attached.

16. ABSTRACT (A 200-word or loss factual summary of most sigrificant information. If document includes a signlficant blbliography or Ilterature survey, mention it here.)

Five solar collectors were tested according to the BSE and ASHRAE test procedures and the results compared. All five collectors tes ted were modular, flat-plate, and waterheating, and included single- and double-glazed designs with and without selectivelycoated absorbers. In both procedures, collector efficiency curves are determined. The ASHRAE procedure consists exclusively of outdoor testing, vhereas the BSE procedure requires a combination of outdoor and indoor testing (no irre.Jiation) to determine the collector's optical and thermal loss characteristics, repectively. During the indoor testing in this study, the environmental test conditions were controlled and regulated by use of specially-built environmental simulators to investigate the effect of wind and "sky" temperature on the thermal loss characteristics of the collectors. The simulators provided stable, uniform wind speeds in the range of 0 to $7.1 \mathrm{~m} / \mathrm{s}$ across the collectors and "sky" temperatures above the collector ranging from t (ambient air temperature) to $\mathrm{t}_{\mathrm{a}}-19^{\circ} \mathrm{K}$.

17. KEY WORDS (six to twelve ontries; alphabetical order; capitalize only the first letter of the first key word unless a proper name; separatod by semicolons)

Instantaneous efficiency; optical efficiency; solar collectors; thermal 1osses; thermal performance testing.
18. AVAILABILITY
[X] Unlimited

For Official Distribution. Do Nlot Release to NTIS

Order From Sup. of Doc., U.S. Government Printing Office, Washington, DC 20402, SD Stock No. SNÓ03-003-

X] Order From National Technical Information Service (NTIS), Springfield, VA. 22161

\begin{tabular}{|l|c|}
\hline $\begin{array}{l}\text { 19. SECURITY CLASS } \\
\text { (THIS REPORT) }\end{array}$ & $\begin{array}{c}\text { 21. NO. OF } \\
\text { PRINTED PAGES } \\
\text { UNCLASSIFIED }\end{array}$ \\
\hline $\begin{array}{l}\text { 20. SECURITY CLASS } \\
\text { (THIS PAGE) }\end{array}$ & 80 \\
UNCLASSIFIED & 22. Price \\
\hline
\end{tabular}



f. 
